\title{
Transcriptional Regulators of Suberin Biosynthesis in Arabidopsis thaliana
}

By: Timothy M. Garant

A thesis submitted to the Faculty of Graduate and Postdoctoral Affairs in partial fulfillment of the requirements for the degree of

Master of Science in Biology

Carleton University

Ottawa, Ontario, Canada

(C) 2021

Timothy M. Garant 


\section{Acknowledgments}

Dr. Owen Rowland and Dr. Jhadeswar Murmu. 


\section{Abstract}

Like all vascular plants, the root endodermis of Arabidopsis thaliana contains aliphatic suberin, a cell wall-associated hydrophobic polymer that helps direct the symplastic movement of water and solutes into the central vasculature. The enzymes involved in suberin biosynthesis are relatively well characterized, but there are many gaps in our knowledge on how suberin biosynthesis is regulated. In this study, I demonstrate that Arabidopsis MYB41, MYB53, MYB92, and MYB93, which are R2R3 MYBtype transcription factors, can activate the transcription of suberin biosynthesis genes through their promoter (region 5' of the translation start site). Using a promoter: reporter deletion series, two regions of the promoter upstream region of the Arabidopsis FAR4 gene, which encodes a suberin biosynthetic enzyme, were determined to be important for specific expression in the root endodermis. AC-rich motifs, which are important for the recognition of DNA by specific MYB-type transcription factors, were enriched in the promoters of suberin biosynthesis genes. Although the important FAR4 promoter DNA segments contained these AC-rich motifs, I found no evidence of direct binding by MYB53, MYB92, and MYB93 using a yeast 1-hybrid assay. Lastly, the promoter of Arabidopsis WRKY56, which also encodes a transcription factor, was transcriptionally activated by MYB41, MYB53, MYB92, and MYB93. While WRKY56 had limited impact on root suberin deposition under non-stress conditions, bioinformatic evidence suggests that WRKY56 has a role under stress conditions. 


\section{Table of Contents}

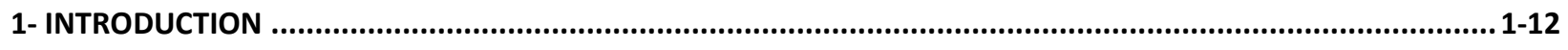

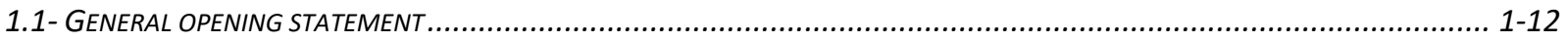

1.2- ARABIDOPSIS THALIANA: A MODEL SYSTEM FOR THE ROOTS OF VASCULAR PLANTS.................................................. 1 -1 12

1.3- DEPOSITION AND FUNCTIONS OF EXTRACELLULAR, HYDROPHOBIC BARRIERS IN ARABIDOPSIS....................................... 1-13

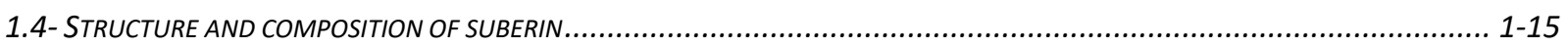

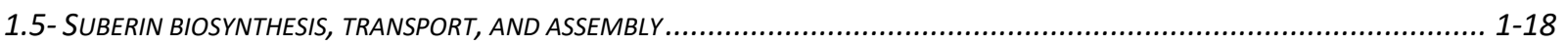

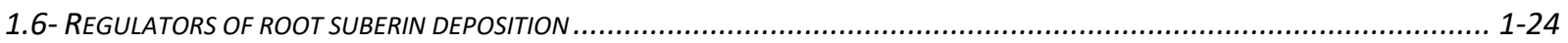

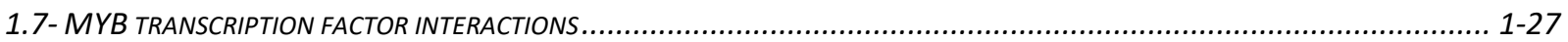

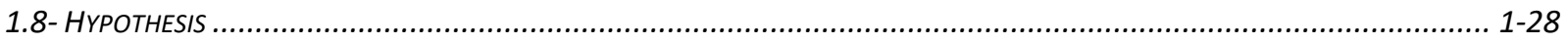

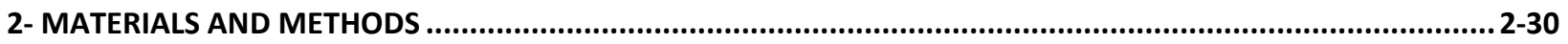

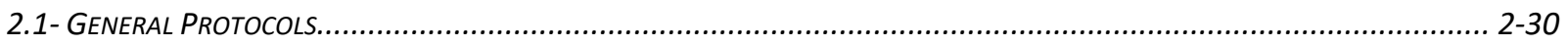

2.1.1- Seed surface sterilization.................................................................................................. 2-30

2.1.2- Growth conditions of $N$. benthamiana infiltrated with Agrobacterium tumefaciens ......................... 2-30

2.1.3- Growth conditions of A. thaliana used for generation of FAR4 promoter: GUS lines ........................ 2-31

2.1.4- Transformation of chemical competent E. coli $(\mathrm{DH} 5 \alpha)$ cells ......................................................... 2-31

2.1.5- Transformation of electrocompetent A. tumefaciens (GV3101::pMP90) cells.................................. 2-31

2.1.6- Preparing and transforming chemically competent yeast cells .................................................... 2-32

2.1.7- Transformation of E. coli DH5 $\alpha$, colony amplification, and vector DNA isolation ............................. 2-33

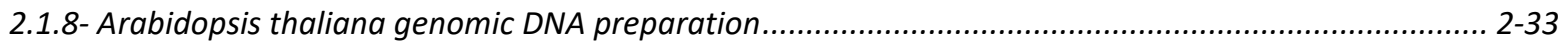

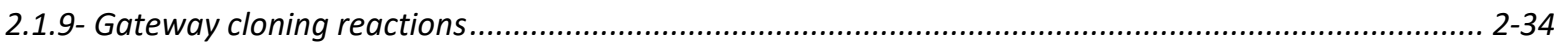

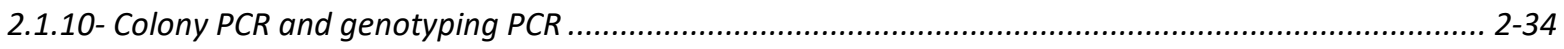

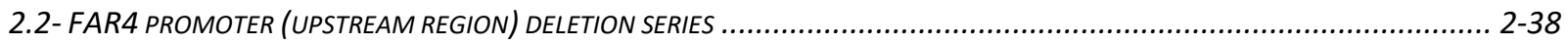

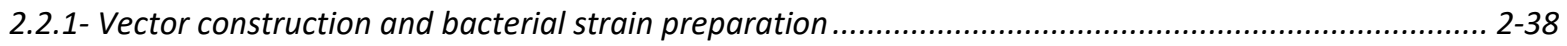

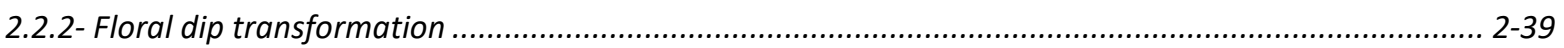

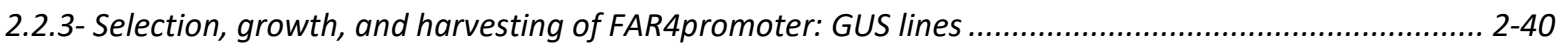

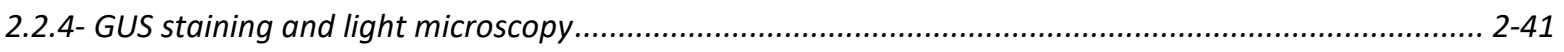

2.3- DUAL-LUCIFERASE PROMOTER ACTIVATION ASSAY VIA AGROBACTERIUM INFILTRATION OF N. BENTHAMIANA LEAVES............ 2-34

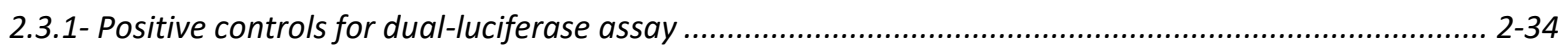

2.3.2- Vector construction and strain preparation for promoter: reporter constructs................................ 2-35

2.3.3- Vector construction and strain preparation for transcription factor over-expression constructs......... 2-36

2.3.4- Infiltration of $N$. benthamiana leaves with mixed Agrobacterium cultures ...................................... 2-37

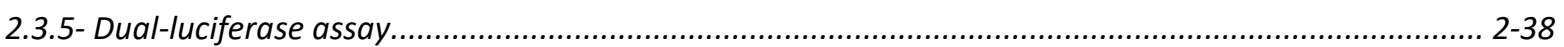

2.4- BIOINFORMATIC PREDICTION OF CIS-ACTING ELEMENTS IN THE FAR4 PROMOTER UPSTREAM REGION............................... 2-41

2.5- YEAST 1-HYBRID TO TEST DIRECT BINDING OF R2R3-MYB TFS TO FRAGMENTS OF THE FAR4 PROMOTER........................ 2-42

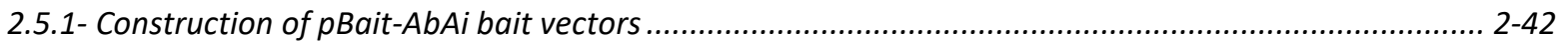

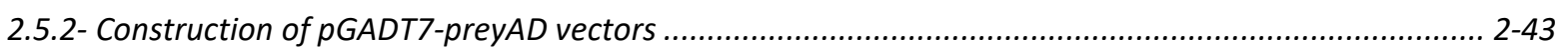

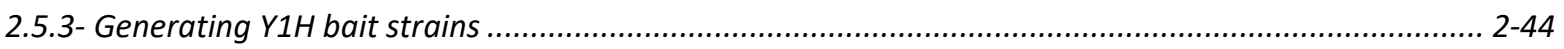

2.5.4- Transformation of pGADT7-preyAD vectors into the Y1HGold-pBaitAbAi strains.............................. 2-44

2.6- CHEMICAL ANALYSIS OF SUBERIN MONOMERS IN WRKY56 T-DNA LOSS-OF-FUNCTION MUTANTS.................................. 2-45

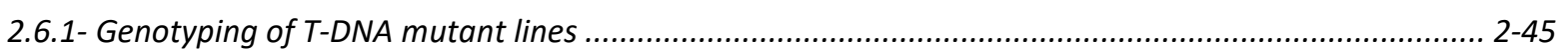

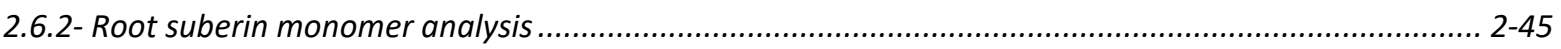

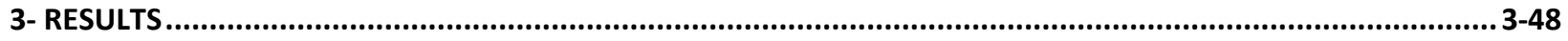


3.1- TRANSCRIPTIONAL ACTIVATION OF SUBERIN BIOSYNTHETIC GENE PROMOTERS.

3.2- MINIMAL FAR4 PROMOTER (UPSTREAM REGION) REQUIRED FOR SPECIFIC EXPRESSION IN ROOT ENDODERMIS.

3.3- BIOINFORMATIC (IN SILICO) ANALYSIS OF FAR4 PROMOTER UPSTREAM REGIONS FOR TF DNA-BINDING ELEMENTS...

3.4- YEAST-ONE-HYBRID ASSAY TO TEST FOR MYB TF BINDING TO FAR4 UPSTREAM REGIONS

3.5- CHEMICAL ANALYSIS OF SUBERIN IN WRKY56 LOSS-OF-FUNCTION MUTANTS.

4- DISCUSSION.

4.1- OPENING STATEMENT . 4-70

4.2- SUBERIN-ASSOCIATED MYB TRANSCRIPTION FACTORS TRANS-ACTIVATE THE PROMOTER UPSTREAM REGIONS OF SUBERIN BIOSYNTHETIC GENES.

4.3- NO EVIDENCE OF ARABIDOPSIS MYB53, MYB92, OR MYB93 BINDING TO THE FAR4 PROMOTER USING YEAST 1-HYBRID ANALYSIS ....

4.4- ARABIDOPSIS WRKY56 MAY HAVE A ROLE IN REGULATING SUBERIN DEPOSITION IN RESPONSE TO ABIOTIC STRESS.

4.5- CONCLUSIONS. 


\section{List of Symbols, Nomenclature, and Abbreviations}

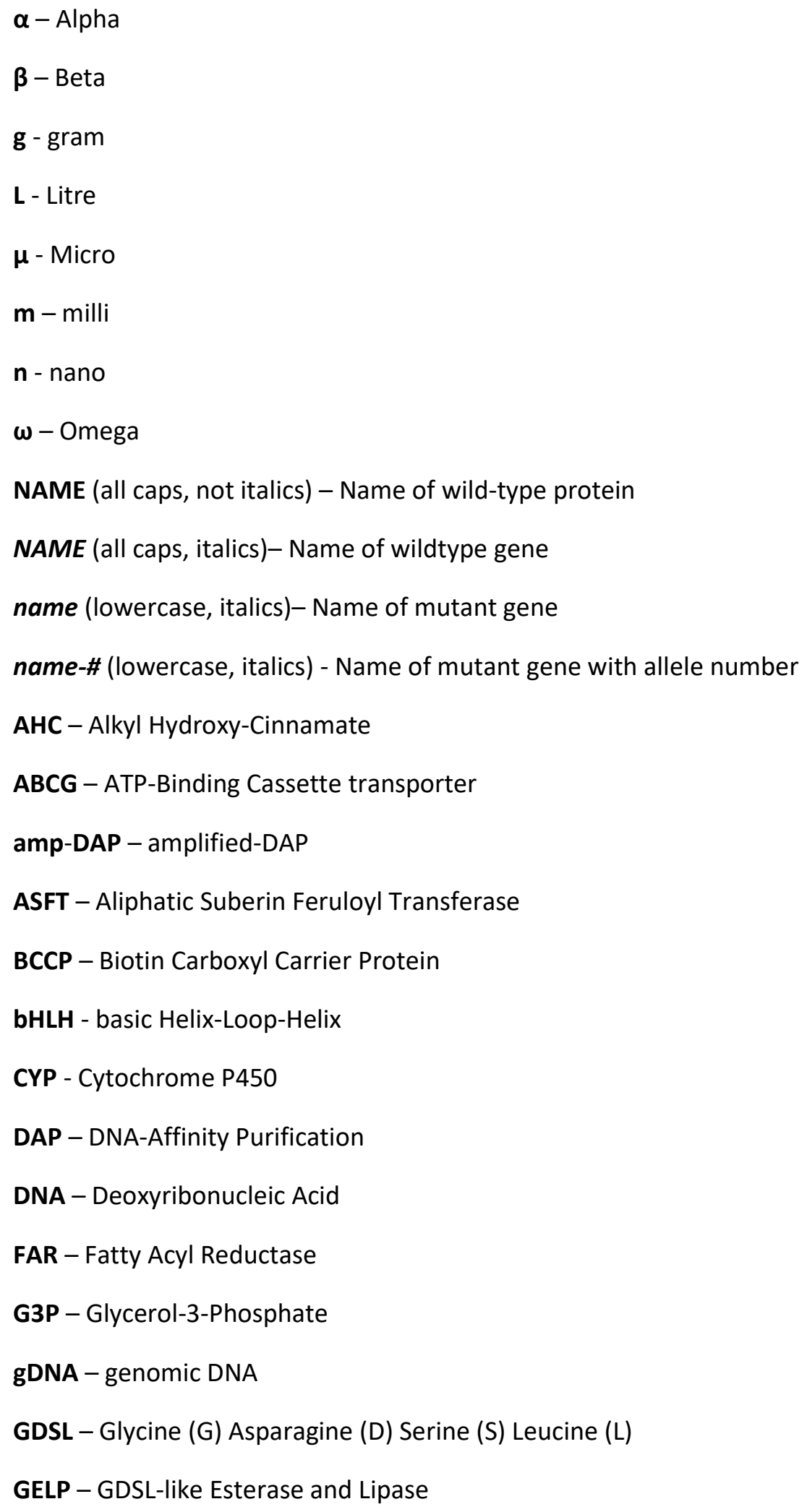


GPAT - Glycerol-3-Phosphate Acyl Transferase

GUS - $\beta$-Glucuronidase

KCS - $\beta$-Ketoacyl-CoA Synthase

LiAc - Lithium Acetate

LACS - Long-chain Acyl-CoA Synthetase

MBW - MYB-bHLH-WD40

MS - Murashige and Skoog

MYB - Myeoblastosis

mRNA - mature Ribonucleic Acid

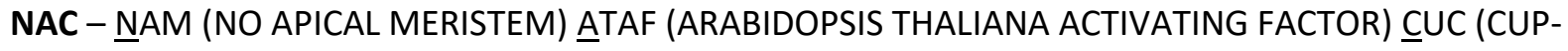
SHAPED COTYLEDON)

PCR - Polymerase Chain Reaction

RT - Room Temperature

PEG-3350 - Poly-Ethylene Glycol (Molecular Weight $3350 \mathrm{~g} / \mathrm{mol}$ )

pro - promoter or 5' region upstream from translation start site

SHR - Short-Root

ssDNA - single stranded DNA

T-DNA - Transfer-DNA

TEM - Transmission Electron Microscopy

TF - Transcription Factor

UV - Ultraviolet

WRKY - Tryptophan (W) Arginine (R) Lysine (K) Tyrosine (Y)

WT - Wild-Type

Y1H - Yeast-One(1)-Hybrid

YPAD - Yeast Peptone Adenine-sulphate Dextrose 


\section{List of Tables}

Table 1: Consensus DNA-binding motifs for R2R3-MYB, bHLH, NAC, and WRKY TFs.

Table 2: Amount of MYB, bHLH, NAC, and WRKY transcription factor cis-elements found in the promoter

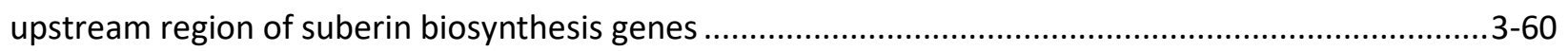




\section{List of Figures}

Figure 1: Schematic diagram of a cross-section of A. thaliana roots during their primary growth stage (left) and after their secondary growth stage (right)...... $1-15$

Figure 2: Structure and composition of the suberin polymer....

Figure 3: Overview of suberin biosynthetic pathway. $1-24$

Figure 4: Transient expression promoter activation assay, testing MYB39's ability to transcriptionally activate the promoter of GPAT5, ASFT, CYP86A1, CYP86B1 and WRKY56

Figure 5: Transient expression promoter activation assay, testing MYB39, MYB41, MYB53, MYB92, and MYB93's ability to transcriptionally activate the promoter of FAR4, GPAT5, ASFT, CYP86A1, and CYP86B1

Figure 6: Transient expression promoter activation assaytesting A) the ability of non root suberinassociated TFs to transcriptionally activate GPAT5 and B) the suberin-associated R2R3-MYB TFs ability to transcriptionally activate the PtANR1 promoter. .3-53

Figure 7: Transient expression promoter activation assay, testing the root suberin-associated R2R3-MYB TFs ability to transcriptionally activate the promoter of WRKY56 3-54

Figure 8: Schematic of the T-DNA region within the pKGWFS7 vector.

Figure 9: Staining pattern of the root tip, root maturation zone, and lateral root initiation of $T_{2}$ seeds containing the $-2300 \mathrm{bp},-2061 \mathrm{bp},-1594 \mathrm{bp},-1171 \mathrm{bp},-545 \mathrm{bp}$, and $-245 \mathrm{bp}$ FAR4 promoter fused the to $\beta$-glucuronidase (GUS) reporter gene.

Figure 10: To-scale map of the FAR4 promoter upstream region, $-2061 \mathrm{bp}$ to $-1594 \mathrm{bp}$ from the translation start site, identifying predicted DNA-binding motifs for MYB and WRKY TFs. 3-61

Figure 11: To-scale map of the FAR4 promoter upstream region, $-1171 \mathrm{bp}$ to $-546 \mathrm{bp}$ from identifying predicted DNA-binding motifs for MYB and WRKY TFs.. 3-61

Figure 12: Colony PCR to confirm pBait-AbAi vector was integrated into the Y1HGold genome $3-63$ 
Figure 13: Y1HGold bait strains growing on SD (-Ura) media containing different concentrations of Aureobasidin $\mathrm{A}(\mathrm{AbA})$ in a dilution series 3-64

Figure 14: Y1H assay showing MYB53 (N-terminal), MYB92 (N-terminal), and MYB93 ability to bind to FAR4 promoter fragments \#3, \#9, \#11, and \#12 3-66

Figure 15: Location of the T-DNA in mutant $A$. thaliana (Col-0) seed lines used for the root suberin analysis. 3-67

Figure 16: A) Total aliphatic suberin in roots of 12-day old Arabidopsis seedlings comparing wild-type to three different wrky56 T-DNA insertion alleles. B) Suberin monomer levels sorted into compound class, comparing wild-type to the three wrky56 T-DNA insertion alleles 3-68 Figure 17: Amount of individual $\omega$-hydroxy fatty acids found in root suberin of wild-type and three wrky56 T-DNA insertion alleles of Arabidopsis 


\section{List of Supplementary Material}

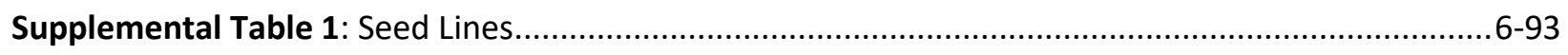

Supplemental Table 2: DNA vectors, host strains, and required antibiotics .................................... $6-94$

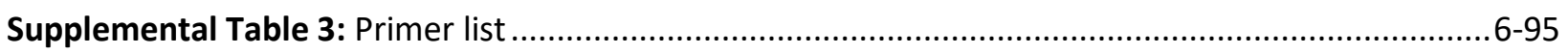

Supplemental Table 4: Constructed vector DNA glycerol stocks................................................6-100

Supplemental Table 5: FAR4pro: GUS deletion series images after GUS staining .............................6-103

Supplemental Table 6: Genes involved in suberin deposition...................................................6-118

Supplemental Table 7: Binding of suberin-associated transcription factors to genes involved in suberin

deposition.

Supplemental Table 8: Total aliphatic suberin from 12-day old roots of various Arabidopsis genotypes6-

120

Supplemental Table 9: Aliphatic suberin compounds of 12-day old roots from various Arabidopsis

genotypes.

Supplemental Figure 1: Map of the FAR4 5' promoter upstream region with specific motifs .............6-123

Supplemental Figure 2: Map of the T-DNA region in pGREENII 0800-LUC .....................................6-124

Supplemental Figure 3: Vector map of pSOUP .......................................................................... $6-124$

Supplemental Figure 4: Vector map of pDONR221 ............................................................ $6-125$

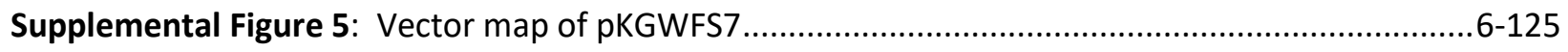

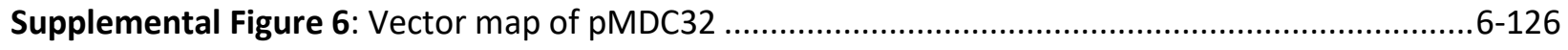

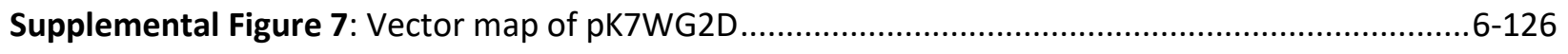

Supplemental Figure 8: Vector map of pVKH18 .................................................................. $6-127$

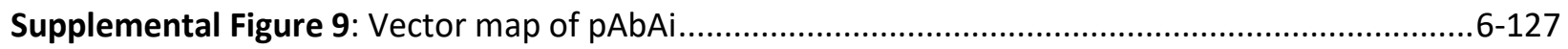

Supplemental Figure 10: Vector map of pGADT7-AD ........................................................... $6-128$ 


\section{1- Introduction}

\section{1- General opening statement}

Vascular plants, or Tracheophyta, represent the overwhelming majority of known plant species. They are present in our forests (e.g. Acer saccharinum - silver maple), our crop fields (e.g. Triticum aestivum bread wheat), and our gardens (e.g. Petunia axillaris - large white petunia). Understanding how vascular plants function will help researchers protect and improve them. All vascular plants contain central lignified tissues known as xylem, which transport water and nutrients from the roots to every other part of the plant, and phloem, which moves sugar from the leaves to non-photosynthesizing parts of the plant. The efficiency of this central bundle of conductive tissue that stretches throughout the entire plant, called the stele, has enabled vascular plants to be more widely distributed than non-vascular plants, or Bryophyta. In the roots of Tracheophyta, surrounding the stele is the endodermis, a single layer of cells whose walls are embedded with a hydrophobic material called suberin that helps maintain the symplastic movement of water and nutrients into the stele (Baxter et al., 2009; Nawrath et al., 2013). In this study, I investigated the regulation of suberin deposition in the root endodermis through the action of transcriptional regulators.

\section{2- Arabidopsis thaliana: a model system for the study of roots in vascular plants}

Taxonomically, vascular plants are initially separated into two groups. There are vascular plants that produce seeds (Spermatophytina) and vascular plants that do not produce seeds (Polypodiophytina and Lycopodiophytina). The Spermatophyhtina are divided into plants that bear naked seeds (Gymnosperms: Cycadopsida, Ginkgoopsida, Pinopsida, and Gnetopsida) and plants that bear seeds within fruit (Angiosperms or Magnoliopsida). Angiosperms are made up of two groups: the monocotyledons (monocots) and eudicotyledons (eudicots), which together comprise most of the vascular plants that are valued for human health, whether it be for food or medicine (Raskin et al., 2002). 
Arabidopsis thaliana (L.) Heynh. is a ubiquitously used plant model organism because it has a short lifecycle, mass seed amplification, a relatively small and diploid genome, and Agrobacterium-mediated transformation has made it easy to produce reporter, over-expression, and knockout mutant strains (Koornneef \& Meinke, 2010). A. thaliana is also a suitable model for studying root hydrophobic barriers in Angiosperms and all vascular plants. Roots are not the reason for the evolutionary divergences in vascular plants until the Angiosperms are divided into eudicots and monocots, so it is reasonable to believe root anatomy and function does not vary significantly across most vascular plants. Monocots usually have an ephemeral root that can be derived from the stems and leaves (adventitious roots) or the mesocotyl (seminal roots) and tend to branch in many directions while remaining near the top of the soil. Eudicots usually have a single primary root (tap root) that is derived from the radicle and can grow vertically into the soil with lateral roots branching from the tap root (Atkinson et al., 2014; Seago \& Fernando, 2013). The stele in the young roots of eudicots and monocots are encircled by an endodermis that contains the cell wall-associated hydrophobic barriers suberin and lignified Casparian strips (Zeier et al., 1999). The same internal root structure is observed in seedless vascular plants like the Polypodiophytina (ferns) (Chapple \& Peterson, 1987), vascular plants bearing naked seeds like Ginkgo biloba (Bonacorsi \& Seago, 2016), vascular plants that bear fruits like the monocot Zea mays (maize) (Zeier et al., 1999) and the eudicot $A$. thaliana (Nawrath et al., 2013). Therefore, A. thaliana is a good model organism for the study of cell-wall associated hydrophobic barriers in the root endodermis of vascular plants.

\section{3- Deposition and functions of extracellular, hydrophobic barriers in Arabidopsis}

Cell wall-associated hydrophobic barriers are integral to the survival of land plants, largely due to their ability to control the movement of water. Aerial plant organs (i.e. leaf) are coated with a hydrophobic barrier called the cuticle. The cuticle, which is composed of a glycerolipid polyester called cutin and 
associated waxes, is deposited on the outer cell wall of epidermal cells. The location and composition of the cuticle means it has a role in preventing uncontrolled water loss via transpiration, protection from plant pathogens, shielding the plant from UV-light, and protecting against various abiotic stresses (Franke et al., 2005; Nawrath et al., 2013). When wounded, the aerial tissues can deposit another hydrophobic barrier, called suberin, to 'seal' the wound (Vishwanath et al., 2015).

Roots contain two distinct hydrophobic barriers: Casparian strips and aliphatic suberin. Casparian strips, which mark stage I of root endodermis differentiation, are deposited in the primary wall of endodermal cells, and take up the entire intercellular space (apoplast) between adjacent endodermal cells. This creates a ring-like barrier along the root endodermis that prevents the uncontrolled apoplastic movement of water and solutes to the stele (Barberon et al., 2016; Barbosa et al., 2019; Naseer et al., 2012). The Casparian strip (names after its founder Robert Caspary) is made of a lignin-like polymer (Naseer et al., 2012). During stage II of root endodermal cell differentiation, aliphatic suberin is deposited on the inner face of the secondary cell wall as to encase the whole cell (Figure 1) (Barberon et al., 2016; Vishwanath et al., 2015). Suberin is a heteropolymer containing glycerol, fatty acids (including omega hydroxy and dicarboxylic fatty acids), fatty alcohols, and phenolic compounds (Vishwanath et al., 2015). In the young root's endodermis, the localization and composition of suberin allows it to regulate the transcellular movement of water and solutes (Barberon et al., 2016; Baxter et al., 2009). Together, Casparian strips and aliphatic suberin direct water and solute flow to the symplastic pathway to the xylem of the roots ( Enstone et al., 2002; Nawrath et al., 2012). Unlike Casparian strips, aliphatic suberin is also deposited at other tissue-tissue or plant-environment interfaces, such as the root exodermis, root and tuber periderms, leaf bundle sheath cells, and the seed coat (Barbosa et al., 2019; Vishwanath et al., 2015). 


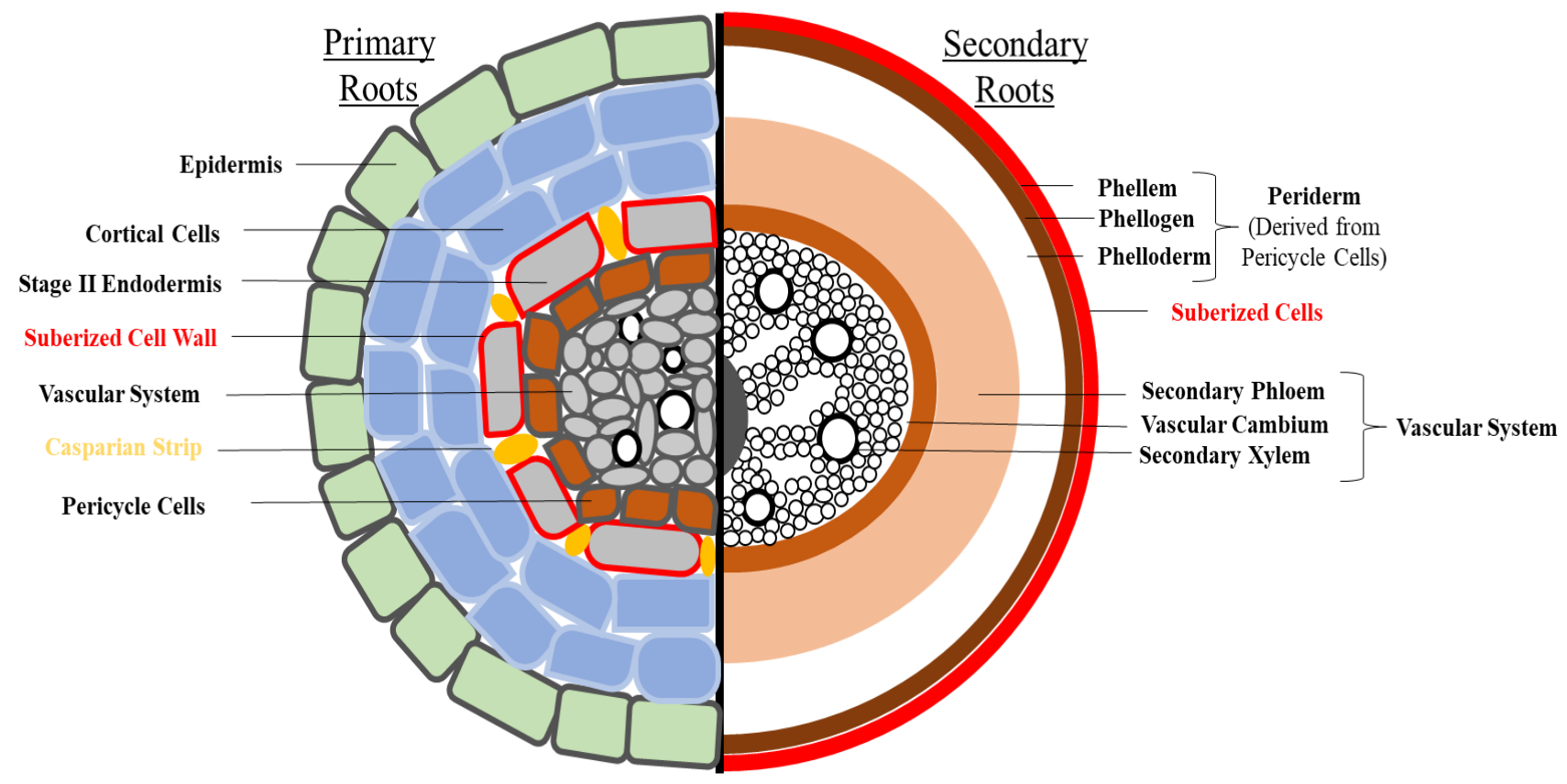

Figure 1: Schematic diagram of a cross-section of A. thaliana roots during their primary growth stage (left) and after their secondary growth stage (right). Gold ovals represent Casparian Strips and red represents suberin encasing endodermis cells (primary growth stage) and suberized cells of the periderm (secondary growth stage).

\section{4- Structure and composition of suberin}

Under transmission electron microscopy (TEM), suberin has a lamellae structure with an alternating light/dark banding pattern, indicating that suberin is not just a single layer, but a multilayered polymer. It has been proposed that these alternating light and dark bands represent distinct polyaliphatic and polyphenolic domains, respectively, but this has not been proven (Franke \& Schreiber, 2007; Graça, 2015; Schreiber, 2010). Some have suggested a simpler definition for suberin: a glycerolipid polyester with minimal phenolic content (i.e. ferulate) that can be closely associated with a phenolic/lignin-like polymer, for example the Casparian strip (Geldner, 2013).

The polyaliphatic nature of suberin is due to the presence of C16-C24 $\omega$-hydroxy fatty acids, $\alpha, \omega-$ dicarboxylic fatty acids, mid-chain oxygenated fatty acids, unsubstituted fatty acids, primary fatty alcohols, and $\alpha, \omega$-diols (Figure 2). Glycerol is a major component of suberin and was initially thought to 
link components of the polyaliphatic domain to the polyphenolic domain via ester linkages (Franke \& Schreiber, 2007; Graça, 2015; Vishwanath et al., 2015). However, glycerol is more likely integrated into the aliphatic suberin polymer to potentially form extensive branching of the polymer, as glycerol does in cutin (Geldner, 2013; Yang et al., 2016). Ferulate has also been shown to be a component of suberin's polyaliphatic domain. Non-covalently linked waxes, including alkyl hydroxycinnamates (AHC's), have also been reported to be associated with the suberin polymer and may confer 'sealing' properties (Delude et al., 2016; Gou et al.,2009; Molina et al., 2009; Vishwanath et al., 2013). Bearing in mind the debates in definition, the rest of this study will view suberin as an aliphatic polyester that contains some phenolic compounds. 
A)

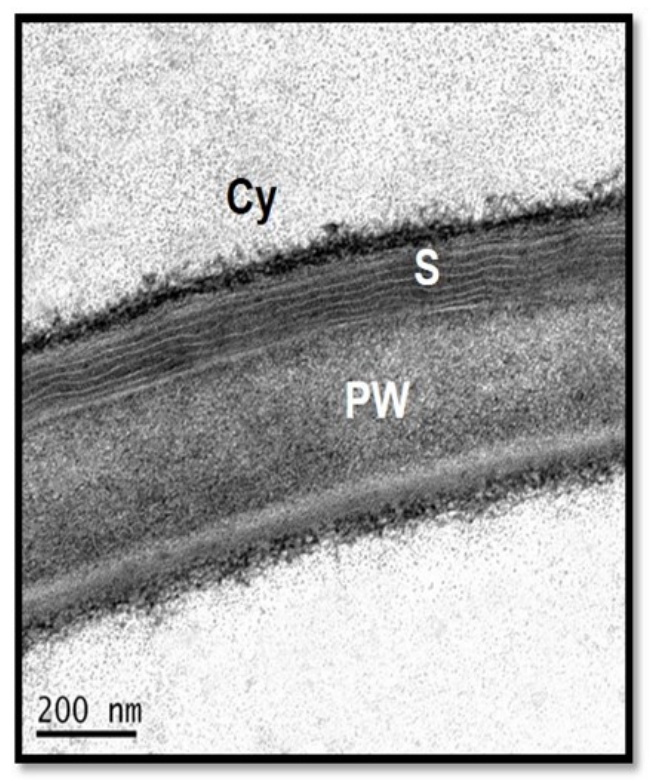

B)

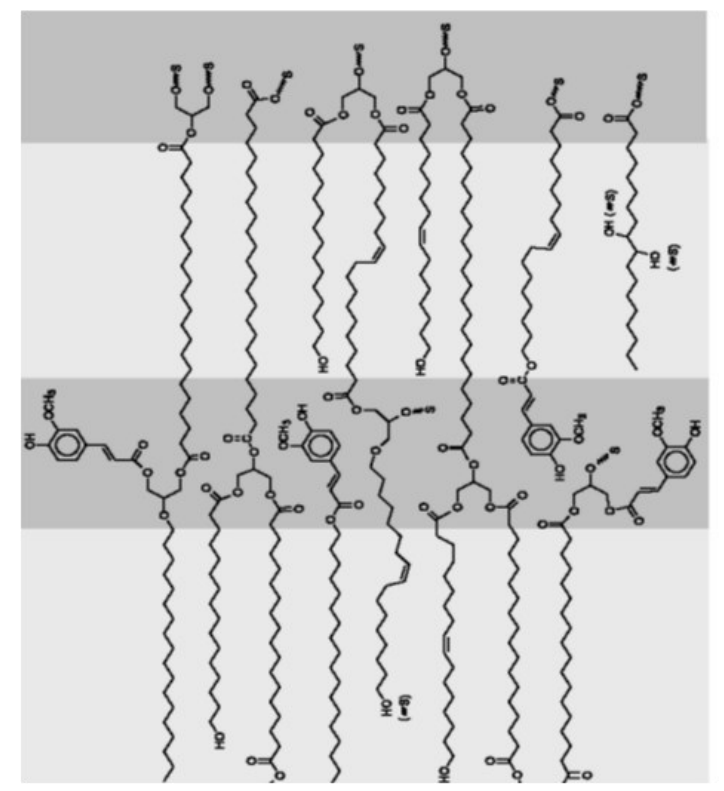

C)
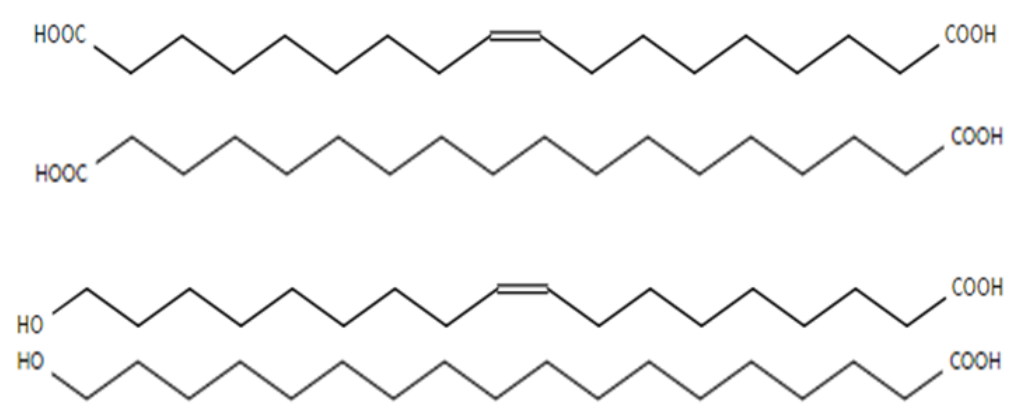

$\mathrm{N}^{\mathrm{COOH}}$

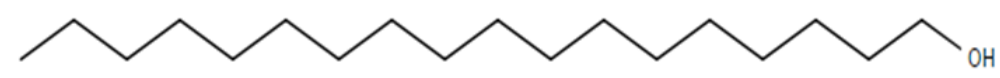

$\alpha, \omega$ - Dicarboxylic Acids

(C16-C22

$\omega$-Hydroxy Fatty Acids

(C16-C24)

Fatty Acids

(C16-C24)

Primary Fatty Alcohols

(C18-C22)<smiles>OCC(O)CO</smiles>

Glycerol

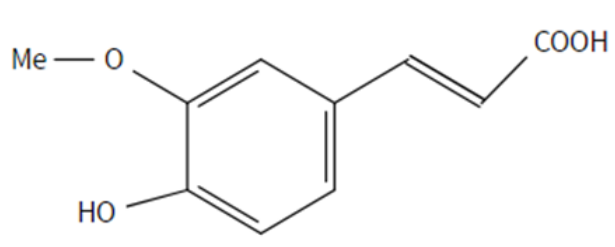

Ferulate

Figure 2: Structure and composition of the suberin polymer. A) TEM image demonstrating the multiple layers and alternating dark/light bands of the suberin polymer (De Silva 2018). B) Hypothesized organizational structure of the suberin polymer (Bernards, 2002). C)Class of monomeric constituents that typically compromise the root suberin polymer. 


\section{5- Suberin biosynthesis, transport, and assembly}

Suberin is composed of various long-chain (C16 and C18) and very-long-chain (C20-C24) fatty acid derivatives, meaning various enzymes from different families are required for its production (Figure 3) (Vishwanath et al., 2015). Suberin biosynthesis starts with 16:0, 18:0, and 18:1 fatty acids that are produced de novo in the plastid by the fatty acid synthase (FAS) cycle. These specific fatty acids are converted to fatty acyl thioesters linked with Coenzyme-A, either at the plastid outer envelope or the endoplasmic reticulum (ER), via the action of long-chain acyl-CoA synthetase (LACS) enzymes. In Arabidopsis, LACS enzymes are known to 'activate' lipid metabolism by generating fatty acyl-CoAs that are subsequently used in cutin and wax biosynthesis, amongst other processes (Shockey et al., 2002; Zhao et al., 2019). Originally found to only be involved in cutin monomer biosynthesis (Bessire et al., 2007; Schnurr et al., 2004), the lacs2 mutant was recently found to reduce the total suberin polymer in the root endodermis by almost half (Ayaz et al., 2021). In terms of suberin biosynthesis, the LACSgenerated fatty acyl thioesters at the ER have three possible fates: the acyl elongation pathway, the acyl reduction pathway, or the acyl oxidation pathway (Vishwanath et al., 2015).

Elongation of fatty acyl-CoAs occurs through the fatty acid elongase (FAE) complex located in the ER. The FAE complex is made up of four enzymes and the first enzyme in this complex, $\beta$-ketoacyl-CoA synthase (KCS), condenses malonyl-CoA with an acyl-CoA of a specific chain length to generate an acyl chain 2 carbons longer (Franke \& Schreiber, 2007; Vishwanath et al., 2015). For example, Arabidopsis KCS2/DAISY and KCS20 are enzymes that elongate 20:0 (very-long-chain) fatty acyl-CoA to 22:0 fatty acyl-CoA (Franke et al., 2009; Lee et al., 2009) and KCS9 catalyzes the elongation of 22:0 fatty acyl-CoA to 24:0 fatty acyl CoA (Kim et al., 2013). Although these KCS enzymes affect suberin biosynthesis, they may elongate fatty acyl-CoAs for other aspects of lipid metabolism. The remaining three enzymes in the FAE complex modify the product of the condensation reaction to regenerate fully reduced acyl-CoAs (Kim et al., 2013). The elongated (C20-C26) fatty acyl CoAs are either incorporated directly into the 
suberin polymer, modified through the acyl oxidation pathway, or modified through the acyl reduction pathways (Vishwanath et al., 2015).

The acyl reduction pathway produces fatty primary alcohols from fatty acyl thioester-CoAs through a two-step NADPH-dependent reaction performed by a single FAR enzyme. Arabidopsis contains eight FAR enzymes but only three, FAR1, FAR4, and FAR5, are expressed at sites of suberin deposition (i.e. root endodermis, leaf wounds, in response to abiotic stress) as revealed by qPCR and promoter: GUS experiments (Domergue et al., 2010). Fatty alcohols with chain lengths of 18, 20, and 22 carbons typically exists in the suberin polymer. Genetic experiments using far1, far4, and far5 single, double, and triple mutants revealed preferences of FAR1 for $\mathrm{C} 22: 0-\mathrm{OH}$, FAR4 for $\mathrm{C} 20: 0-\mathrm{OH}$, and FAR5, for $\mathrm{C} 18: 0-\mathrm{OH}$, with FAR4 also contributing to $\mathrm{C22}: 0-\mathrm{OH}$ production (Domergue et al., 2010; Vishwanath et al., 2013). Transgenic expression experiments in yeast confirmed the FAR chain-length preferences, while showing each FAR is a capable of using substrates of each chain-length (Delude et al., 2016; Domergue et al., 2010; Vishwanath et al., 2013). While $20 \%$ of fatty alcohols produced by FAR1, FAR4, and FAR5 can then be incorporated into the root suberin polymer, $\sim 80 \%$ of root fatty alcohols are found in soluble waxes thought to be associated, not covalently linked, with the suberin polymer (Delude et al., 2016; Vishwanath et al., 2013). Interestingly, the far1 far4 far5 mutant did not show any alterations to the root suberin lamellae or have root physiological affects, but the seed coat showed an increased permeability of tetrazolium salt and an increased sensitivity to abscisic acid (Delude et al., 2016; Vishwanath et al., 2013).

The acyl oxidation pathway converts fatty acyl chains from 16 to 24 carbons in length into $\omega$-hydroxy fatty acids and $\alpha, \omega$-dicarboxylic fatty acids. Analysis of root suberin composition in Arabidopsis at three different root stages revealed $\omega$-hydroxy fatty acids (37-52 \%) and $\alpha, \omega$-dicarboxylic acids (28-31 \%) were the most prominent components and the percentage of $\omega$-hydroxy acids and $\alpha, \omega$ - dicarboxylic acids increases with age (Delude et al., 2016; Höfer et al., 2008). Suberin-associated cytochrome P450 
(CYP) monooxygenases from Arabidopsis were first characterized via heterologous expression in yeast, where AtCYP86A1 was shown to act as an $\omega$-hydroxylase on saturated fatty acids ranging from 12 to 18 carbons in length (Benveniste et al., 2006). CYP86A1 is localized to the ER and is specifically expressed in the root endodermis (Höfer et al., 2008). More importantly, a T-DNA knockout of the CYP86A1 gene revealed a $60 \%$ reduction in total suberin polymer compared to wild-type, led by the loss of $16: 0$ and 18:0 $\omega$-hydroxy acids and $\alpha, \omega$-dicarboxylic acids (Höfer et al., 2008). CYP86B1 is another $\omega$-hydroxylase localized to the ER and highly expressed in the root endodermis (Compagnon et al., 2009). The T-DNA cyp86b1 loss-of-function mutants have strong and specific reductions in C22:0 and C24:0 w-hydroxy acids and $\alpha, \omega$-dicarboxylic fatty acids (Compagnon et al., 2009; Molina et al., 2009)TEM analysis of cyp86b1 revealed a disturbance to the suberin lamellar structure in root periderm, furthering demonstrating the involvement of CYP86B1 in suberin biosynthesis and the importance of $\omega$-hydroxy acids and $\alpha, \omega$-dicarboxylic fatty acids to integrity of the suberin polymer (Compagnon et al., 2009). Although CYP86A1 hydroxylates the $\omega$-position of $16: 0$ and 18:0 fatty acids and CYP86B1 acts identically on 22:0 and 24:0 fatty acids, it is not clear if they also then produce the $\alpha, \omega$-dicarboxylic fatty acids with a subsequent oxidation step. The decrease of $\alpha, \omega$ - dicarboxylic fatty acids in the cyp86a1 and cyp86b1 loss-of-function mutants could be attributed to another unknown enzyme that converts $\omega$ hydroxy fatty acids to $\alpha, \omega$-dicarboxylic fatty acids. If this were the case, then the decrease of $\alpha, \omega$ dicarboxylic fatty acids in the cyp86a1 and cyp86b1 mutants would be attributed to the pool of the precursors ( $\omega$-hydroxy fatty acids) being depleted (Compagnon et al., 2009; Höfer et al., 2008).

Two other CYP genes, CYP94B1 and CYP94B3, are also involved in suberin biosynthesis (Krishnamurthy et al., 2020; Krishnamurthy et al., 2021). Under non-stress conditions CYP94B1 was expressed throughout the entire Arabidopsis plant. Under salt stress a 4-fold increase was observed in the roots, with a specific localization to the endodermis. CYP94B1 overexpression, complementation (with Arabidopsis officinalis CYP94B1), and mutant experiments demonstrated a role for CYP94B1 in providing 
$\omega$-hydroxy fatty acid (C16 and C22) and $\alpha, \omega$-dicarboxylic fatty acids (C16) that are important for the diffusion barrier properties of the suberin polymer, and ultimately has a positive role in Arabidopsis' response to salt-stress (Krishnamurthy et al., 2020). The same role was found for CYP94B3 (Krishnamurthy et al., 2021). It appears that these two CYP94 genes complement the CYP86 suberin biosynthesis genes in the root endodermis to enhance suberin deposition under salt-stress, and it is possible that this same concept can be applied to the other genes involved in suberin biosynthesis.

Partial root suberin depolymerization experiments led to the discovery that the suberin polymer contains fatty acids and their derivatives ( $\omega$-hydroxy fatty acids and $\alpha, \omega$-dicarboxylic fatty acids) linked to glycerol through ester bonds. A family of eight GPAT genes in Arabidopsis are a land plant-specific adaption of GPATs that are unique for building extracellular lipid polymers like cutin and suberin (Graça \& Santos, 2006; Yang et al., 2012b). GPAT5 is primarily expressed in all cell layers of the roots, along with flowers and seeds. A gpat5 knockout resulted in a $20-50 \%$ reduction in suberin-associated 20:0 - 24:0 fatty acids and their derivatives in 1-week-old Arabidopsis roots (Beisson et al., 2007). When GPAT5 was ectopically expressed in yeast and wheat (germ cell-free) translation systems, there was a preference for substrates greater than 20 carbons in length, with no discrimination to oxidation state (i.e. fatty acid, $\omega$ hydroxy fatty acid, or $\alpha, \omega$-dicarboxylic fatty acid), which agrees with the in vivo knockout results of gpat5 mutants. The most closely related enzyme to GPAT5 is GPAT7, and although it is not expressed in roots it is expressed in response to leaf wounding. Over-expression of GPAT7 resulted in the production of monoacylglycerols containing $22: 0$ and $24: 0$ fatty acids and derivatives, indicating it has the same substrate specificity as GPAT5 but has a specialized role in suberin production following wounding and likely acts in response to other stresses (Yang et al., 2012).

GPAT5 and GPAT7, along with most of the Arabidopsis GPATs, show a preference for the sn-2 positions of glycerol-3-phosphate (G3P) over the sn-1 position that GPATs found in other kingdoms have only been known to use (Yang et al., 2012). The ability to transfer acyl-CoA compounds to the sn-1 and sn-2 
positions of G3P is in-line with partial depolymerization experiments done on cork suberin, which revealed the presence of diacylglycerol fragments (Graça \& Santos, 2006). All Arabidopsis GPATs have a phosphatase domain, with GPAT4 and GPAT6 having phosphatase activity and forms monoacylglycerols (MAG) from G3P and acyl-CoA substrates in yeast and wheat (germ cell-free) translation systems (Yang et al., 2012). Interestingly, GPAT5 has mutations at important phosphatase catalytic residues and can only form lysophosphatidic acid (LPA), which is an intermediate to MAGs (Yang et al., 2012). Why GPAT5 lacks phosphatase activity and what could perform this necessary step in place of GPAT5 has not yet been investigated, while GPAT7 was not tested for phosphatase activity. Fatty alcohols are a part of the suberin polymer, but the amount of fatty alcohols in suberin is not affected by GPAT5 or GPAT7 overexpression or in knockout lines. The use of fatty alcohols as substrates by GPATs were not investigated in the yeast and wheat (germ cell-free) translation systems (Yang et al., 2012). Currently, the enzyme that links fatty alcohols into the suberin polymer is unknown.

The lipids that form cuticle (cutin and waxes) in Arabidopsis are transported, at least in part, through the secretory pathway from the ER to the plasma membrane (PM). The transport mechanism for suberinbased lipids produced in the ER is probably similar to that of cuticle-based lipids considering the chemical similarities (McFarlane et al., 2014). Transfer of these suberin-based lipids from the PM to the cell wall are thought to be catalyzed by ATP-binding cassettes $(A B C)$ transporters, which are localized in the PM. Single mutants of $a b c g 2, a b c g 6$, and $a b c g 20$ did not have a suberin phenotype, while triple mutants of these three $A B C$ transporter genes result in seed coat and root suberin lamellae having perturbed structures, compositions, and properties (Yadav et al., 2014). GPI-anchored nonspecific lipid transfer proteins (nsLTP), like AtLTP1-4, transfer long-chain fatty acids and very-long chain fatty acids from the plasma membrane to the cell well (Deeken et al., 2016; Edstam et al., 2013). Although nsLTPs have a broad range of substrates, their expression in specific cell types partly dictates what they can transport and it is possible they facilitate the transport suberin precursors. 
Once at the inner-face of the cell wall, the suberin-based lipids must be polymerized... Ursache et al. (2021) discovered five GDSL-type esterases/lipases (GELPs) that are required for suberin production in the root endodermis. A quintuple mutant of the five GELPs (gelp22, 38, 49, 51 and 96) lacks suberin in the root endodermis. These five GELPs are also repressed by auxin, which initiates lateral root growth, as suberin needs to be depolymerized to make way for the lateral root. A separate set of five GELPs (GELP12, 55, 72, 73 and 81) are induced by auxin and subsequently required for suberin depolymerization during lateral root formation (Ursache et al., 2021). Biochemical studies need to be done to prove the enzymatic activity of the ten GELPs and understand the large family of GELP enzymes.

Outside of aliphatic compounds, phenolic compounds, especially hydroxycinnamates (from the phenylpropanoid pathway), are also incorporated into the suberin polymer. The BAHD family of enzymes, which are specific to land plants, are acyl-CoA dependent acyltransferases that have the unique function of connecting cinnamate-CoA thioesters to an acyl chain, like an $\omega$-hydroxy fatty acid (Gou et al., 2009). An aliphatic suberin feruloyl transferase (asft) T-DNA knockout mutant showed a specific reduction of ferulate in the root and seed coat suberin polymer of Arabidopsis and had no effect on suberin-associated waxes (Molina et al., 2009a). Growth and development sensitivities for asft were found when grown in media containing higher than normal levels of salt, revealing a role for ferulate in controlling ion movement as part of the suberin polymer (Gou et al., 2009). Fatty Alcohol:Caffeoyl-CoA Caffeoyl Transferase (FACT), was found to add suberin-acyl chains to caffeate-CoA specifically and fact mutants clearly decreased alkyl hydroxy caffeate content in seed coat suberin, root suberin, and root waxes (Kosma et al., 2012). The action of these suberin-associated BAHD family of enzymes likely takes place in the ER, but evidence is not concrete. 


\begin{tabular}{|c|c|}
\hline \multirow[t]{2}{*}{ Plastid } & Fatty Acid Synthesis - $16: 0,18: 0$, and $18: 1$ fatty acids produced are transported to the ER \\
\hline & LACS enzymes converts fatty acids to fatty acyl-CoA \\
\hline \multirow{6}{*}{$\begin{array}{l}\text { Endoplasmic } \\
\text { Reticulum }\end{array}$} & Acyl Elongation - KCS2, KCS9, and KCS20 extend fatty acids up to $20-26$ carbon chains \\
\hline & Acyl Reduction - FAR1, FAR4, and FAR5 produce C18-C22 fatty alcohol \\
\hline & $\begin{array}{l}\text { Acyl Oxidation- CYP86A1, CYP86B1, CYP94B1, and CYP94B3 produce C16-C24 } \omega \text {-hydroxy fatty acids and } \\
\alpha, \omega \text {-dicarboxylic acids }\end{array}$ \\
\hline & Glycerol Transfer-GPAT5 link $\omega$-hydroxy fatty acids and $\alpha, \omega$-dicarboxylic acids to glycerol \\
\hline & Cinnimate Link - ASFT adds $\omega$-hydroxy fatty acids to ferulate \\
\hline & vesicle trafficking system \\
\hline \multirow[t]{2}{*}{$\begin{array}{l}\text { Plasma } \\
\text { Membrane }\end{array}$} & $\begin{array}{l}\text { Export - ABCG2, ABCG6, and ABCG20 transport 'suberin monomers' from inside the cell to the } \\
\text { extracellular space }\end{array}$ \\
\hline & $\checkmark$ \\
\hline Inner Cell Wall & Polymerization-GELP22, GELP38, GELP49, GELP51, GELP96 help form the suberin polymer \\
\hline
\end{tabular}

Figure 3: Overview of suberin biosynthetic pathway

\section{6- Regulators of root suberin deposition}

MYB41 is an R2R3-MYB transcription factor (MYB TF) from the model plant Arabidopsis thaliana capable of upregulating the synthesis, export, assembly, and cell wall-localized deposition of suberin (Kosma et al., 2014). Only in response to abiotic stress (e.g. high salt) is MYB41 expressed in the root endodermis, and its overexpression corresponds with an increase in the levels of transcripts encoding suberin biosynthetic enzymes (i.e. CYP86A1, CYB86B1, GPAT5, FAR1, FAR4, FAR5, and ASFT) (Kosma et al., 2014). AtMYB39 (or 'SUBERMAN') has been shown to promote suberin biosynthesis in the root endodermis, under stress free conditions, using knockout and over-expression lines. Importantly, promoter: reporter gene assays in leaves of Nicotiana benthamiana demonstrated that AtMYB39 can transcriptionally activate multiple Arabidopsis suberin biosynthetic genes via their promoter ( $5^{\prime}$ region upstream of translation start site) regions (Cohen et al., 2020). AtMYB107 and AtMYB9 are two other R2R3-MYB TFs, highly related to AtMYB39, that regulate the biosynthesis of seed coat suberin and are strongly responsive to osmotic stress in the seed coat (Gou et al., 2017; Lashbrooke et al., 2016). Furthermore, AtMYB107 was found to bind directly to the promoters of suberin biosynthesis genes FAR1, GPAT5, 
FACT, and CYP86A1 in Y1H and ChIP assays (Gou et al., 2017). In addition to AtMYB39, transcription factors that regulate suberin biosynthesis constitutively (under non-stress conditions) in root endodermis have been discovered in Dr. Rowland's lab: AtMYB53, AtMYB92, and AtMYB93.

MYB53, MYB92, and MYB93 comprise subgroup 24 of the Arabidopsis family of R2R3-MYB TFs (Kelemen et al., 2015; Stracke et al., 2001). Through a promoter: reporter gene fusion, it was found that AtMYB53 and AtMYB93 are specifically expressed in the root endodermis, while AtMYB92 is expressed in the root endodermis and root pericycle (Murmu et al., manuscript in preparation, Rowland Lab). All three of these R2R3-MYB TFs have been implicated in positively regulating suberin biosynthesis in the root endodermis under typical development conditions. Overexpression of any one of these R2R3-MYB TFs in leaves of Nicotiana N. benthamiana causes ectopic deposition of suberin lamellae (Murmu et al., manuscript in preparation; To et al., 2020). Based on chemical analysis of suberin using AtMYB53/92/93 single, double, and triple mutants, it is suggested that all three R2R3-MYB TFs regulate suberin biosynthesis in the root endodermis in an overlapping fashion (Hu, 2018).

AtMYB93 has been previously indicated as a repressor of lateral root development through its binding to the ARABIDILLO-1 protein, a promoter of lateral root growth (Gibbs et al., 2014). It is possible AtMYB93 has the unique role of inducing suberin deposition in regions where lateral roots are not formed in response to specific developmental and environmental cues. An AtMYB93 homolog, MdMYB93, that was found to be expressed in russetted apple fruit skins and ectopically activates suberin biosynthesis in N. benthamiana leaves when over-expressed (Legay et al., 2016). AtMYB92 has been found to bind to the promoter of $B C C P 2$, whose encoded protein is part of the acetyl-CoA carboxylate complex that catalyzes the biotin-dependent carboxylation of acetyl-CoA to malonyl-CoA for fatty acid synthesis in plastids (To et al., 2020). Interestingly, AtMYB92 was only capable of binding to and activating the BCCP2 promoter when two adjacent AC-rich MYB TF binding sites were not mutated. Therefore, there is likely a 
need for AtMYB92 to dimerize with itself or another MYB TF for DNA binding to the BCCP2 promoter. Transient transactivation assays also demonstrated that AtMYB92 could transcriptionally activate other promoters in the fatty acid biosynthesis pathway, such as ACP1 and LPD1 (To et al., 2020). Further analysis revealed that over-expression of AtMYB92 increased the abundance of suberin biosynthesis mRNA transcripts and suberin deposition, in-line with data found in the Rowland lab ((Murmu et al., manuscript in preparation; To et al., 2020). Therefore, MYB92 may help induce suberin deposition by increasing the pool of fatty acid precursors available to the suberin biosynthetic pathway. To date, no publications have reported a function for AtMYB53. Phylogenetic analysis of the R2R3-MYB TFs reveal subgroup 24, which contains AtMYB53, AtMYB92 and AtMYB93, is closely related to subgroup 11 (containing AtMYB41) and subgroup 10 (AtMYB39, AtMYB107 and AtMYB9) (Kelemen et al., 2015; Stracke et al., 2001). It is therefore possible that R2R3-MYB TF subgroups 28,10 , and 11 all regulate suberin biosynthesis in various plant tissues, some of which are functioning together or in a partially redundant manner. Outside of the R2R3-MYB TF family, NAC046 was shown to promote suberin biosynthesis in the roots of $A$. thaliana when overexpressed (Mahmood et al., 2019), however NACO46 has also been shown to promote chlorophyll degradation and leaf senescence in Arabidopsis, so its connection to root suberin production is in question (Oda-Yamamizo et al., 2016). In Solanum tuberosum (Potato), NAC103 repressed the production of suberin-associated waxes in the tuber phellem but had no impact on the suberin polymer (Soler et al., 2020). From the WRKY TF family, WRKY33 and WRKY9 were found to directly upregulate CYP genes (CYP94B1 and CYP94B3, respectively) that they coexpress with during salt stress. ChIP, Y1H, and promoter: reporter assays demonstrated that WRKY33 directly binds to and activates the CYP94B1 promoter; and in-turn 16:0 to 22:0 w-hydroxy fatty acids are increased in the root endodermis (Krishnamurthy et al., 2020). ChIP and EMSA revealed WRKY9 could bind directly to the CYP94B3 and CYP86B1 promoters. CYP94B3 was connected to the production of root endodermis suberin lamellae, more specifically the 20:0 fatty alcohol, 16:0 $\omega$-hydroxy acids, and 16:0 $\alpha$, 
$\omega$-dicarboxylic acids that make up the suberin polymer (Krishnamurthy et al., 2021). WRKY56 is of interest as it was substantially upregulated in roots over-expressing MYB39 (Cohen et al., 2020) and MYB53, and was downregulated in roots of myb53 myb92 myb93 triple knockouts (Klein, 2019). Lashbrooke et al. (2016) also identified WRKY56 as part of the multi-species gene signature for suberin deposition. Although WRKY33 and WKRY9 were not shown to interact with a R2R3-MYB TF, they have been shown to directly regulate specific genes involved in suberin biosynthesis and it is possible that WRKY56 has a similar role.

\section{7- MYB transcription factor interactions}

R2R3-MYB TFs have the potential to bind DNA and other proteins. Arabidopsis MYB53, MYB92, and MYB93, preferentially bind to synthesized AC-rich MYB TF cis-elements in EMSA and/ or Y1H assays (Dubos et al., 2014; Kelemen et al., 2015). However, they have not been shown to bind to the promoters of suberin biosynthetic genes. As described earlier, MYB92 can bind to AC-rich elements in the BCCP2 promoter, a fatty acid synthesis gene (To et al., 2020). AtMYB39 can transcriptionally activate suberin biosynthetic genes. Y1H assays found evidence of AtMYB39 binding to the FAR5 'promoter', but none of the nine other suberin biosynthetic gene 'promoters' were tested. This leaves the possibility that AtMYB39 indirectly activates suberin biosynthesis (i.e. higher up in a transcriptional cascade) or requires the activity of another transcription factor (i.e. dimerization, like with MYB92 or a non-MYB TF). No other R2R3-MYB TF in subgroups 28,10 , and 11 have been shown to bind to a specific gene promoter.

Most research on protein-protein interactions involving R2R3-MYB TFs has focused on bHLH TF and WD40 proteins, which form a MBW complex, for example in the context of flavonoid biosynthesis (Amato et al., 2019; Gil-Muñoz et al., 2020; S. Li, 2014). The MBW complex has been mostly studied in relation to proanthocyanin biosynthesis and it allows for increased complexity, diversity, and adaptability of transcriptional regulation. In Vitis vinifera (grape vine), WRKY26 enhances the expression of specific 
target genes when interacting with the MYB5a/b-MYC1(bHLH TF)-WD40 complex (Amato et al., 2019). There is also evidence of direct interactions between WRKY and MYB TFs in V. vinifera, as the stilbene synthase gene was shown to be regulated by different combinations of MYB15 or MYB14 and WRKY3, WRKY24, WRKY43, WRKY52, or WRKY53 (Vannozzi et al., 2018). Although WRKY33 and WRKY9 directly regulate suberin biosynthesis genes alone, it is still possible that they or other WRKY TFs interact with the suberin-associated MYB TFs to regulate transcription of suberin biosynthetic genes.

\section{8- Hypothesis}

I hypothesize that Arabidopsis MYB41, MYB53, MYB92, and MYB93 directly activate the transcription of suberin biosynthetic genes via binding to the 5 ' region upstream of the translation start site (the 'promoter'). I predict that each root suberin-associated R2R3-MYB TF will bind to AC-rich cis-elements in the promoter of suberin biosynthetic genes. These results will support the redundancies previously observed between MYB53, MYB92, and MYB93 single, double, and triple knockout lines (Murmu et al, Rowland Lab, manuscript in preparation). Also, I hypothesize that root suberin-associated R2R32-MYB TFs will activate the promoter of WRKY56 and that WRKY56 regulates suberin biosynthesis.

\section{9- Experimental Objectives}

First, the ability of the root suberin-associated R2R3-MYB TFs to transcriptionally activate the promoter of suberin biosynthesis genes was tested. The TFs were cloned into over-expression vectors, as transcriptional fusions with the 35S promoter, and the promoters were cloned into the pGREENII 0800LUC reporter vector, as transcriptional fusions with FIREFLY LUCIFERASE. The over-expression and reporter vectors were each transformed into Agrobacterium tumefaciens, and these cultures were coinfiltrated into the leaves of $N$. benthamiana. Plant cells containing the over-expression and reporter vectors, transferred from the Agrobacterium, will produce FIREFY LUCIFERASE if the TF activates the promoter. Second, a single suberin biosynthesis gene promoter (FAR4) was used to determine if and 
where root suberin-associated R2R3-MYB TFs bind directly. The minimal size of the FAR4 promoter required for expression in the root endodermis (where suberin is deposited) was determined. For this, a deletion series of the FAR4 promoter was made and each deletion was cloned into a reporter gene vector. Multiple stable plant lines expressing each promoter:reporter construct were generated and stained for the expression of the reporter gene. Regions of the FAR4 promoter identified as important for root endodermis expression were then analyzed using bioinformatics for potential TF binding sites and divided into multiple 100-200 bp fragments. A Y1H assay was used to determine if the root suberinassociated R2R3-MYB TFs could bind to the $100-200$ bp fragments of the FAR4 promoter determined to be important of root endodermis expression. Third, the involvement of WRKY56 in regulating root suberin biosynthesis was characterized using T-DNA insertion mutants. 


\section{2- Materials and Methods}

\section{1- Plant Materials}

A. thaliana ecotype Columbia (Col)-0 and $N$. benthamiana ecotype Lab were used in this study. Three TDNA insertion lines, wrky56-1, wrky56-2, and wrky56-3 were obtained from the Arabidopsis Biological Resource Centre (ABRC), Ohio State University (Supp. Table 1).

\section{2- General Protocols}

\subsection{1- Seed surface sterilization}

Arabidopsis thaliana (Col-0) and Nicotiana benthamiana seeds (Supp. Table 1) were gently mixed in 70 $\%(\mathrm{v} / \mathrm{v})$ ethanol for 1 minute and washed with sterile distilled $\mathrm{H}_{2} \mathrm{O}\left(\mathrm{dH}_{2} \mathrm{O}\right)$. Next, the seeds were gently washed with a $1.8 \%(\mathrm{v} / \mathrm{v})$ sodium hypochlorite solution for 2 minutes and washed with sterile $\mathrm{dH}_{2} \mathrm{O}$ five times, or until there was no smell of the sodium hypochlorite (bleach) solution. After sterilization, all seeds were re-suspended in sterile $\mathrm{dH}_{2} \mathrm{O}$. A. thaliana (Col-0) seeds were stratified in the dark at $4{ }^{\circ} \mathrm{C}$ for 3 days before being sown. N. benthamiana seeds did not undergo stratification.

\subsection{2- Growth conditions of $N$. benthamiana infiltrated with Agrobacterium tumefaciens}

Sterilized N. benthamiana seeds were sown into autoclaved soil (Pro-mix BX-General Purpose Growing Medium) that had been water saturated with a fertilizer (fertilizer solution had concentrations of $0.2 \%$ (w/v) 20-20-20 macronutrient mix [Plant-Prod] and 0.0125\% (w/v) chelated micronutrient mix [PlantProd]). Plants were grown under a 16 -hr light $\left(180-210 \mu \mathrm{mol} \cdot \mathrm{m}^{2} \cdot \mathrm{s}^{-1}, 22^{\circ} \mathrm{C}\right)$ and 8 -hr dark $\left(21^{\circ} \mathrm{C}\right)$ cycle, with the first week of growth under a plastic cover to increase humidity and help promote germination. After the first week, the plant soil was lightly fertilized once a week as described above and additionally watered about twice per week for 5-8 weeks total. Plant watering was stopped three days prior to the infiltration of leaves with Agrobacterium tumefaciens. 


\subsection{3- Growth conditions of A. thaliana used for generation of FAR4 promoter: GUS lines}

Sterilized $A$. thaliana (Col-0) seeds were incubated in the dark at $4{ }^{\circ} \mathrm{C}$ for three days, then sown into autoclaved soil (Pro-mix BX-General Purpose Growing Medium) that had been water saturated with fertilizer (fertilizer solution had concentrations of $0.2 \%(w / v)$ 20-20-20 macronutrient mix [Plant-Prod] and $0.0125 \%(\mathrm{w} / \mathrm{v})$ chelated micronutrient mix [Plant-Prod]). To plants used for floral dip transformation were grown under a 16 -hr light $\left(100-130 \mu \mathrm{mol} \cdot \mathrm{m}^{2} \cdot \mathrm{s}^{-1}, 21^{\circ} \mathrm{C}\right)$ and $8 \mathrm{hr}$ dark $\left(21^{\circ} \mathrm{C}\right)$ cycle. All successive generations were grown under $24 \mathrm{hr}$ of light $\left(100-130 \mu \mathrm{mol} \cdot \mathrm{m}^{2} \cdot \mathrm{s}^{-1}, 21^{\circ} \mathrm{C}\right)$ for seed amplification.

\subsection{4- Transformation of chemical competent E. coli $(\mathrm{DH} 5 \alpha)$ cells}

Chemical competent E. coli $(\mathrm{DH} 5 \alpha)$ cells (stored at $-80^{\circ} \mathrm{C}$ ) were thawed on ice for 15 minutes. $50 \mu \mathrm{L}$ of cells were mixed with $10 \mathrm{ng}$ of vector (v) DNA or $2 \mu \mathrm{L}$ of cloning reaction, and incubated on ice for 15 minutes with gentle mixing every 5 minutes. The cell / DNA mixture was heat shocked for 1 minute at 42 ${ }^{\circ} \mathrm{C}$, placed on ice for 1 minute, then $450 \mu \mathrm{L}$ of LB media was added. The transformed cells were incubated at $37^{\circ} \mathrm{C}$ for 1 hour with shaking, then centrifuged at $4,700 \times g$ for 1 minute. The supernatant was discarded and the pellet was re-suspended in $100 \mu \mathrm{L}$ of LB. $90 \mu \mathrm{L}$ and $10 \mu \mathrm{L}$ of the resuspended pellet were added separately to LB agar (0.7\%) plates with the appropriate antibiotic (Supp. Table 2) and left to incubate overnight at $37^{\circ} \mathrm{C}$, in the dark.

\subsection{5- Transformation of electrocompetent A. tumefaciens (GV3101::pMP90) cells}

Electrocompetent A. tumefaciens (GV3101::pMP90) cells (stored at $-80^{\circ} \mathrm{C}$ ) were thawed on ice for 15 minutes. $50 \mu \mathrm{L}$ of cells were mixed with $50 \mathrm{ng}$ of vector DNA (Suppl. Table 4) and incubated on ice for 15 minutes with gentle mixing every 5 minutes. If more than one vector was being transformed into the same cells (i.e. pGREENII 0800-LUC reporters and pSOUP), $50 \mathrm{ng}$ of each vector was used. The cell-DNA mixture was transferred to a pre-chilled electroporation cuvette, and all moisture was wiped off. Electroporation was done at $2.2 \mathrm{kV}, 10 \mu \mathrm{F}$ capacitance, and $630 \mathrm{Ohm}$ resistance on a MicroPulser Electroporator (Bio-Rad). Following electroporation, $450 \mu \mathrm{L}$ of LB media was immediately added to the 
cells. Transformed cells were left to incubate at $30^{\circ} \mathrm{C}$ for 2 hours with shaking. The transformed cell culture was centrifuged at 4,700 $\mathrm{g}$ for 1 minute, the supernatant discarded, and the pellet was resuspended in $100 \mu \mathrm{L}$ of LB. $90 \mu \mathrm{L}$ and $10 \mu \mathrm{L}$ of the resuspended pellet were added separately to LB agar $(0.7 \%)$ plates with the appropriate antibiotics (Supp. Table 2 ) and left to incubate for 2 days at $30^{\circ} \mathrm{C}$, in the dark.

\subsection{6- Preparing and transforming chemically competent yeast cells}

A single yeast colony was inoculated in $5 \mathrm{~mL}$ of YPAD (or appropriate selective media) and incubated overnight at $30{ }^{\circ} \mathrm{C}$ with shaking. The entire yeast culture was added to $45 \mathrm{~mL}$ of YPAD (or appropriate selective media), pre-warmed to $30{ }^{\circ} \mathrm{C}$, and left to grow at $30{ }^{\circ} \mathrm{C}$ with shaking until the $\mathrm{OD}_{600 \mathrm{~nm}}$ of the 50 $\mathrm{mL}$ yeast culture doubled twice ( 8 hours). The $50 \mathrm{~mL}$ yeast culture was centrifuged at $1,811 \times \mathrm{g}$ for 2 minutes. The supernatant was discarded, and the yeast pellet was resuspended in $25 \mathrm{~mL}$ sterile $\mathrm{dH}_{2} \mathrm{O}$. The yeast culture was centrifuged at 1,811 x $g$ for 2 minutes, the supernatant was discarded, and the yeast pellet was resuspended in $1 \mathrm{~mL}$ of $100 \mathrm{mM}$ LiAc (prepared fresh). The $1 \mathrm{~mL}$ yeast culture was centrifuged at 6,200 $\times g$ for 5 seconds, the supernatant was discarded, and the pellet was resuspended in $100 \mathrm{mM}$ LiAc, up to a volume of $500 \mu \mathrm{L} .50 \mu \mathrm{L}$ of the now chemically competent yeast culture was added to $500 \mathrm{ng}$ of DNA and put-on ice. In order, the following were added to each $50 \mu \mathrm{L}$ chemically competent yeast sample: $240 \mu \mathrm{L}$ of $50 \%$ (w/v) PEG 3350, $36 \mu \mathrm{L} 1 \mathrm{M} \mathrm{LiAc}$, and $50 \mu \mathrm{L}$ of $2 \mathrm{mg} / \mathrm{mL}$ sheared salmon DNA (single-stranded DNA that was incubated for 10 minutes in boiling water, then put-on ice immediately before adding). Each sample was vortexed for 1 minute, then the samples were heat shocked for 20 minutes at $42^{\circ} \mathrm{C}$. Samples were centrifuged at $6,200 \times g$ for five seconds, the supernatant was discarded, and the pellet was resuspended in $1 \mathrm{~mL}$ of YPAD media. Samples were then left to grow at $30^{\circ} \mathrm{C}$ for 2 hours with shaking, then centrifuged at $6,200 \times g$ for five seconds. The supernatant was discarded, and the pellet was re-suspended in $500 \mu \mathrm{L}$ of sterile $\mathrm{dH}_{2} \mathrm{O}$. The sample was centrifuged at 6,200 $\mathrm{xg}$ for five seconds, the supernatant was discarded, and the pellet was re- 
suspended in $100 \mu \mathrm{L}$ of sterile $\mathrm{dH}_{2} \mathrm{O}$. Samples were spread onto Selective Dropout Agar Yeast Media (without specific amino acids or nucleotides; Suppl. Table 2) plates and incubated $2-4$ days at $30{ }^{\circ} \mathrm{C}$.

\subsection{7- Transformation of E. coli DH5 $\alpha$, colony amplification, and vector DNA isolation}

For amplification and isolation of vDNA from a single colony after a plasmid transformation or streaking out of a glycerol stock, the following procedure was used. A single $E$. coli colony was used to inoculate 5 $\mathrm{mL}$ of LB (25 g/L) with appropriate antibiotic (Supp. Table 2), and then the cells were grown overnight at $37^{\circ} \mathrm{C}$ with shaking. The entire $5 \mathrm{~mL}$ bacterial culture was harvested through centrifugation and the vDNA was isolated using a High-Speed Plasmid Mini Kit (Geneaid, Cat. \# PD300) following the manufacturer's protocol. The quantity and purity of the isolated vDNA was analyzed using a ThermoFisher Nanodrop 1000.

\subsection{8- Arabidopsis thaliana genomic DNA preparation}

About $20 \mathrm{mg}$ of fresh leaf tissue from a young $A$. thaliana (Col-0) plant (2-3 weeks old) was placed in a microcentrifuge tube and ground with an autoclaved pestle, then $400 \mu \mathrm{L}$ of Extraction Buffer (200 mM Tris- $\mathrm{HCl}$ (pH 7.5), $0.5 \%$ SDS, $25 \mathrm{mM}$ EDTA (pH 8.0), $250 \mathrm{mM} \mathrm{NaCl}$ ) was added and the leaf tissue was further homogenized. Crude lysates were centrifuged at $16,200 \times g$ for 10 minutes (RT) and the genomic DNA (gDNA)-containing supernatant was transferred to a new tube. $350 \mu \mathrm{L}$ of isopropanol was mixed with the supernatant to precipitate the gDNA and the mixture was centrifuged at $21,000 \times g$ for 10 minutes, and the supernatant was discarded. $800 \mu \mathrm{L}$ of $70 \%(\mathrm{v} / \mathrm{v})$ ethanol (EtOH) was added to the gDNA pellet to remove excess salts. The solution was centrifuged at $21,000 \times g$ for 5 minutes, the supernatant was discarded, and the gDNA pellets were left to air-dry for 30 minutes. Crude gDNA was resuspended in $100 \mu \mathrm{L}$ sterile $\mathrm{dH} 2 \mathrm{O}$ and stored at $4{ }^{\circ} \mathrm{C}$ until needed. 


\subsection{9- Gateway cloning reactions}

The $4 \mu \mathrm{L}$ BP cloning reaction contained $150 \mathrm{ng}$ of donor vector, $50 \mathrm{ng}$ of attB1-targetDNA-attB2 PCR product, a $1 \mathrm{X}$ concentration of GATEWAY ${ }^{\circledR}$ BP Clonase $^{\mathrm{TM}}$ II Enzyme Mix, and TE buffer (pH 8.0). The BP cloning reaction was incubated for 2 hours at $25^{\circ} \mathrm{C}$, then spiked with $1 \mu \mathrm{g}$ of Proteinase $\mathrm{K}$ (ThermoFisher, Cat. \# AM2548) and incubated for 10 minutes at $37^{\circ} \mathrm{C}$ to stop the reaction. The $5 \mu \mathrm{L} \mathbf{R}$ cloning reaction contained $150 \mathrm{ng}$ of expression vector, $50 \mathrm{ng}$ of donor vector, a $1 \mathrm{X}$ concentration of GATEWAY ${ }^{\circledR}$ LR Clonase ${ }^{\mathrm{TM}}$ II Enzyme Mix, and TE buffer (pH 8.0). The LR cloning reaction was incubated for 2 hours at $25^{\circ} \mathrm{C}$, then spiked with $1 \mu \mathrm{g}$ of Proteinase K (ThermoFisher, Cat. \# AM2548) and incubated for 10 minutes at $37^{\circ} \mathrm{C}$. Reaction products were immediately used or stored at $-20^{\circ} \mathrm{C}$.

\subsubsection{0- Colony PCR and genotyping PCR}

All PCRs contained $2 \mu \mathrm{L}$ of colony suspension (colony from plate re-suspended in $20 \mu \mathrm{L}$ of sterile distilled water), or $2 \mu \mathrm{L}$ of genomic DNA (dissolved in $100 \mu \mathrm{L}$ of sterile distilled water), and $18 \mu \mathrm{L}$ of PCR mix $(0.25$ mM dNTP, 0.3 $\mu \mathrm{M}$ Forward Primer, 0.3 $\mu \mathrm{M}$ Reverse Primer, 0.5 Units Taq Polymerase, and 1X PCR Buffer [20 mM Tris- $\mathrm{HCl} \mathrm{pH} \mathrm{8.4,} 50 \mathrm{mM} \mathrm{KCl]}$ ). PCRs had 3 stages. Stage $1: 95^{\circ} \mathrm{C}$ for 5 minutes. Stage 2: $94{ }^{\circ} \mathrm{C}$ for 30 seconds, $55^{\circ} \mathrm{C}$ for 30 seconds, and $72{ }^{\circ} \mathrm{C}$ for $1 \mathrm{~min} . / 1 \mathrm{Kbp}$. Stage 2 was repeated 34 more times.

Stage $3: 72^{\circ} \mathrm{C}$ for 7 minutes.

\section{3- Dual-luciferase promoter activation assay via Agrobacterium infiltration of $N$. benthamiana leaves}

\subsection{1- Positive controls for dual-luciferase assay}

Populus trichocarpa (Pt) transcription factors and associated promoter were used as a positive control for the dual-luciferase assay via Agrobacterium infiltration of $N$. benthamiana leaves (James et al., 2017). PtMYB134 and PtbHLH131 coding sequences were inserted downstream of the 35 S promoter in pMDC32 (Suppl. Figure 6) and are overexpression plasmids. PtANR1promoter was cloned in the Notl site of the pGREENII 0800-LUC (luciferase) vector (Suppl. Figure 3) and is the reporter plasmid. These vector 
constructs were a gift from Dr. Peter Constabel from the University of Victoria, Canada. The two overexpression plasmids were individually transformed, while the reporter plasmid was co-transformed with the pSOUP (Suppl. Figure 4) vector into A. tumefaciens (GV3101: pMP90) via electroporation

\section{(2.2.5).}

\subsection{2- Vector construction and strain preparation for promoter: reporter constructs}

The pGREENII 0800-LUC (Suppl. Fig. 2) reporter vector was obtained from The New Zealand Institute for Plant \& Food Research Ltd. The pGREENII 0800-LUC expression cassette, which is flanked by left border (LB) and right border (RB) sites, consists of a renilla luciferase gene under control of a 35S promoter and a firefly luciferase gene downstream of a multiple cloning site (Suppl. Fig. 2). The Takara Bio In-Fusion Primer Design Tool was used to design primers (Suppl. Table 3) for the amplification of the FAR4, GPAT5, CYP86A1, CYP86B1, ASFT, and WRKY56 promoter upstream regions and subsequent insertion between the HindIII and BamHI restriction sites of pGREENII 0800-LUC. Upstream regions were amplified from A. thaliana (Col-0) genomic DNA (2.2.8) using iProof ${ }^{\mathrm{TM}}$ High-Fidelity DNA Polymerase (Bio-Rad, Cat\# 1725330) following the manufacturer's instructions. PCR products were run on a $1 \%$ agarose gel and the desired PCR product was excised from the gel and column purified using the NucleoSpin ${ }^{\circledR}$ Gel and PCR Clean-Up Kit (Takara-Bio, Cat. \# 740609.250) following the manufacturer's instructions. The PCRamplified products were quantified, and purity analyzed using a ThermoFisher Nanodrop 1000.

The pGREENII 0800-LUC vector was transformed into chemically competent DH5 $\alpha$ E. coli cells (2.2.4). A single colony was amplified and the pGREENII 0800-LUC reporter vector was isolated and purified (2.2.7). HindIII and BamHI restriction enzymes were used to digest pGREENII 0800-LUC in preparation for cloning. The $20 \mu \mathrm{L}$ digest contained: $2 \mu \mathrm{L}$ 10X CutSmart Buffer, $0.5 \mu \mathrm{L}$ HindIII, $0.5 \mu \mathrm{L}$ BamHI, $1000 \mathrm{ng}$ of pGREEN II 0800-LUC, and topped off with sterile $\mathrm{dH}_{2} \mathrm{O}$. Digests were incubated at $37^{\circ} \mathrm{C}$ for 3 hours and digested DNA then purified with the NucleoSpin ${ }^{\circledR}$ Gel and PCR Clean-Up Kit (Takara-Bio, Cat. \# 740609.250) following the manufacturer's instructions. The linearized pGREENII 0800-LUC was 
quantified on the ThermoFisher Nanodrop 1000. The PCR-amplified upstream regions were individually inserted into the linearized pGREENII 0800-LUC vector with the In-Fusion HD Cloning Kit following the manufacturer's instructions. Two (2) $\mu \mathrm{L}$ of the completed cloning reaction were immediately transformed into chemically competent $E$. coli $(\mathrm{DH} 5 \alpha)$ cells (2.2.4). Colony PCR (2.2.10) was used to confirm colonies containing successfully DNA constructs, using primers from Suppl. Table 3. A single successful colony was amplified and vDNA (pGREENII 0800 promoter: LUC) was extracted from the culture (2.2.7). The insertion was then confirmed via sequencing. pGREENII 0800 promoter: LUC constructs were co-transformed with pSOUP into Agrobacterium tumerfaciens (GV3101::pMP90; 2.2.5).

\subsection{3- Vector construction and strain preparation for transcription factor over-expression constructs}

The coding sequence for AtMYB39 was amplified from cDNA derived from RNA extracted from the roots of wild-type Arabidopsis (Col-0) by Dr. Jhadeswar Murmu. Primers (Suppl. Table 3) were designed to amplify the AtMYB39 coding sequence while adding attB1 and attB2 sites to the $5^{\prime}$ and $3^{\prime}$ end, respectively. PCR products were run on a $1 \%$ agarose gel and the desired PCR product was excised from the gel and column purified using the NucleoSpin ${ }^{\circledR}$ Gel and PCR Clean-Up Kit (Takara-Bio, Cat. \# 740609.250) following the manufacturer's instructions. The quantity and purity of the attB1-AtMYB39attB2 PCR product was analyzed using a ThermoFisher Nanodrop 1000. The attB1-AtMYB39-attB2 amplicon was used to recombine AtMYB39 into pDONR211 (Suppl. Fig. 4) via GATEWAY BP cloning (2.2.9), generating pDONR221:AtMYB39. Two $\mu \mathrm{L}$ of the completed cloning reaction were immediately transformed into chemically competent E. coli ( $\mathrm{DH} 5 \alpha)$ (2.2.4). Colony PCR was used to confirm colonies containing successfully cloned constructs (2.2.10, primers in Suppl. Table 3). A single positive colony was amplified and vDNA (pDONR221:AtMYB39) was extracted and purified (2.2.7). The LR cloning reaction

(2.2.9) was done with pK7WG2D (Supp. Fig. 7) as the destination vector. Colony PCR was used to confirm colonies containing successfully cloned constructs (2.2.10, primers in Suppl. Table3). A single successful colony was amplified and vDNA (pK7WG2D:AtMYB39) was extracted and purified from the culture 
(2.2.7). The cloning was then confirmed via Sanger DNA sequencing and pK7WG2D:AtMYB39 was transformed into Agrobacterium tumefaciens (GV3101::pmp90, 2.2.5). The Rowland lab already had AtMYB41 (pK7WG2D), AtMYB53 (pK7WG2D), AtMYB92 (pMDC32), AtMYB93 (pVKH18), AtMYB45 (pK7WG2D), and AtMYB67 (pK7WG2D) coding regions in over-expression vectors in Agrobacterium tumefaciens (GV3101::pMP90), as well as pBIN19-p19 in Agrobacterium tumefaciens (C58C1::pCH32;

\section{Supp. Table 2).}

\subsection{4- Infiltration of N. benthamiana leaves with mixed Agrobacterium cultures}

Three days before infiltration, glycerol stocks containing Agrobacterium strains with the required plasmids (Suppl. Table 4) were used to streak out bacteria on LB agar plates with the appropriate antibiotics (Suppl. Table 2) and incubated at $30^{\circ} \mathrm{C}$ for 2 days in the dark. Two colonies for each Agrobacterium strain were inoculated separately into $5 \mathrm{~mL}$ of LB with appropriate antibiotics (Supp.

Table 2) and grown overnight at $30^{\circ} \mathrm{C}$, with shaking, for 16 to 20 hours. Each infiltration assay contained Agrobacteria with pBIN-p19, which encodes the p19 viral suppressor of silencing, an over-expression vector, and a reporter vector.

Each Agrobacterium strain was washed three times with $5 \mathrm{~mL}$ infiltration buffer (50 mM MES (pH 5.6), 2 $\mathrm{mM} \mathrm{Na}_{3} \mathrm{PO}_{4} \bullet 12 \mathrm{H}_{2} \mathrm{O}, 0.1 \mathrm{mM}$ acetosyringone, $5 \mathrm{mg} / \mathrm{mL}$ glucose) and then re-suspended in $3 \mathrm{~mL}$ of infiltration buffer. The infiltration cultures were mixed so that overexpression strains and reporter strains were in a ratio of 10:1, and with overexpression strains in a 1:1 ratio with p19. Each infiltration mixture had a final $\mathrm{OD}_{600 \mathrm{~nm}}=0.6$. The mixtures were left in the dark for 2 hours at RT. An hour before the infiltration, multiple plants with healthy and similarly sized leaves were removed from the growth chambers and placed under incandescent light. Plants were selected such that six infiltrations could be sufficiently spaced on each leaf. Plants were watered 30 minutes before the infiltration. After a slight puncture with a razor blade to the abaxial epidermal cells, each infiltration culture was injected into the leaf until the infiltration area had a diameter greater than $1 \mathrm{~cm}$. The leaves used were $2-4$ leaf positions 
away from the apical meristem. The infiltrated leaf area was circled and labelled with marker, and this was done on four separate plants for each infiltration mix $(n=4)$. Infiltrated plants were placed back in the growth chamber and their regular watering/fertilization schedule was continued for 72 hours.

\subsection{5- Dual-luciferase assay}

Infiltrated plants were removed from the growth chambers after 72 hours. A 0.7 mm-diameter leaf disc was punched out of each infiltrated leaf area and immediately frozen in liquid nitrogen. Leaf tissues were ground to a powder with a sterile pre-chilled pestle (give dimensions or brand) and then warmed to room temperature before $250 \mu \mathrm{L}$ of $1 \mathrm{X}$ Passive Lysis Buffer (PLB) was added to the powdered samples. The samples were re-ground with the same pestle and then incubated for 15 minutes at room temperature to complete the cell lysis. Samples were centrifuged for 20 minutes at $20,817 \times g$ and $4{ }^{\circ} \mathrm{C}$, then kept on ice. $5 \mu \mathrm{L}$ of supernatant was removed to a single well of a white flat-bottom 96-well plate (Nunclon). $30 \mu \mathrm{L}$ of Luciferase Assay Reagent (LAR) II was added and the chemiluminescence was measured. $30 \mu \mathrm{L}$ of Stop \& Glow ${ }^{\mathrm{TM}}$ was added and the chemiluminescence was measured again. Luciferase measurements were taken with a five second delay and 10 second integrated measurement on the CYTATION5 (BioTek) plate imaging reader. The ratio of firefly luciferase (suberin gene promoter controlled): renilla luciferase (35S promoter controlled) for each sample was calculated and averaged between biological replicates.

\section{4- FAR4 promoter deletion series}

\subsection{1- Vector construction and bacterial strain preparation}

Constructs containing fragments of the FAR4 promoter ( $5^{\prime}$ upstream from the translation start site) were made by Lena Watkins and Dr. Jhadeswar Murmu, as described below. These regions were PCRamplified with iProof ${ }^{\mathrm{TM}}$ High-Fidelity DNA Polymerase (Bio-Rad, Cat\# 1725330) following the manufacturer's instructions, using $A$. thaliana genomic DNA (2.2.8) as template. For each region, an 
attaB1 'forward' primer specific to each deletion and the same attaB2 'reverse' primer immediately upstream of the FAR4 ATG start codon were used (Supp. Table 3). The PCR products were run on a $1 \%$ agarose gel and the desired PCR product was excised from the gel (under UV light detection) and column purified using the NucleoSpin ${ }^{\circledR}$ Gel and PCR Clean-Up Kit (Takara-Bio, Cat. \# 740609.250) following the manufacturer's instructions. The attaB1-FAR4upstreamregion-attaB2 PCR products were quantified, and purity analyzed with a ThermoFisher Nanodrop 1000. For each promoter in the deletion series, the attaB1-FAR4upstreamregion-attaB2 construct was recombined into pDONR221 donor vector (Supp. Figure 4), via GATEWAY BP cloning (2.2.9), generating pDONR221:FAR4upstream region (Supp. Table 4) for each DNA segment in the promoter deletion series. Transformation of the BP cloning reaction, colony PCR confirmation (2.2.10, primers in Supp. Table 3), colony amplification, and vDNA extraction were done (2.2.7). LR Gateway cloning (2.2.9) was then used to transfer the FAR4 upstream regions into the expression vector pKGWFS7 (Supp. Figure 5; Karimi et al., 2002). Transformation of the LR cloning reaction, colony PCR confirmation (primers in Supp. Table 3), colony amplification, and vDNA extraction was done (2.2.7). The inserts and flanking regions of the plasmid constructs were confirmed via Sanger DNA sequencing. Each pKGWFS7:FAR4upstreamregion plasmid in the promoter deletion series was transformed into A. tumefaciens (GV3101: pMP90; 2.2.5) and made into glycerol stocks for long-term storage at $-80^{\circ} \mathrm{C}$ (Supp. Table 4).

\subsection{2- Floral dip transformation}

Wild-type Arabidopsis (Col-0) seeds were sterilized, stratified, and grown (2.2.3). Plants were ready for the floral dip after their second set of inflorescence flowers had bolted, but not opened (5-6 weeks old). Watering was stopped three days before the floral dip. All siliques and opened inflorescence flowers were removed the day of transformation

Three days before the floral dip transformation, the glycerol stock for each Agrobacterium (GV3101: pMP90) strain containing the pKGWFS7: FAR4upstreamregion plasmids were streaked on LB agar plates 
with the appropriate antibiotics (Supp. Table 2) and incubated at $30^{\circ} \mathrm{C}$ for 2 days. A single colony for each strain was separately inoculated in $5 \mathrm{~mL}$ of liquid LB with appropriate antibiotics (Supp. Table 2) and incubated overnight at $30^{\circ} \mathrm{C}$ in the dark with shaking. $2.5 \mathrm{~mL}$ of the overnight culture were diluted $10 X$ in liquid LB (gentamycin, $40 \mu \mathrm{g} / \mathrm{mL}$; and spectinomycin, $100 \mu \mathrm{g} / \mathrm{mL}$ ) and incubated at $30{ }^{\circ} \mathrm{C}$ with shaking for 16 hours. Cultures were centrifuged at $4,700 \times g$ for 10 minutes (RT) and the supernatant was removed. Pellets were re-suspended in infiltration buffer (5 \% (w/v) sucrose, $0.02 \%(v / v)$ Silwet-77) to an $\mathrm{OD}_{600 \mathrm{~nm}}=0.8$.

For each FAR4pro:GUS construct, two pots containing six Arabidopsis (Col-0) WT plants were dipped in each Agrobacterium infiltration culture $\left(\mathrm{OD}_{600 \mathrm{~nm}}=0.8\right.$. $)$ for 1 minute, so that only the unopened inflorescence flowers were in the culture. Floral dipped plants were placed back in their growth chambers with a plastic cover and wrapped in a black garbage bag. After 24 hours, the plastic cover and garbage bag were removed and the plants grew under normal light conditions until fully developed siliques formed. Seeds from the 12 plants for each FAR4pro: GUS constructs were harvested individually and designated the $T_{1}$ generation.

\subsection{3- Selection, growth, and harvesting of FAR4promoter: GUS lines}

Harvested $T_{1}$ seeds were surface sterilized and stratified as previously described, then $\sim 100$ seeds were placed onto an $0.5 \%$ agar plate supplemented with $1 / 2$ strength Murashige \& Skoog (MS) basal medium with Gamborg vitamins, $1 \%$ sucrose, and $50 \mu \mathrm{g} / \mathrm{mL}$ kanamycin. These $\mathrm{T}_{1}$ seeds were plated along with $A$. thaliana (Col-0) wild-type seeds as the negative control, and kanamycin-resistant seeds previously generated in Dr. Rowland's lab as the positive control. After a week of growth under constant light (100$130 \mu \mathrm{mol} \cdot \mathrm{m}^{2} \cdot \mathrm{s}^{-1}, 21^{\circ} \mathrm{C}$ ) on selection agar plates, healthy kanamycin-resistant $\mathrm{T}_{1}$ seedlings (ones that matched the growth and colour of the positive control) were transplanted to soil and grown for seed amplification as described above. This was done until $\sim 20$ individual (independent) $T_{1}$ seedlings were selected, amplified, and harvested for their $\mathrm{T}_{2}$ seeds for each FAR4pro: GUS line in the deletion series. 
For all independent lines, $50 \mathrm{~T}_{2}$ seeds were grown on a $0.5 \%$ agar plate, supplemented with $1 / 2$ strength Murashige \& Skoog (MS) basal medium with Gamborg vitamins, $1 \%$ sucrose, and $50 \mu \mathrm{g} / \mathrm{mL}$ kanamycin for 1 week and the ratio of kanamycin resistant (alive): kanamycin sensitive (dead) seedlings was recorded to identify single loci T-DNA insertion lines (3:1 alive:dead ratio). These seedlings were then genotyped (2.2.10)

\subsection{4- GUS staining and light microscopy}

Healthy seedlings from the $T_{2}$ generation selected using kanamycin were transferred from the selection plate to GUS Staining solution (1 $\mathrm{M} \mathrm{NaPO}_{4}(\mathrm{pH} 7), 4 \mathrm{mM} \mathrm{KFe}(\mathrm{CN}), 0.1 \%(\mathrm{v} / \mathrm{v})$ Triton-x-100, $0.05 \%$ (w/v) X-glucuronidase (dissolved in DMF), and $\mathrm{dH}_{2} \mathrm{O}$ ) and incubated for 20 hours at $37^{\circ} \mathrm{C}$, in the dark. Seedlings were soaked in $70 \% \mathrm{EtOH}$ for 24 hours at room temperature. This step was repeated if the seedlings still contained chlorophyll. The $70 \% \mathrm{EtOH}$ solution was changed, and the stained seedlings were stored indefinitely within sealed glass scintillation vials. Whole plants were placed on a slide, suspended in $25 \%$ glycerol, and placed under a coverslip before being imaged. Bright-field microscopy of GUS activity was observed using a Zeiss AXIO Imager.M2 (compound microscope) with a 10X ocular lens and a 10X objective lens. Images were captured through a Zeiss AxioCam ICc1 camera and analyzed using AxioVision 4.8 software. Automated scale bars of $300 \mu \mathrm{m}$ were used.

\section{5-Bioinformatic prediction of cis-acting elements in the FAR4 promoter upstream region}

The FAR4 promoter (2300 bp 5' from the FAR4 translation start site) was analyzed for known cis-acting elements (consensus DNA motifs; Table 1) for MYB, WRKY, bHLH, and NAC transcription factors using PlantPAN3.0 software (http://plantpan.itps.ncku.edu.tw/promoter.php), PLACE

(https://www.dna.affrc.go.jp/PLACE/?action=newplace), and AGRIS (https://agrisknowledgebase.org/AtcisDB/) (Chow et al., 2019; Higo et al., 1999; Yilmaz et al., 2011). A manual sequence search was also done for confirmation. 


\section{6- Yeast 1-hybrid to test direct binding of R2R3-MYB TFs to fragments of the FAR4 promoter}

\subsection{1- Construction of pBait-AbAi bait vectors}

The Takara Bio In-Fusion Primer Design Tool was used to design primers (Supp Table 1) for the amplification of six different FAR4 promoter regions, based on the in silico FAR4 promoter analysis, and subsequent insertion between the HindIII and Xhol restriction sites of the pAbAi vector (Suppl. Figure 8). FAR4 promoter regions were amplified from A. thaliana (Col-0) gDNA (2.2.8) using iProof ${ }^{\mathrm{TM}}$ High-Fidelity DNA Polymerase (Bio-Rad, Cat\# 1725330), following the manufacturer's instructions and using primers listed in Suppl. Table 3. PCR products were column purified using the NucleoSpin ${ }^{\circledast}$ Gel and PCR Clean-Up Kit (Takara-Bio, Cat. \# 740609.250) following the manufacturer's instructions. The PCR-amplified FAR4 upstream region DNA products were analyzed for quantity and purity using a ThermoFisher Nanodrop 1000. The pAbAi vector was transformed into chemically competent $\mathrm{DH} 5 \alpha$ E. coli cells, a single colony was amplified, and the pAbAi vector was isolated $(2.2 .4,2.2 .7)$. The HindIII and Xhol restriction enzymes were used to digest pAbAi in preparation for cloning. The $20 \mu \mathrm{L}$ reaction contained: $2 \mu \mathrm{L} 10 \mathrm{X}$ CutSmart Buffer, $0.5 \mu \mathrm{L}$ HindIII, $0.5 \mu \mathrm{L}$ Xhol, $1000 \mathrm{ng}$ of pAbAi, and topped off with sterile $\mathrm{dH} 2 \mathrm{O}$. Digests were incubated at $37^{\circ} \mathrm{C}$ for 3 hours and was DNA purified using the NucleoSpin ${ }^{\circledast}$ Gel and PCR Clean-Up Kit (Takara-Bio, Cat. \# 740609.250) following the manufacturer's instructions. The linearized pAbAi was quantified using the ThermoFisher Nanodrop 1000. The PCR-amplified FAR4 upstream regions were individually inserted into the linearized pAbAi vector using the In-Fusion HD Cloning Kit following manufacture's protocols. Two $\mu \mathrm{L}$ of the completed cloning reaction were immediately transformed into chemically competent E. coli (DH5 2 ) (2.2.4). Colony PCR was used to confirm colonies containing successfully clones constructs $(\underline{2.2 .10})$ with primers listed in Suppl. Table 3. A single successful colony was amplified and vDNA (pBait-AbAi) was extracted from the culture (2.2.7). The constructs were verified via Sanger DNA sequencing (primers in Suppl. Table 3). 


\subsection{2- Construction of pGADT7-preyAD vectors}

The Takara Bio In-Fusion Primer Design Tool was used to design primers (Suppl. Table 3) for the amplification of MYB53, MYB92, and MYB93 full-length and N-terminal coding sequences, and subsequent insertion between the EcoRI and BamHI restriction sites of the pGADT7-AD vector (Suppl. Figure 9). Upstream regions were amplified from cDNA (preparation described above) prepared by Dr. Jhadeswar Murmu, using iProof ${ }^{\mathrm{TM}}$ High-Fidelity DNA Polymerase (Bio-Rad, Cat\# 1725330), following the manufacturer's instructions. PCR products were column purified using the NucleoSpin ${ }^{\circledR}$ Gel and PCR Clean-Up Kit (Takara-Bio, Cat. \# 740609.250) following the manufacturer's instructions. The PCRamplified cDNA products were analyzed for quantity and purity using a ThermoFisher Nanodrop 1000. The pGADT7-AD vector was transformed into chemically competent DH5 $\alpha$ E. coli cells, a single colony was amplified, and the pGADT7-AD vector was isolated (2.2.4, 2.2.7). EcoR1 and BamHI restriction enzymes were used to digest pGADT7-AD vector in preparation for cloning. The $20 \mu \mathrm{L}$ reaction contained: $2 \mu \mathrm{L}$ 10X CutSmart Buffer, $0.5 \mu \mathrm{L}$ EcoRI, $0.5 \mu \mathrm{L}$ BamHI, $1000 \mathrm{ng}$ of pGADT7-AD, and topped off with sterile dH2O. Digests were incubated at $37^{\circ} \mathrm{C}$ for 3 hours and was cleaned-up with the NucleoSpin ${ }^{\circledast}$ Gel and PCR Clean-Up Kit (Takara-Bio, Cat. \# 740609.250) following the manufacturer's instructions. The linearized pGADT7-AD was quantified on the ThermoFisher Nanodrop 1000. The PCR-amplified cDNA regions were individually inserted into the linearized pGADT7-AD vector with the In-Fusion HD Cloning Kit following manufacture's protocols. Two $\mu \mathrm{L}$ of the completed cloning reaction were immediately transformed into chemically competent E. coli $(\mathrm{DH} 5 \alpha)$ (2.2.4). Colony PCR was used to confirm colonies containing successfully cloned constructs (2.2.10) with primers from Suppl. Table 3. A single successful colony was grown, and vDNA (pGADT7-preyAD) was extracted and purified (2.2.7). The constructs were verified via Sanger DNA sequencing (primers in Suppl. Table 3). 


\subsection{3- Generating $\mathrm{Y} 1 \mathrm{H}$ bait strains}

To generate yeast bait strains, $\mathrm{pBait}-\mathrm{AbAi}$ vectors generated above were integrated into the genome of the Y1HGold yeast strain (Genotype: MATa, ura3-52, his3-200, ade2-101, trp1-901, leu2-3,112, gal44, gal804, met-, MEL1; Takara Bio). Each pBait-AbAi vector (Suppl. Table 4) was linearized with BstBI for integration into the ura3-52 locus, via recombination, of the Y1HGold genome. The $20 \mu \mathrm{L}$ linearization reaction contained: $2 \mu \mathrm{L}$ 10X CutSmart Buffer, $0.5 \mu \mathrm{L}$ BstBI (20,000 units/mL), 500 ng of pBait-AbAi vector, and topped off with sterile $\mathrm{dH} 2 \mathrm{O}$. Digests were incubated at $65^{\circ} \mathrm{C}$ for 3 hours and purified with the NucleoSpin ${ }^{\circledR}$ Gel and PCR Clean-Up Kit (Takara-Bio, Cat. \# 740609.250) following the manufacturer's instructions. The linearized pBait-AbAi vectors were quantified on the ThermoFisher Nanodrop 1000. 500 ng of each linearized pBait-AbAi vector was individually transformed into the Y1HGold yeast strain (2.2.6) and plated on SD (-URA) agar media. Colony PCR was done (2.2.10), with the primers in Suppl. Table 3, to confirm the bait in the pBait-Abai was correct. A second colony PCR was done with the Matchmaker Insert Check PCR Mix 1 (Cat. No. 630496, comes with own primers), as described by the manufacturer, to confirm the linearized pBait-AbAi vector was integrated into the yeast genome.

Each Y1HGold bait strain (Suppl. Table 4) was tested for the minimal concentration of Aureobasidin A required to completely inhibit its growth. A single large colony of each Y1HGold bait strain was resuspended in $1 \mathrm{~mL}$ of sterile $\mathrm{dH}_{2} \mathrm{O}$, then diluted to an $\mathrm{OD}$ of 0.002 . Dilution of 10 and 100 and were made, then $20 \mu \mathrm{L}$ of all three concentrations were spot plated on SD (-URA) agar media plates containing $100 \mathrm{ng} / \mathrm{mL}, 150 \mathrm{ng} / \mathrm{mL}$, or $200 \mathrm{ng} / \mathrm{mL}$ of Aureobasidin A. The plates were left to grow for 3 days at $30^{\circ} \mathrm{C}$.

\subsection{4- Transformation of $\mathrm{pGADT7-preyAD} \mathrm{vectors} \mathrm{into} \mathrm{the} \mathrm{Y1HGold-pBaitAbAi} \mathrm{strains}$}

Each pGADT7-preyAD vector (Suppl. Table 4) was individually transformed into each Y1HGold bait strain (2.2.6) then then plated on SD (-Leu) agar media, and SD (-Leu) agar media containing the minimal inhibitory Aureobasidin A concentration for that Y1HGold bait strain. 


\section{7- Chemical analysis of suberin monomers in wrky56 T-DNA loss-of- function mutants}

\subsection{1- Genotyping of T-DNA mutant lines}

Seeds for three independent T-DNA mutant lines of wrky56 were obtained from the Arabidopsis Biological Resource Center. A gene map for the following lines is shown in Figure 13: SAIL_737_DO1 (wrky56-3, T-DNA present in exon 1), SALK_201886C (wrky56-1, T-DNA present in the only intron), SAIL_1287_G04 (wrky56-2, T-DNA present in an exon 2). Left (LP) and right (RP) primers, used in combination with the common T-DNA left border primer (LbB1), were designed using the T-DNA Primer Design Tool (SIGnAL:SALK) and are listed in Suppl. Table 3. The A. thaliana (Col-0) seeds for each T-DNA mutant line were surface sterilized and grown (2.2.3). After $\sim 2$ weeks, leaf tissue was harvested from young seedling and gDNA was extracted (2.2.8). The genotype of individual plants for each T-DNA mutant line was determined via PCR (2.2.10) using primer combinations of LP + RP and LbB1 + RP (Suppl. Table 4) Individual plants that were determined to be homozygous for the T-DNA insertion in the gene of interest were left to grow, and the seeds were harvested. From these seeds', plants were grown for seed amplification, and re-genotyped to verify homozygous insertions prior to suberin analysis.

\subsection{2-}

Sterilized A. thaliana (Col-0) WT and homozygous T-DNA mutant seeds (Supp. Table 1) were stratified for 3 days in the dark at $4{ }^{\circ} \mathrm{C}$, and then evenly spread on $0.5 \%$ agar plates containing $1 / 2 \mathrm{MS}$ with vitamins (Phytotech Labs, Product ID: M404) and $1 \%$ sucrose. One biological replicate $(n)$ required six plates with $\sim 40$ seeds per plate, and each T-DNA mutant and WT A. thaliana (Col-0) seed line was analyzed using 4 biological replicates $(n=4)$. Seeded plates were left under $24 \mathrm{hr}$ light $\left(100-120 \mu \mathrm{mol} \cdot \mathrm{m}^{2} \cdot \mathrm{s}^{-1}, 21^{\circ} \mathrm{C}\right)$ for 12 days. 
The remaining experiments were all performed with HPLC-grade chloroform rinsed glassware. Roots for each biological replicate were harvested together, finely minced with a razor blade, and placed in preweighed glass tubes. The samples were incubated at $80^{\circ} \mathrm{C}$ for 20 minutes in isopropanol (pre-heated to $80^{\circ} \mathrm{C}$ ) to inactivate lipases. The samples were cooled to room temperature and further homogenized with a hand-held homogenizer. Root samples were left to incubate, with rocking, in the isopropanol for 24 hours with a solution change after the first 8 hours. Roots were sequentially incubated in 2:1 (v/v) chloroform:methanol, 1:1 (v/v) chloroform:methanol, 1:2 (v/v) chloroform:methanol, and then 100\% methanol to remove soluble lipids. The methanol was removed, and root samples were left to dry in a fume-hood for 3 days followed by a desiccator containing orange-indicating silica gel beads for at least 4 days. Root samples were considered fully dry once their weight stopped changing from day-to-day, and the final mass of root tissue was recorded.

For suberin depolymerization, 10-35 mg of solvent extracted, dry root tissue was used, which was transferred to new glass tubes. $20 \mu \mathrm{g}$ of heptadecanoic acid and omega-pentalactone (which is linearized to omega hydroxy 15:0 fatty acid methyl ester during the depolymerization step) standards were added to each dry root sample along with $1.5 \mathrm{~mL}$ of depolymerization mix (60 \% v/v methanol, 15 $\% \mathrm{v} / \mathrm{v}$ methyl acetate, $25 \% \mathrm{v} / \mathrm{v}$ sodium methoxide). Suberin samples were vortexed vigorously and incubated at $60^{\circ} \mathrm{C}$ for 2 hours with vortexing every 30 minutes to cause depolymerization via basecatalyzed methanolysis. Suberin monomer samples were cooled to room temperature and then acidified to a $\mathrm{pH}$ between 4 and 5 with glacial acetic acid. Suberin monomers were extracted in $2.5 \mathrm{~mL}$ of dichloromethane, then washed three times with $2 \mathrm{~mL}$ of $0.5 \mathrm{M} \mathrm{NaCl}$ (keeping the organic phase each time), and anhydrous sodium sulphate added to remove any residual aqueous phase. The dichloromethane phase was dried under a gentle stream of nitrogen while heated to $37^{\circ} \mathrm{C}$. To acetylate the suberin monomers, they were re-suspended in $200 \mu \mathrm{L}$ of $1: 1(\mathrm{v} / \mathrm{v})$ pyridine: acetic anhydride, 
vortexed, and incubated at $60^{\circ} \mathrm{C}$ for 1 hour with vortexing every 15 minutes. Acetylated suberin monomers were dried under a gentle stream of nitrogen, while heated to $37^{\circ} \mathrm{C}$, and stored at $-20^{\circ} \mathrm{C}$. Acetylated suberin monomers were re-suspended in $200 \mu \mathrm{L}$ of a 1:1 (v/v) toluene: heptane mixture and analyzed by gas chromatography on an Agilent Technologies 7820a GC system equipped with a flame ionization detector (FID). A $30 \mathrm{~m}$ by $0.25 \mathrm{~mm} \mathrm{HP}-5$ column, with $0.25 \mu \mathrm{m}$ film thickness, was used and the carrier gas $(\mathrm{He})$ had a $1.5 \mathrm{~mL} /$ minute flow rate. A $1 \mu \mathrm{L}$ splitless injection was done at $300{ }^{\circ} \mathrm{C}$ and the detector had a temperature of $350^{\circ} \mathrm{C}$. The oven was programmed to hold for 3 minutes at $140{ }^{\circ} \mathrm{C}$, raised to $310^{\circ} \mathrm{C}$ at a rate of $10{ }^{\circ} \mathrm{C} /$ minute, and held for 17 minutes at $310^{\circ} \mathrm{C}$. Quantification of the suberin samples was based on the FID-generated peaks areas, relative to heptadecanoic acid methyl ester and acetylated 15-hydroxypentadecanoic fatty acid methyl ester internal standards. Composition of the suberin monomer samples was confirmed through GC-MS at the Carleton Mass Spectrometry Centre. Gas chromatography was performed exactly as described above but with MS detection performed using an Agilent Technologies 5977E MS detector. MS data was run through the database of the National Institute for Standards and Technology's Mass Spectrometry Data Centre. 


\section{3- Results}

\section{1- Transcriptional activation of suberin biosynthetic gene promoters}

The first goal was to determine whether Arabidopsis MYB41, MYB53, MYB92, or MYB93 can

transcriptionally activate the promoters ( $5^{\prime}$ upstream regions from translation start site) of suberin

biosynthetic genes. The full-length coding sequences of these transcription factors (and control

transcription factors) were inserted into over-expression vectors (Supp. Table 2, Supp. Fig. 6, 7, 8) that

were compatible with Agrobacterium tumefaciens, a bacterium capable of transferring T-DNA into a

plant cell genome. The promoters of suberin biosynthetic genes FAR4 (2300 bp), GPAT5 (2164 bp), ASFT

(1768 bp), CYP86B1 (1523 bp), and CYP86A1 (1788 bp), as well as the candidate WRKY56 (1333 bp),

were inserted into the $A$. tumefaciens compatible vector pGREENII 0800-LUC (Supp. Fig. 2) as

transcriptional fusions with the Firefly Luciferase gene (Hellens et al., 2005). In this system, when the T-

DNAs harbouring the over-expressed transcription factors and promoter: reporter gene fusions are co-

transferred into the same plant cell, we can test if the transcription factors transcriptionally activate the Firefly Luciferase reporter gene. The luminescence of the Firefly Luciferase protein is measured to quantify transcriptional activation (in the absence or presence of transcription factors). The pGREENII 0800-LUC vector also contains a Renilla Luciferase gene transcriptionally fused with a 355 promoter, and luminescence of the Renilla Luciferase protein is measured to normalize the amount of luminescence from the Firefly Luciferase protein between samples. Normalization was done by dividing the relative Firefly Luminescence by the relative Renilla Luminescence, and this is reported as Luciferase Activity.

The ability of Arabidopsis MYB39 (SUBERMAN) to activate the promoter of suberin biosynthesis genes using our transient $N$. benthamiana leaf dual-luciferase assay system was compared to similar work previously reported by Cohen et al. (2020). In my study, AtMYB39 increased luciferase activity of GPAT5, ASFT, CYP86B1, and CYP86A1 promoters by 218 -fold, 31-fold, 49 -fold, and 68 -fold, respectively, when 
compared to the empty vector (EV) control (Figure 4). The increase in luciferase activity induced by AtMYB39 was statistically significant for each promoter, except for CYP86A1, when compared to the EV control. The work done by Cohen et al. (2020) was thus verified, establishing AtMYB39 as a positive control for our transient dual-luciferase promoter activation assays using AtMYB41, AtMYB53, AtMYB92, and AtMYB93.

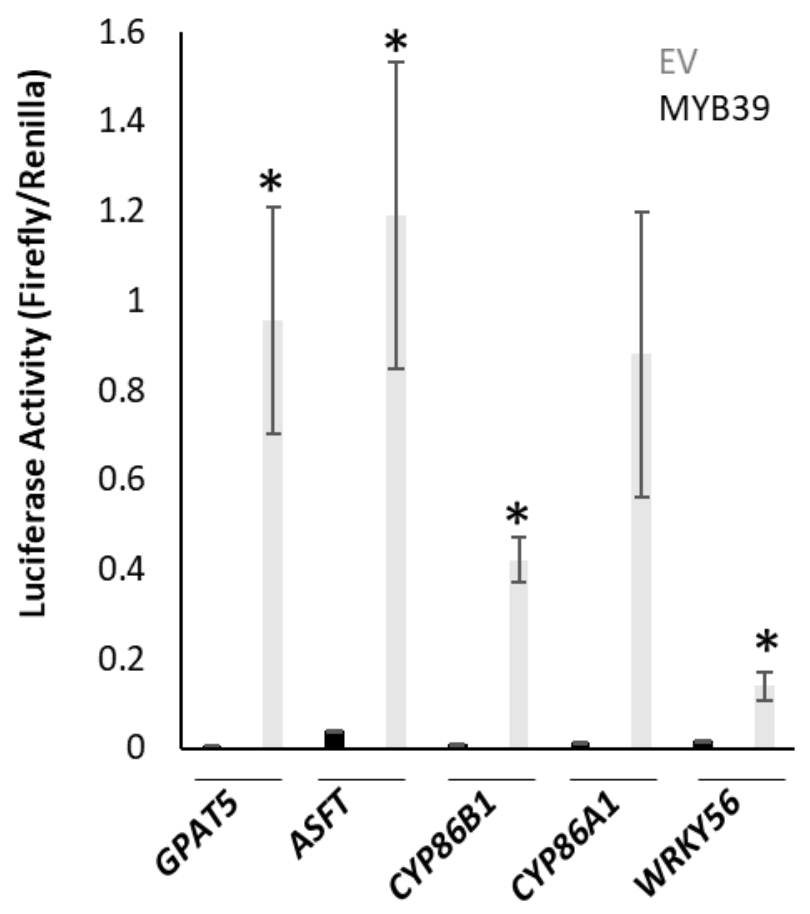

Figure 4: Transient expression promoter activation assay, testing MYB39's ability to transcriptionally activate the promoter of GPAT5, ASFT, CYP86A1, CYP86B1 and WRKY56. The y-axis displays the ratio of Firefly to Renilla Luciferase Activity. The transcription factors tested here are found in the legend (right side) and as bars indicated by their respective colours along the x-axis. The promoters are transcriptionally fused to Firefly Luciferase. The $35 \mathrm{~S}$ promoter is transcriptionally fused to Renilla Luciferase and acts to normalize each individual replicate. Data in bars represent mean \pm SE of 4 biological replicates, each from a different $N$. benthamiana plant. An asterisk indicates that the mean Luciferase Activity ratio (Firefly/Renilla) caused by a transcription factor is statistically different from the EV control. Statistical significance was found by first using the F-test to determine if variances between two groups were equal or unequal, followed by the two-tailed student t-test $(p<0.05)$. 
All five Arabidopsis R2R3-MYB TFs (MYB39, MYB41, MYB53, MYB92, and MYB93) increased the Luciferase Activity (Firefly/Renilla ratio) of the FAR4, GPAT5, CYP86A1, CYP86B1, and ASFT promoters, when compared to the empty expression vector control (Figure 5). With the FAR4 promoter, the Luciferase Activity was increased 9.0-fold, 6.1-fold, 5.1-fold, 3.6-fold, and 3.0-fold by AtMYB39, AtMYB41, AtMYB53, AtMYB92, and AtMYB93, respectively. With the GPAT5 promoter, the Luciferase Activity was increased 40-fold, 13-fold, 17-fold, 10 -fold, and 16-fold by MYB39, MYB41, MYB53, MYB92, and MYB93, respectively. With the CYP86A1 promoter, the Luciferase Activity was increased 80-fold, 20fold, 39-fold, 21-fold, and 114-fold by AtMYB39, AtMYB41, AtMYB53, AtMYB92, and AtMYB93, respectively. With the CYP86B1 promoter, the Luciferase Activity was increased 104-fold, 78-fold, 88fold, 50-fold, and 51-fold by AtMYB39, AtMYB41, AtMYB53, AtMYB92, and AtMYB93, respectively. With the ASFT promoter, the Luciferase Activity was increased 37-fold, 25-fold, 28-fold, 20-fold, and 47-fold by AtMYB39, AtMYB41, AtMYB53, AtMYB92, and AtMYB93, respectively. The mean Luciferase Activity caused by each R2R3-MYB TF, on each suberin biosynthesis gene promoter, was statistically compared to the corresponding empty vector (EV) controls to see if there were significant differences. If a R2R3MYB TF caused a statistically significant change in Luciferase Activity, when compared to the EV control, an asterisk was placed above the bar in Figure 5. Most R2R3-MYB TF/'promoter' combinations caused a significant change in Luciferase Activity compared to the EV control. AtMYB39 did not significantly increase Luciferase Activity when tested on the FAR4 and GPAT5 promoters. The same occurred for AtMYB41 when tested on the CYP86B1 promoter and AtMYB53 when tested on the GPAT5 promoter. These four R2R3-MYB TF - suberin biosynthesis gene promoters combinations show activation but have a large standard error compared to the rest of the samples in Figure 5. 


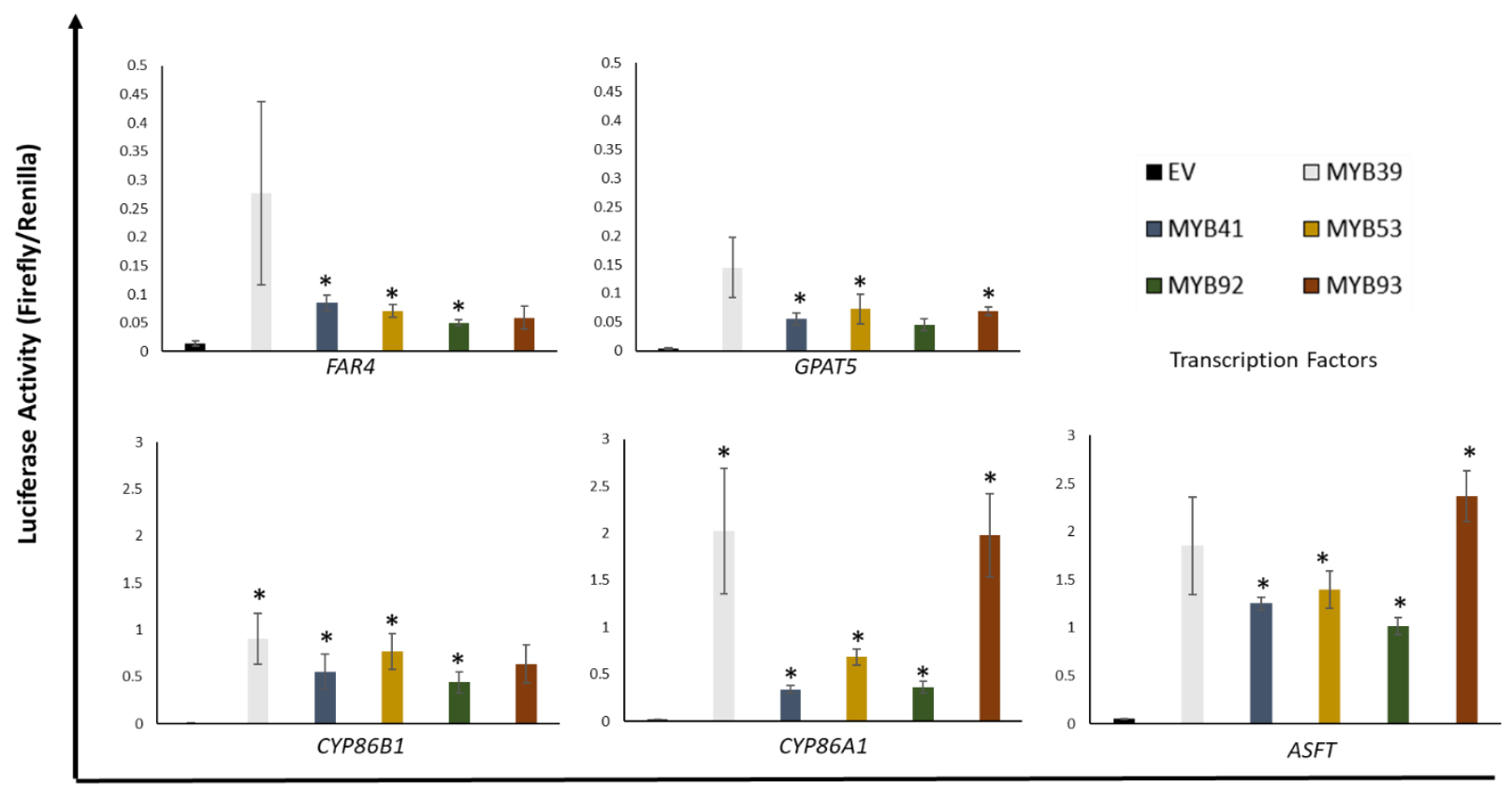

Suberin Gene Promoter

Figure 5: Transient expression promoter activation assay, testing MYB39, MYB41, MYB53, MYB92, and MYB93's ability to transcriptionally activate the promoter of FAR4, GPAT5, ASFT, CYP86A1, and CYP86B1. The $y$-axis displays the ratio of Firefly to Renilla Luciferase Activity. The transcription factors tested here are found in the legend (top right) and as bars indicated by their respective colours along the $x$-axis. The promoters are transcriptionally fused to Firefly Luciferase. The $35 \mathrm{~S}$ promoter is transcriptionally fused to Renilla Luciferase and acts to normalize each individual replicate. Data in bars represent mean \pm SE of 3-4 biological replicates, each from a different $N$. benthamiana plant. An asterisk indicates that the mean Luciferase Activity ratio (Firefly/Renilla) caused by a transcription factor is statistically different from the EV control. Statistical significance was found by first using the F-test to determine if variances between two groups were equal or unequal, followed by the two-tailed student t-test $(p<0.05)$.

Next, to assess specificity, the ability of non-suberin associated TFs to activate the GPAT5 promoter (a gene unique to suberin biosynthesis) using the transient dual-luciferase assay system was tested. From Arabidopsis, MYB67 (subgroup at103;) and MYB45 (subgroup 16) were selected as they are not closely related to suberin-associated R2R3-MYB TFs, their over-expression does not result in an accumulation in suberin, and they are not expressed in the root endodermis (Kelemen et al., 2015; Kosma et al., 2014; Winter et al., 2007). From Poplar, MYB134 and bHLH131 were chosen as they are a transcription factors that together activate many flavonoid promoters such as the ANR1 gene, a gene required for 
proanthocyanidin biosynthesis (James et al., 2017). PtMYB134 and PtbHLH131 caused a 4.4-fold and 1.8fold increase in Luciferase Activity on the PtANR1 promoter, respectively. In combination, PtMYB134 + PtbHLH131 caused a 185-fold increase in Luciferase Activity with the PtANR1 promoter (Figure 6A), confirming what was determined by James et al. (2017). AtMYB45, AtMYB67, PtMYB134, PtbHLH131, and PtMYB134 + PtbHLH131 caused statistically non-significant changes in Luciferase activity of 0.92fold, 1-fold, 1.6-fold, 1.9-fold, and 1.3-fold, respectively, on the GPAT5 promoter when compared to the EV control (Figure 6A). AtMYB92 was used as a positive control, as it had the lowest activation strength on the GPAT5 promoter (Figure 5) and induced a statistically significant 64-fold increase in Luciferase Activity on the GPAT5 promoter (Figure 6A). The ability of AtMYB45 to induce a change in Luciferase Activity on the CYP86A1, CPY86B1, and ASFT promoters was also tested. No statistically significant changes to Luciferase Activity were found, and a 1.2-fold increase on the CYP86B1 promoter was the highest recorded by MYB45 (data not shown).

Finally, the ability of suberin-associated R2R3-MYB TFs to activate the promoter of a non-suberin associated gene was tested to further define the specificity suberin-associated R2R3-MYB TFs have for suberin biosynthetic genes. The ANR1 promoter, from Populus trichocarpa (Pt), which James et al. (2017) showed to be regulated by PtMYB134 + PtbHLH131 was used. Transcription factor combinations of PtMYB134, PtbHLH131, and PtMYB134 + PtbHLH131 acted as positive controls and demonstrated 3.2fold, 1.7-fold, and 39-fold change in Luciferase Activity on the PtANR1 promoter (Figure 6B), respectively. The change in Luciferase Activity caused by PtMYB134 and PtMYB134+PtbHLH131 were statistically significant. AtMYB39 and AtMYB93 caused statistically significant 5.8-fold and 5.8-fold increases in Luciferase Activity on the PtANR1 promoter, compared to the EV control, respectively. AtMYB41, AtMYB53, and AtMYB92 caused statistically non-significant 1.6-fold, 4.3-fold, and 4.3-fold increases in Luciferase Activity, when compared to the EV control, respectively. When compared to the positive control combination of PtMYB134+PtbHLH131, the transcription factors PtMYB134, AtMYB39, 
and AtMYB93 have a lesser ability to activate the luciferase reporter gene through the PtANR1

promoter(Figure 6B).

A)

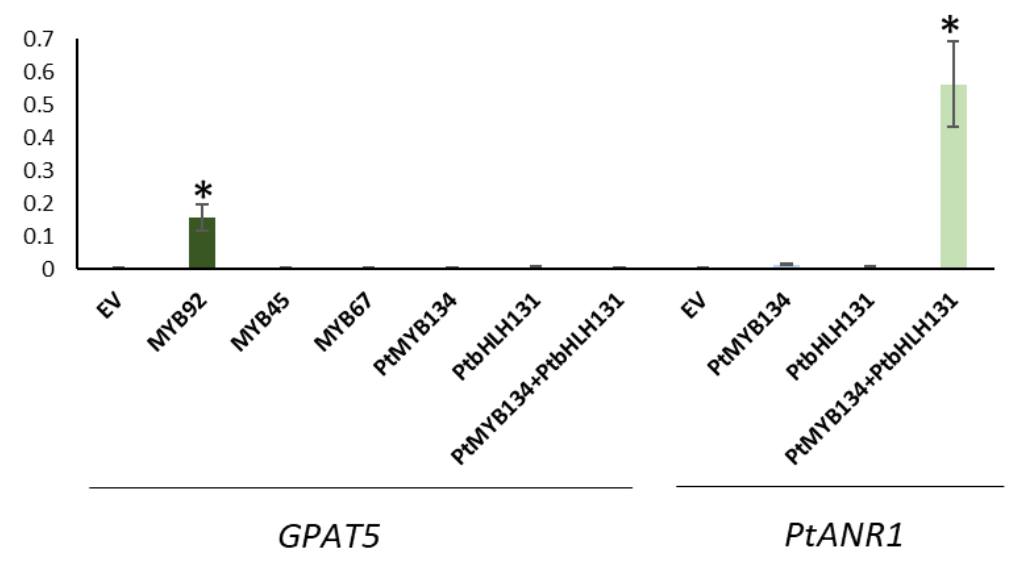

B)

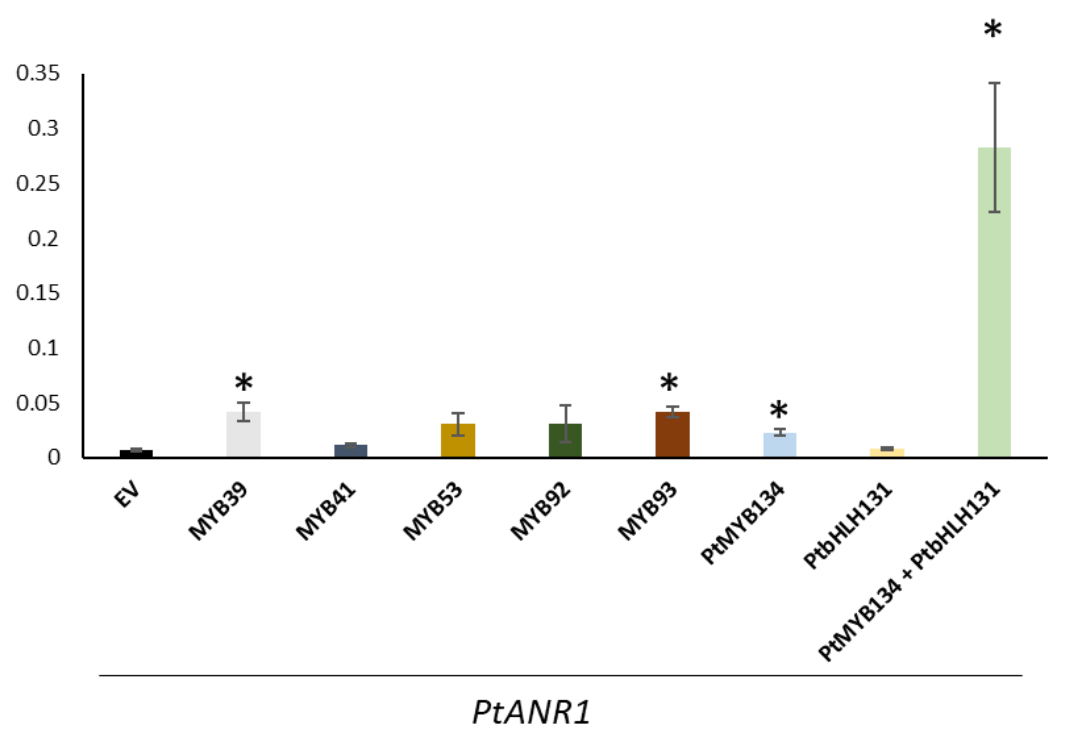

Figure 6: Transient expression promoter activation assay testing $A$ ) the ability of non root suberinassociated TFs to transcriptionally activate GPAT5 and B) the ability of suberin-associated R2R3-MYB TFs to transcriptionally activate the PtANR1 promoter. The y-axis displays the ratio of Firefly to Renilla Luciferase Activity. The TFs tested here are found as bars indicated along the $x$-axis. The gene whose promoter upstream region is being tested is indicated under the $x$-axis. The promoters are transcriptionally fused to Firefly Luciferase. The $35 \mathrm{~S}$ promoter is transcriptionally fused to Renilla Luciferase and acts to normalize each individual replicate. Data in bars represent mean \pm SE of 4 biological replicates, each from a different $N$. benthamiana plant. An asterisk indicates that the mean Luciferase Activity ratio (Firefly/Renilla) caused by a transcription factor is statistically different from the EV control. Statistical significance was found by first using the F-test to determine if variances between two groups were equal or unequal, followed by the two-tailed student $t$-test $(p<0.05)$. 
The five suberin-associated R2R3-MYB TFs were then tested for their ability to transcriptionally activate the WRKY56 promoter. MYB39, MYB41, MYB53, MYB92, and MYB93 induced a 4-fold,7-fold, 3.3-fold, 1.8-fold, and 4.4-fold change in Luciferase Activity with the WRKY56 promoter transcriptionally fused to the Firefly Luciferase gene (Figure 7). The change in Luciferase Activity for MYB92 was not statistically significant when compared to the EV control.

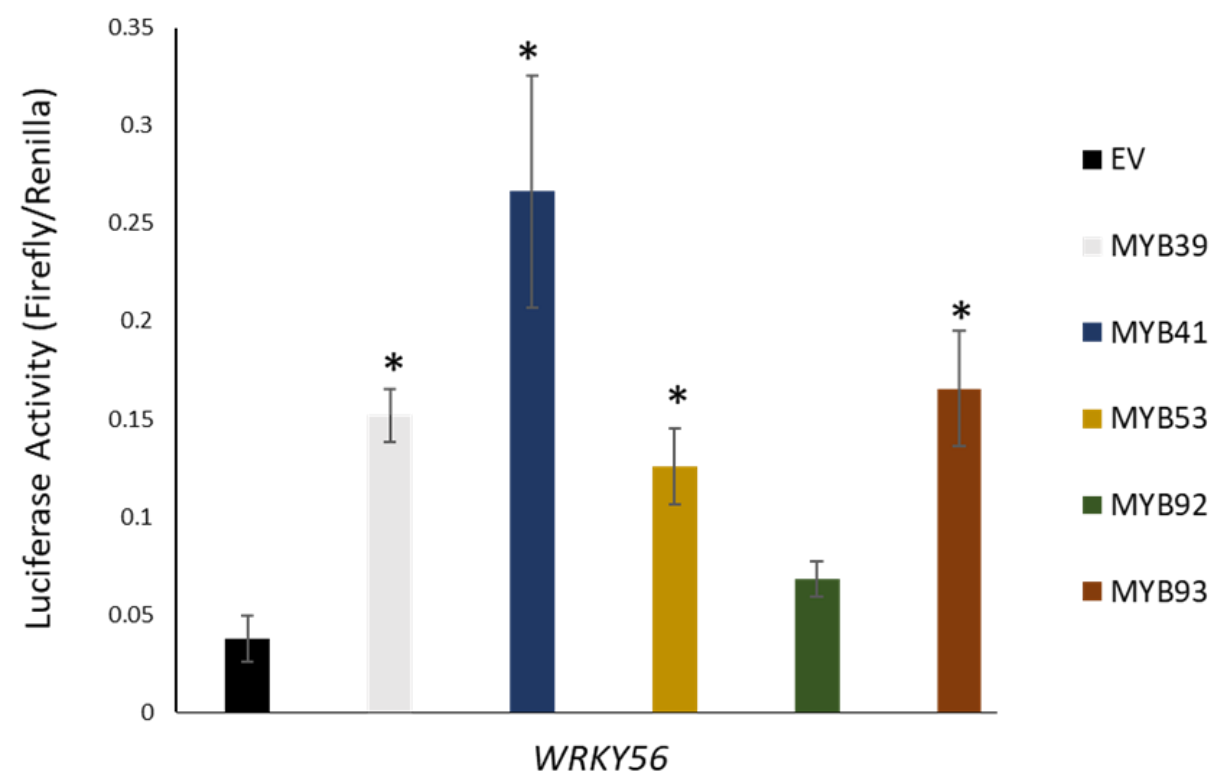

Figure 7: Transient expression promoter activation assay, testing the root suberin-associated R2R3-MYB TFs ability to transcriptionally activate the promoter of WRKY56. The $y$-axis displays the ratio of Firefly to Renilla Luciferase Activity. The transcription factors tested here are found in the legend (right side) and as bars indicated by their respective colours along the $\mathrm{x}$-axis. The WRKY56 promoter is transcriptionally fused to Firefly Luciferase. The $35 \mathrm{~S}$ promoter is transcriptionally fused to Renilla Luciferase and acts to normalize each individual replicate. Data in bars represent mean \pm SE of 4 biological replicates, each from a different $N$. benthamiana plant. An asterisk indicates that the mean Luciferase Activity ratio (Firefly/Renilla) caused by a transcription factor is statistically different from the EV control. Statistical significance was found by first using the F-test to determine if variances between two groups were equal or unequal, followed by the two-tailed student t-test $(p<0.05)$. 


\section{2- Minimal FAR4 promoter (upstream region) required for specific expression in root endodermis}

The Arabidopsis FAR4 gene is often used as a marker for sites of root suberin deposition (Domergue et al., 2010b; Kosma et al., 2014). Above, it was demonstrated that the 2300 bp upstream of the FAR4 translation start site can be used by suberin-associated R2R3-MYB TFs to activate transcription of a downstream reporter gene (Figure 5). Next, I wanted to find potential binding sites for these R2R3-MYB TFs, if they do indeed bind directly to the FAR4 promoter region. To narrow down the search, the minimal size of the $5^{\prime}$ upstream region from the FAR4 translation site (promoter) required for expression in the root endodermis was determined. FAR4 promoters (FAR4pro) of -2300 bp, -2061 bp, -1594 bp, $1171 \mathrm{bp},-545 \mathrm{bp}$, and -254 bp were inserted into pKGWFS7 (Figure 8) to generate a 'promoter' deletion series. Typically the transcription start site, which is upstream of the translation start site, is designated ' 0 ' and nucleotide bases upstream are given a (-) designation and nucleotide bases downstream a (+) designation. For the most part, plant-based research has simplified the scope of the promoter to the region $5^{\prime}$ of the translation start site, as done in this study. For that reason, the (-) in front of each number designates that the promoter is $5^{\prime}$, or upstream, and the number represents the number of nucleotide bases from the translation start site. This means, that the transcription start site will have a () designation since it is upstream of the translation start site. With all nucleotide bases in the promoter being $(-)$, the promoter is easier to define and search.

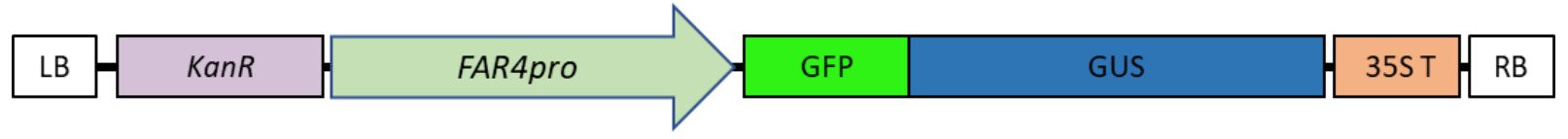

Figure 8: Schematic of the T-DNA region within the pKGWFS7 vector that the differently sized FAR4 regions upstream of translation start site were inserted upstream of a GFP/GUS reporter gene fusion. The DNA between the left border (LB) and right border (RB) sites are transferred from Agrobacterium to plant genomic DNA. 
The different sized FAR4 promoters were transcriptionally fused with the 6-Glucuronidase (GUS) gene, the reporter gene used here, within the pKGWFS7 vector. These recombinant plasmids were then transformed into A. tumefaciens, which in turn is used to incorporate the FAR4pro: GUS fusion within the T-DNA of the pKGWFS7 vector into the Arabidopsis genome via the floral dip method to generate stable transformant plant lines. Seeds recovered from 'floral dipped' plants were screened on Kanamycin media, and each seedling that survived represented an independent FAR4pro: GUS plant line (T1 generation). Multiple independent lines were analyzed for each promoter deletion (i.e. the same TDNA harboring a FAR4pro: GUS fusion randomly incorporated into different positions of the Arabidopsis nuclear genome), and they are: -2300 bp (16), -2061 bp (18), -1594 bp (9), -1171 bp (14), -545 bp (16), and -245 bp (14) (\# of independent T1 lines tested is indicated in brackets). The second generation (T2) of each independent FAR4pro: GUS line was stained for $\beta$-glucuronidase (GUS) activity. Entire 12-day old seedlings were imaged for GUS activity and one representative independent line for each FAR4pro: GUS construct in the deletion series is presented in Figure 9. Images for every independent line for each FAR4pro: GUS are found in Supp. Table 5. For the -2300 bp FAR4pro, GUS activity was found in the root endodermis, and at lateral root junctions, as was reported by Domergue et al. (2010), which matches the deposition of suberin at the same growth stage. Shortening FAR4pro to -2061 bp did not change the pattern or intensity of GUS activity, however a reduction to -1594 bp consistently decreased GUS activity seen in the root endodermis and the lateral root junctions. Further shortening of FAR4pro to $-1171 \mathrm{bp}$ did not cause an obvious change in GUS activity or pattern compared to the -1594 bp FAR4pro. Once down to $-545 \mathrm{bp}$, the FAR4pro showed no expression in the root endodermis nor at lateral root junctions. No GUS activity was seen in the -245 bp FAR4pro. The regions of the FAR4 promoter from $2061 \mathrm{bp}$ to $-1594 \mathrm{bp}$ and $-1171 \mathrm{bp}$ to $-545 \mathrm{bp}$ were thus analyzed in silico for transcription factor cisbinding elements, with a focus on R2R3-MYB TF binding sites, as these regions of the FAR4 promoter clearly influence root endodermis expression. 


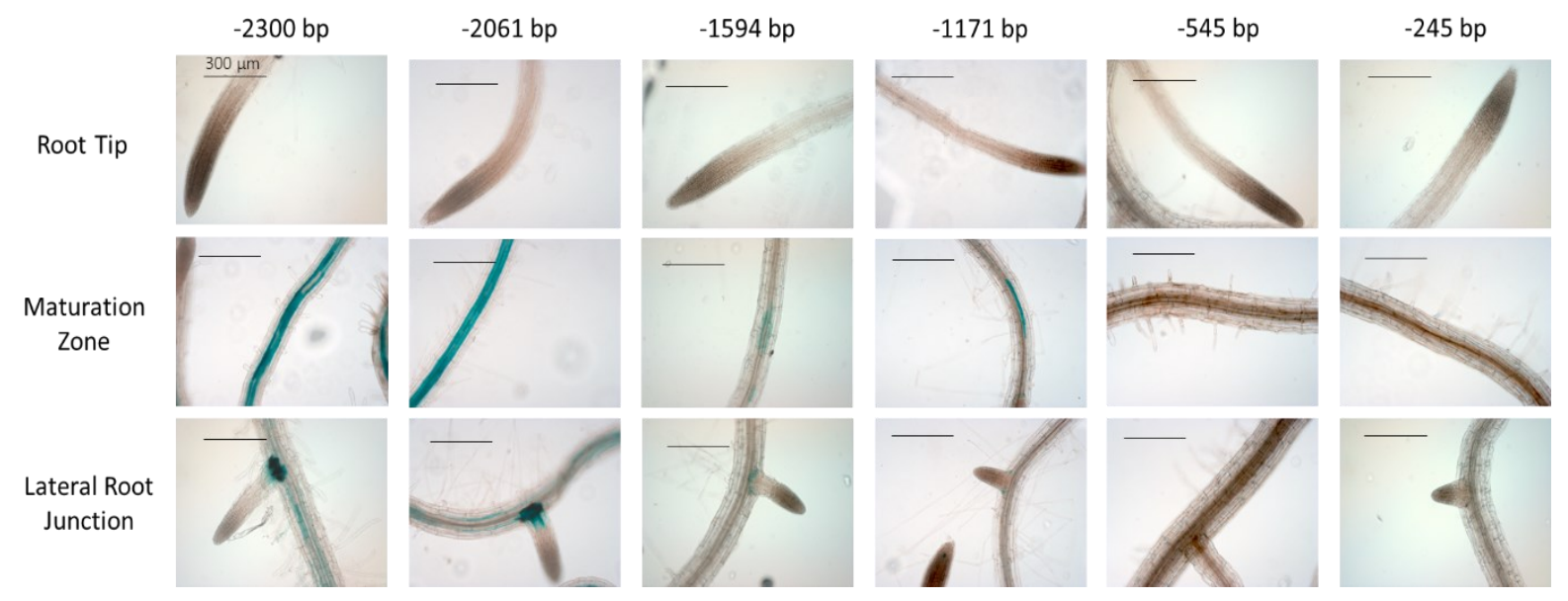

Figure 9: Staining pattern of the root tip, root maturation zone, and lateral root initiation of $T_{2}$ seeds containing the $-2300 \mathrm{bp},-2061 \mathrm{bp},-1594 \mathrm{bp},-1171 \mathrm{bp},-545 \mathrm{bp}$, and $-245 \mathrm{bp}$ FAR4 promoter fused the to b-glucuronidase (GUS) reporter gene. Seeds were grown for 12 days on $1 / 2 \mathrm{MS}$ agar with $50 \mu \mathrm{g} / \mathrm{mL}$ Kanamycin and stained for GUS activity. Whole seedlings were incubated in the dark for $24 \mathrm{hr}$ at $37{ }^{\circ} \mathrm{C}$ in a x-gluc buffer. Multiple independent lines were stained for each construct (Supp. Table 5), with only one representative line for each promoter deletion shown here.

\section{3- Bioinformatic (in silico) analysis of the FAR4 promoter for TF DNA- binding elements}

R2R3-MYB, WRKY, and NAC transcription factors have previously been shown to influence suberin biosynthesis (Cohen et al., 2020; Kosma et al., 2014; Krishnamurthy et al., 2020, 2021; Mahmood et al., 2019; To et al., 2020). With five R2R3-MYB TFs transcriptionally activating suberin biosynthesis genes (Figure 5) and WRKY56 (Klein, 2019)(Figure 7), MYB and WRKY TF DNA-binding motifs were the focus of cis-element search of the suberin biosynthesis gene promoters. Kelemen et al. (2015) determined that Arabidopsis R2R3-MYB TFs have at least two different consensus DNA-binding motifs by analyzing all known R2R3-MYB TF interactions with DNA reported in the literature. The two consensus motifs are MYBcore (YNGTTR) and AC-rich (ACCWHH or ACCWAMY) (Table 1). Yeast 1-hybrid assays with synthesised DNA fragments showed that AtMYB53, AtMYB92, AtMYB93 preferred binding to AC-rich ciselements, although they could bind to MYBcore cis-elements (Dubos et al., 2014; Kelemen et al., 2015). However, no in-depth analysis of how R2R3-MYB TF bind to specific motifs in suberin biosynthetic gene promoters have been done. Rather, MYB92 could bind and activate the promoter of a fatty acid 
synthesis gene, $B C C P 2$, and these actions required the presence of two adjacent AC-rich motifs (To et al., 2020). WRKY33 and WRKY9 were found to bind to W-boxes with a sequence of TTGAC in the promoters of CYP86B1, CYP94B1, and CYP94B3 (Krishnamurthy et al., 2020, 2021). Since some R2R3-MYB TFs are known to interact with bHLH TFs and a WD40-repeat protein to form a MBW complex, bHLH DNAbinding motifs were also searched. An exhaustive search using PlantPAN3.0 software (http://plantpan.itps.ncku.edu.tw/promoter.php), PLACE (https://www.dna.affrc.go.jp/PLACE/?action=newplace), and AGRIS (https://agrisknowledgebase.org/AtcisDB/) (Chow et al., 2019; Higo et al., 1999; Yilmaz et al., 2011) was used to ensure no important binding site were missed (Table 1). 
Table 1: Consensus DNA-binding motifs for R2R3-MYB, bHLH, NAC, and WRKY TFs

\begin{tabular}{|c|c|}
\hline Class of Transcription Factor & Consensus DNA-Binding Motifs (Name) \\
\hline $\begin{array}{c}\text { R2R3-MYB } \\
\text { (Kelemen et al., 2015) }\end{array}$ & $\begin{array}{l}\text { YNGTTR (MYB core) } \\
\text { ACCWAMY (AC-rich) } \\
\text { ACCWHH (AC-rich) }\end{array}$ \\
\hline $\begin{array}{c}\text { bHLH } \\
\text { (Atchley \& Fitch, 1997; Hartmann et al., 2005) }\end{array}$ & $\begin{array}{c}\text { CANNTG (E-box) } \\
\text { CACNTG (G-box) } \\
\text { NRCGTG (non E-box) domain) } \\
\text { CACGRG (N-box) GGKCCKRWC (GCG-box) }\end{array}$ \\
\hline $\begin{array}{c}\text { NAC } \\
\text { (Lindemose et al., 2014; Zhong et al., 2010) }\end{array}$ & 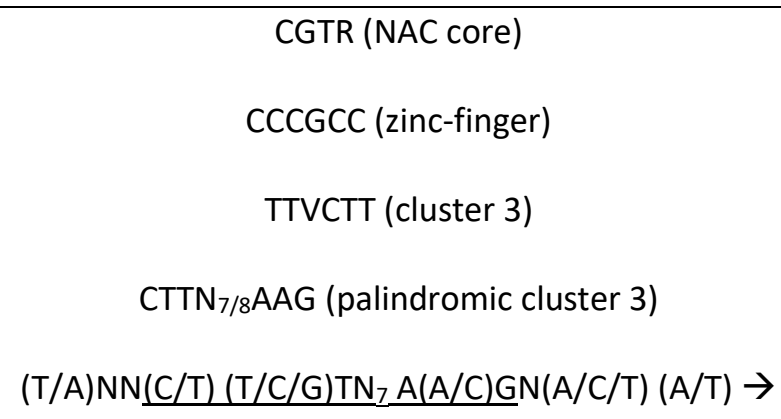 \\
\hline $\begin{array}{l}\text { WRKY } \\
\text { (Elucidating the Evolutionary Conserved DNA- } \\
\text { Binding Specificities of WRKY Transcription } \\
\text { Factors by Molecular Dynamics and in Vitro } \\
\text { Binding Assays, 2013; Kanofsky et al., 2017; Van } \\
\text { Verk et al., 2008) }\end{array}$ & $\begin{array}{l}\text { TGAC (core) or TTGACY } \\
\text { GACTTT (WT-box core) } \\
\text { TTTTCCAC (WK-box) }\end{array}$ \\
\hline
\end{tabular}

${ }^{*} \mathrm{Y}=\mathrm{C} / \mathrm{T}, \mathrm{W}=\mathrm{A} / \mathrm{T}, \mathrm{R}=\mathrm{A} / \mathrm{G}, \mathrm{M}=\mathrm{A} / \mathrm{C}, \mathrm{H}=\mathrm{A} / \mathrm{C} / \mathrm{T}, \mathrm{V}=\mathrm{A} / \mathrm{C} / \mathrm{G}, \mathrm{N}=\mathrm{A} / \mathrm{C} / \mathrm{T} / \mathrm{G}$

All of the promoters of genes transcriptionally activated by the suberin-associated R2R3-MYB TFs (Figure 5) contained MYB, WRKY, NAC, and bHLH transcription factor cis-elements (Table 2). Therefore, the enrichment of these motifs (Table 1 ) in the 3000 bp upstream from the translation start site ('promoter') of all suberin biosynthetic genes was done using the Analysis of Motif Enrichment (AME) 
software, with default settings, from MEME Suite 5.3.3 (https://meme-suite.org/meme/tools/ame)

(Supp. Table 6). Compared to randomly generated control sequences, the R2R3-MYB TF AC-rich motif was enriched, but the MYBcore motif was not enriched (Table 2). No other consensus DNA-binding motifs from the bHLH, WRKY, and NAC TF families was enriched in the FAR4 promoter analyzed.

Table 2: Amount of MYB, bHLH, NAC, and WRKY transcription factor cis-elements found in the promoter upstream region of suberin biosynthesis genes

\begin{tabular}{|c|c|c|c|c|c|c|}
\hline $\begin{array}{c}\text { Potential } \\
\text { Binding TF }\end{array}$ & $\begin{array}{c}\text { Cis-element } \\
\left(\mathbf{5}^{\prime} \rightarrow \mathbf{3}^{\prime}\right)\end{array}$ & $\begin{array}{c}\text { ASFT } \\
(3000 \mathrm{bp})\end{array}$ & $\begin{array}{c}\text { GPAT 5 } \\
(2164)\end{array}$ & $\begin{array}{c}\text { FAR 4 } \\
(2300 \mathrm{bp})\end{array}$ & $\begin{array}{c}\text { CYP86 A1 } \\
(3000 \mathrm{bp})\end{array}$ & $\begin{array}{c}\text { CYP86 B1 } \\
(3000 \mathrm{bp})\end{array}$ \\
\hline R2R3-MYB & YNGTTR & 37 & 50 & 46 & 68 & 54 \\
\hline R2R3-MYB & ACCWHH & 73 & 61 & 43 & 64 & 69 \\
\hline bHLH & CANNTG & 36 & 34 & 18 & 57 & 40 \\
\hline WRKY & TGAC & 31 & 39 & 18 & 27 & 24 \\
\hline WRKY & GGACTTTC & 0 & 0 & 0 & 0 & 0 \\
\hline WRKY & TTTCCAC & 0 & 4 & 2 & 0 & 1 \\
\hline NAC & CGTR & 41 & 59 & 29 & 47 & 27 \\
\hline NAC & CCCGCC & 0 & 1 & 0 & 0 & 0 \\
\hline NAC & TTVCTT & 20 & 17 & 7 & 11 & 21 \\
\hline $\begin{array}{c}\text { CCAAT-box } \\
\text { binding } \\
\text { proteins }\end{array}$ & CCAAT & 13 & 8 & 9 & 12 & 11 \\
\hline $\begin{array}{c}\text { RNA- } \\
\text { Polymerase } \\
\text { II }\end{array}$ & TATAWAW & 14 & 20 & 29 & 22 & 18 \\
\hline
\end{tabular}

Since the AC-rich motifs are enriched in the suberin gene promoters and considering the results from the FAR4 promoter deletion series, the $-2061 \mathrm{bp}$ to $-1594 \mathrm{bp}$ and $-1171 \mathrm{bp}$ to $-545 \mathrm{bp}$ regions of the FAR4 promoter upstream region was broken up into multiple fragments based on the appearance of adjacent AC-rich motifs. There are six fragments of the FAR4 promoter upstream region that became of most interest: -2037 bp to -1838 bp, -1825 bp to -1626 bp (Figure 10), -965 bp to -774 bp, -797 bp to $632 \mathrm{bp},-658 \mathrm{bp}$ to $-563 \mathrm{bp}$ (Figure 11), and $-551 \mathrm{bp}$ to $-401 \mathrm{bp}$ (not shown). The last fragment from -551 
to $-401 \mathrm{bp}$, or bait $\# 12$, was outside of the determined range from the deletion series and was done out of curiosity as it still contained adjacent AC-rich MYB-DNA binding motifs.

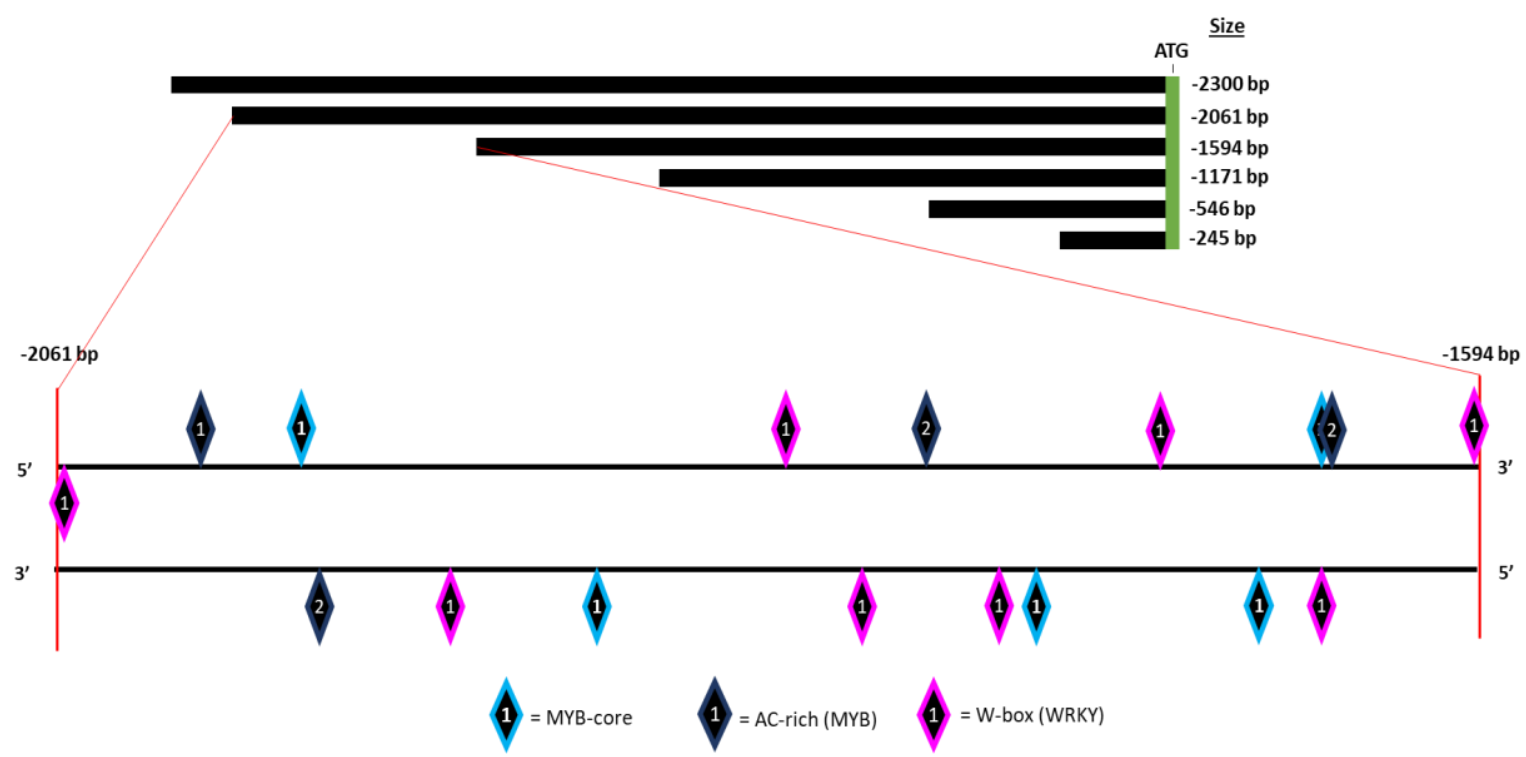

Figure 10: To-scale map of the FAR4 promoter upstream region, -2061 bp to $-1594 \mathrm{bp}$ from the translation start site, identifying predicted DNA-binding motifs for MYB and WRKY TFs.

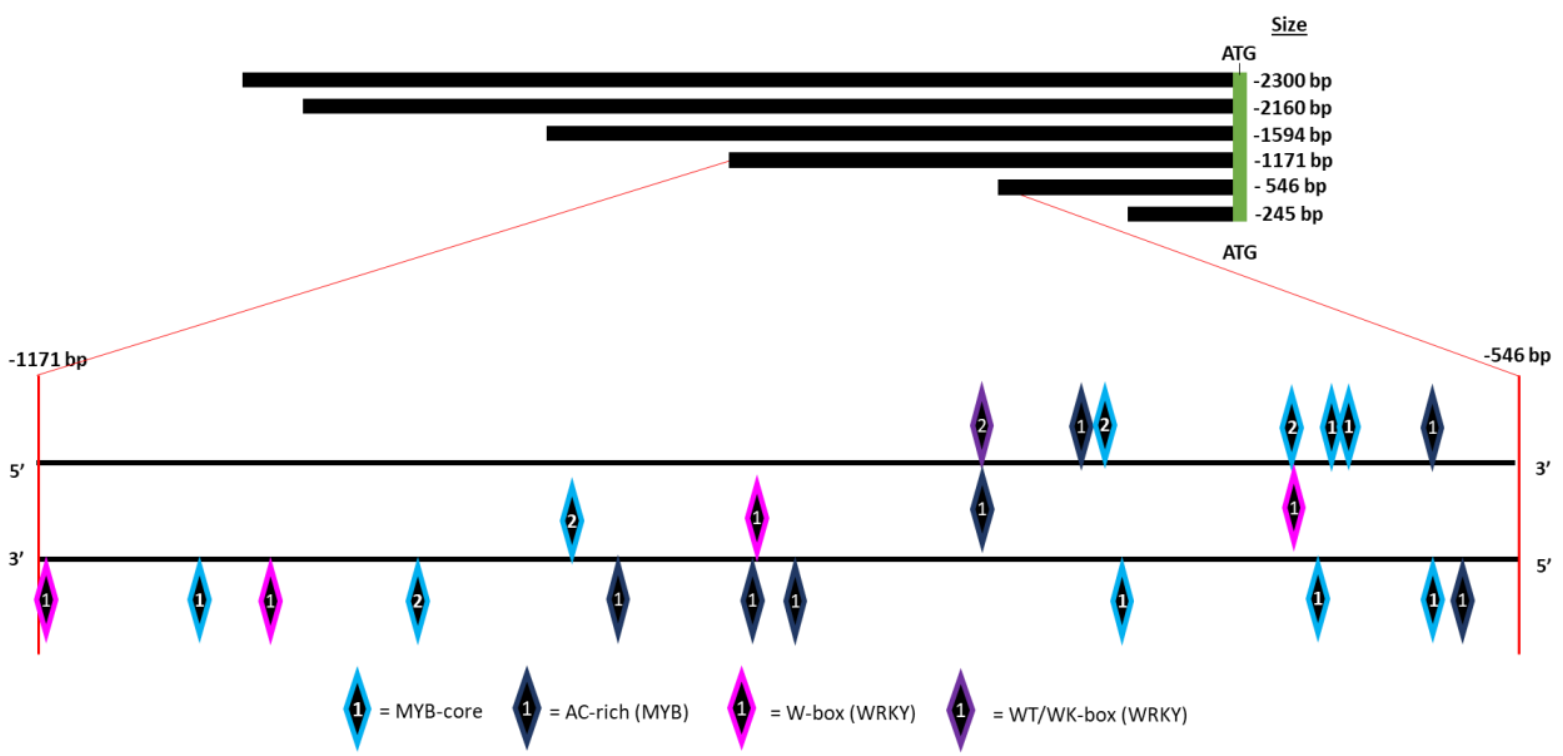

Figure 11: To-scale map of the FAR4 promoter upstream region, $-1171 \mathrm{bp}$ to $-546 \mathrm{bp}$ from identifying predicted DNA-binding motifs for MYB and WRKY TFs. 
3.4- Yeast-one-hybrid assay to test for MYB TF binding to FAR4 upstream regions

The FAR4 promoter fragments \#3, \#4, \#9, \#10,\#11, and \#12 (Figure 10 and 11) were inserted into the pAbAi vector, such that they were transcriptionally fused to the Aureobasidin A resistance gene (AUR1-

C), to form pBait:AbAi vectors. The transcription factors (prey) being tested are fused with a yeast GAL4activation domain (AD) in the pGADT7-AD vector. Any transcription factor capable of binding to the FAR4 promoter fragments should activate AUR1-C, via the the translationally fused GAL4-AD, and provide resistance to the antibiotic Aureobasidin A.

Each pBait:AbAi plasmid was linearized by the BstBI restriction enzyme, which has a recognition site in the functional URA locus of the plasmid. The linearized pBait:AbAi vectors were transformed into Y1HGold yeast cells, where they recombine with the non-functional ura3-52 locus in the Y1HGold genome to generate a functional URA locus. These transformed $\mathrm{Y} 1 \mathrm{HGold}$ yeast cells were plated on media lacking uracil, and colonies were screened to confirm the pBait:AbAi vectors were successfully recombined into the $\mathrm{Y} 1 \mathrm{HGold}$ genome to generate $\mathrm{Y} 1 \mathrm{HGold}$ bait strains (Figure 12). 

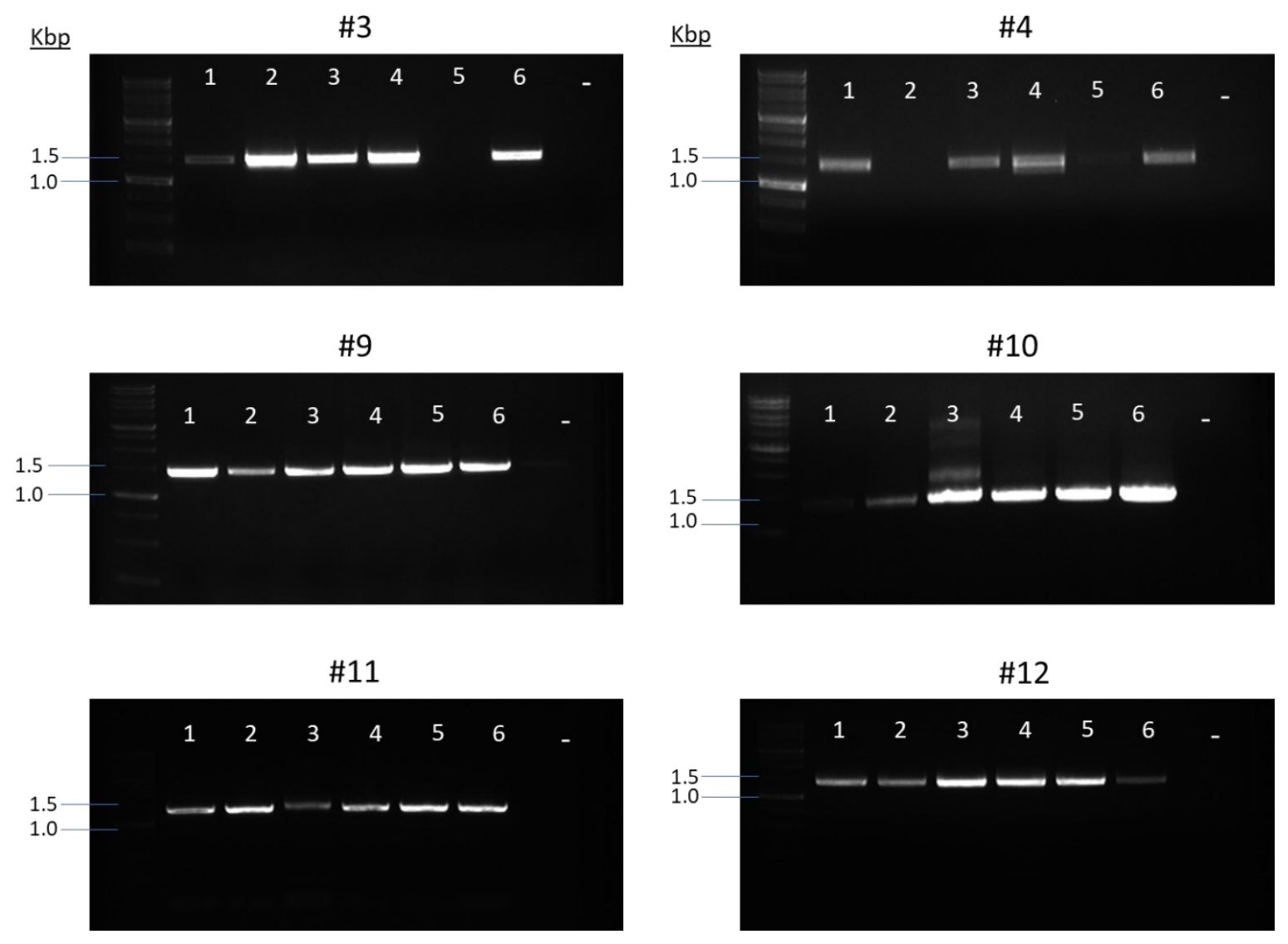

Figure 12: Colony PCR to confirm pBait-AbAi vector was integrated into the Y1HGold genome. PCRs were run on a $1 \%$ agarose gel. A $1 \mathrm{Kbp}$ DNA ladder (FroggaBio) was used to determine the size of each band. Band sizes were expected to be $1.4-1.5 \mathrm{Kbp}$.

To test the ability of an endogenous yeast transcription factor to bind to the FAR4 promoter upstream region fragments and activate the Aureobasidin A resistance gene, each Y1HGold Bait strain was plated on SD (-Ura) media containing $100 \mathrm{ng} / \mathrm{mL}, 150 \mathrm{ng} / \mathrm{mL}$, and $200 \mathrm{ng} / \mathrm{mL}$ of Aureobasidin A. None of the Y1HGold bait strains grew on SD (-Ura) containing any amount of Aureobasidin A, but they did grow on SD (-Ura) plates lacking Aureobasidin A as expected (Figure 13). The $100 \mathrm{ng} / \mathrm{mL}$ Aureobasidin A concentration was selected to test the ability of suberin-related R2R3 MYB TF to bind to the FAR4 promoter upstream region fragments. 

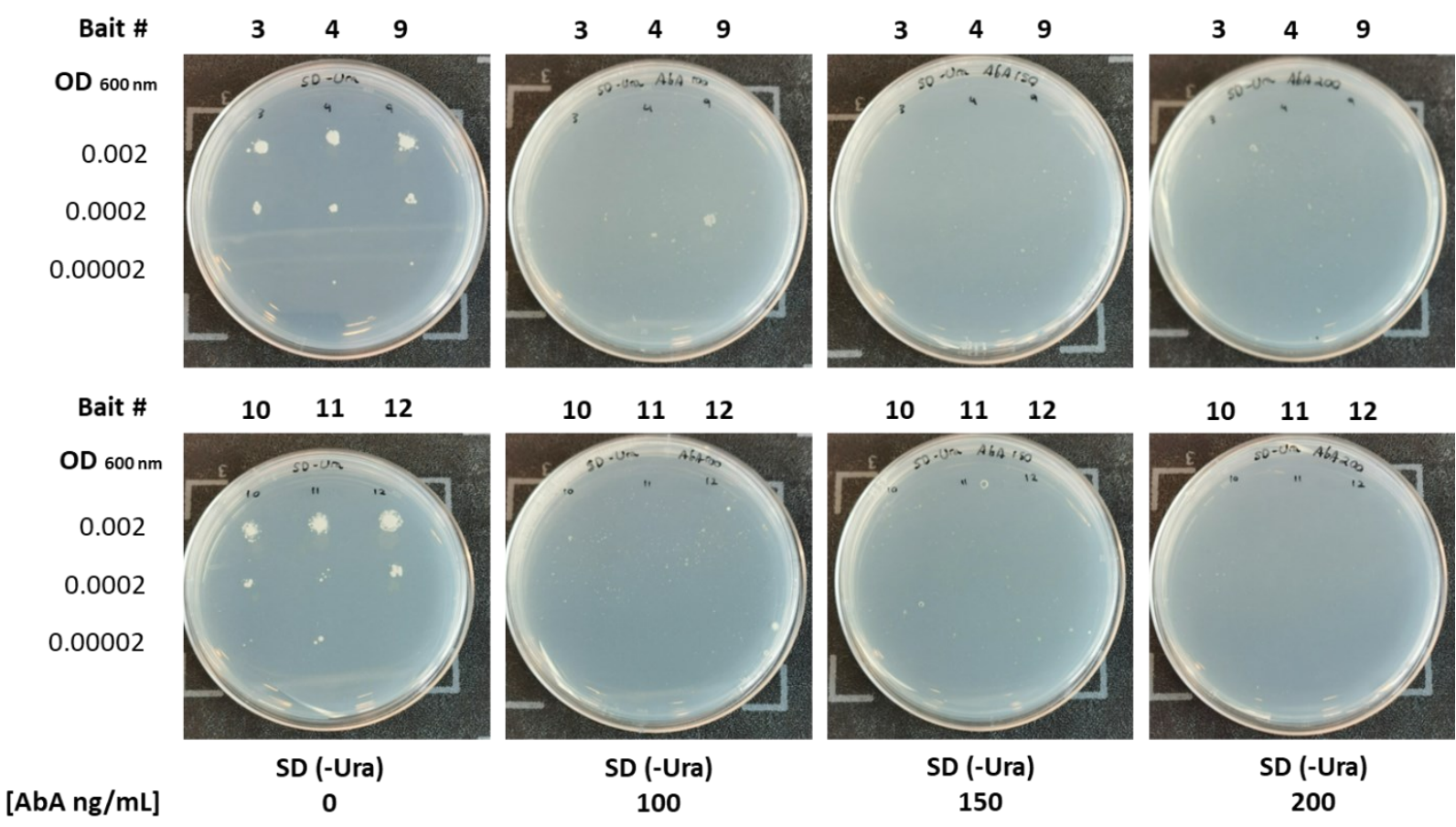

Figure 13: Y1HGold bait strains growing on SD (-Ura) media containing different concentrations of Aureobasidin $\mathrm{A}(\mathrm{AbA})$ in a dilution series. The yeast was plated as a dilution series $(0.002,0.002$ and $0.0002 \mathrm{OD} 600 \mathrm{~nm})$. The FAR4 promoter fragment numbers are indicated on the plates.

The full-length coding sequences of MYB53, MYB92, and MYB93 were inserted into PGADT7-AD (primers in Supp. Table 3) as translational fusions with the GAL4 Activation Domain. The full-length sequence of MYB92 and MYB53 were found to be toxic to the $\mathrm{Y} 1 \mathrm{H}$ (yeast) cells. For this reason the $\mathrm{N}$-terminal coding sequence for each R2R3-MYB TF was cloned into the PGADT7-AD vector because the N-terminal contains the DNA-binding domain and can still induce suberin production when overexpressed (Klein, 2019). If the transcription factors can bind to the FAR4pro fragment, the GAL4 AD will interact with the basal transcriptional machinery thereby activating transcription of AUR1-C and allowing the yeast to grow in media containing $100 \mathrm{ng} / \mathrm{mL}$ of Aureobasidin A (AbA).

Each transformation of prey vectors into the bait strains was plated onto two types of SD agar media: Leucine and -Leucine with $100 \mathrm{ng} / \mathrm{mL} \mathrm{AbA}$ (Figure 14). For the negative $\left(\mathrm{H}_{2} \mathrm{O}\right)$ control, no yeast colonies grew on either type of media. For the EV (pGADT7-AD) control, colonies grew for each bait strain on the 
-Leucine plates. For -Leucine + Aba plates the EV was found to grow well for bait \#12 and slightly on bait $\# 11$, but no growth was found on the EV control for bait \#3 and \#9. Figure 12 is a representative figure from three trials for each type of transformation, and bait \#4 and \#10 are not shown below due to inconsistencies between the three trials. Bait \#3 and \#9 show no yeast growth on -Leu + Aba plates for MYB53 (N-term), MYB92 (N-term), and MYB93 (FL). Bait \#11 showed some yeast growth at the highest cell density for the EV, but no yeast growth for MYB53 (N-term), MYB92 (N-term), and MYB93 (FL). On Leucine + AbA media bait \#12 with MYB53 (N-term), MYB92 (N-term), and MYB93 (FL) showed lots of yeast growth, but the EV did as well so binding cannot be confirmed. Bait \#12 had a single colony growing at $100 \mathrm{ng} / \mathrm{mL}$ when determining the minimal inhibitory concentration of AbA for the bait strains, however it was not anticipated that this much autoactivation was occurring. Bait \#12 will have to be tested at $150 \mathrm{ng} / \mathrm{mL}$ of AbA since 0 bait \#12 colonies grew (Figure 13). 

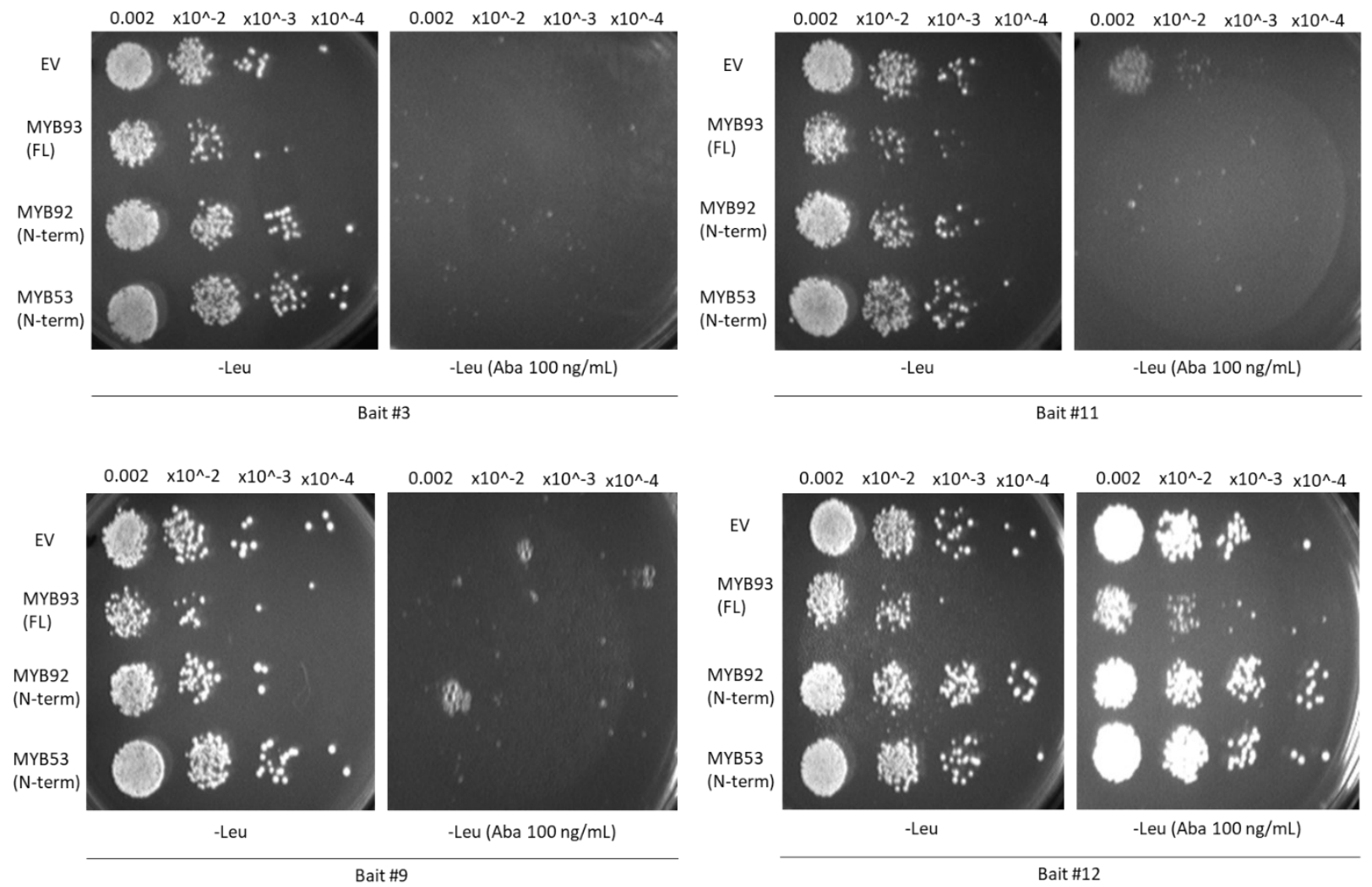

Figure 14: $\mathrm{Y} 1 \mathrm{H}$ assay showing MYB53 (N-terminal), MYB92 (N-terminal), and MYB93 ability to bind to FAR4 promoter fragments \#3, \#9, \#11, and \#12. pGADT7-AD empty vector was used as a negative control. The representative growth of yeast cells on SD/-Leu agar medium without and with $100 \mathrm{ng}$ of Aureobasidin $\mathrm{A}$ at various relative densities is shown.

\section{5- Chemical analysis of suberin in wrky56 loss-of-function mutants}

The names of the three wrky56 T-DNA mutant line are: SAIL_737_DO1 (wrky56-3: exon), SALK_201886C (wrky56-1: intron), SAIL_1287_G04 (wrky56-2: exon). The location of the T-DNA insertion in the WRKY56 gene for each mutant line is shown in Figure 12. The $T_{2}$ generation of each line was genotyped by PCR and only plants that were homozygous for the T-DNA insertion were used for suberin analysis. Sequencing still needs to be performed to confirm the precise locations of the T-DNA inserts, as well as transcript analysis to determine whether the T-DNA mutants are knockdowns or knockouts. 


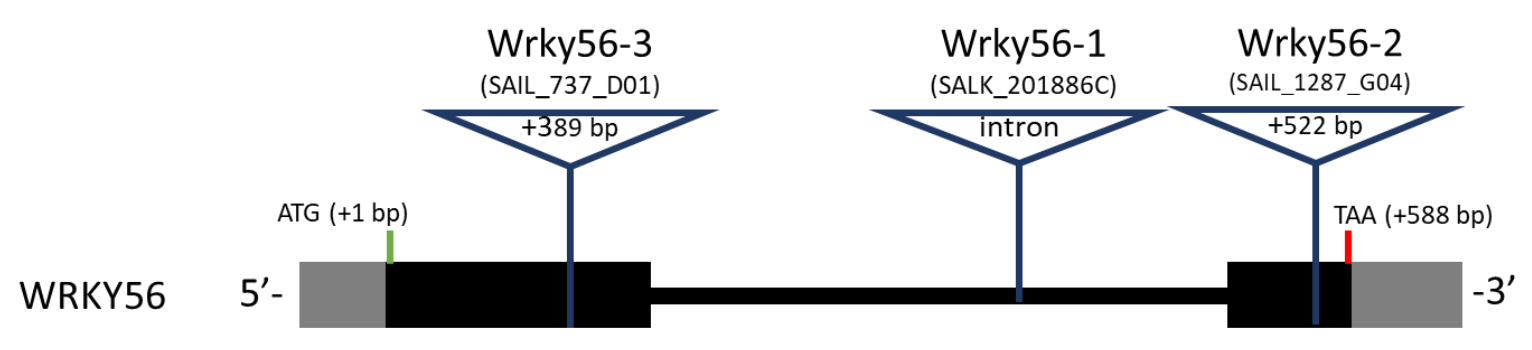

$200 \mathrm{bp}$

Figure 15: Location of the T-DNA in mutant $A$. thaliana ( $\mathrm{Col}-0$ ) seed lines used for the root suberin analysis. Each blue triangle represents a single T-DNA mutant. Grey areas are the UTR's, thick black lines are exons, and the thin black line is the intron.

The mean total aliphatic root suberin content for wrky56-1, wrky56-2, and wrky56-3 T-DNA mutants were $127.79 \pm 8.97 \mu \mathrm{mol} / \mathrm{g}, 123.37 \pm 3.17 \mu \mathrm{mol} / \mathrm{g}$, and $133.67 \pm 8.40 \mu \mathrm{mol} / \mathrm{g}$, respectively, none of which were significantly different from the $122.216 \pm 7.55 \mu \mathrm{mol} / \mathrm{g}$ of the wild-type plants (Figure 16A; Supp. Table 7). When total aliphatic suberin was broken down into classes of compounds (Figure 16B; Supp. Table 8), significant differences between the wrky56-1 and wrky56-3 T- DNA mutant lines and the wild-type plants were found in the $\omega$-hydroxy fatty acids. The wrky56-1 and wrky56-3 mutants had $50 \pm$ $2.00 \mu \mathrm{mol} / \mathrm{g}$ and $48.39 \pm 2.08 \mu \mathrm{mol} / \mathrm{g}$, respectively, of $\omega$-hydroxy fatty acids in the polyester, an increase from $40.66 \pm 2.32 \mu \mathrm{mol} / \mathrm{g}$ in the wild-type plants. This increase is due to an increase in 18:1 $\omega$-hydroxy fatty acid (Figure 17; Supp. Table 9). 


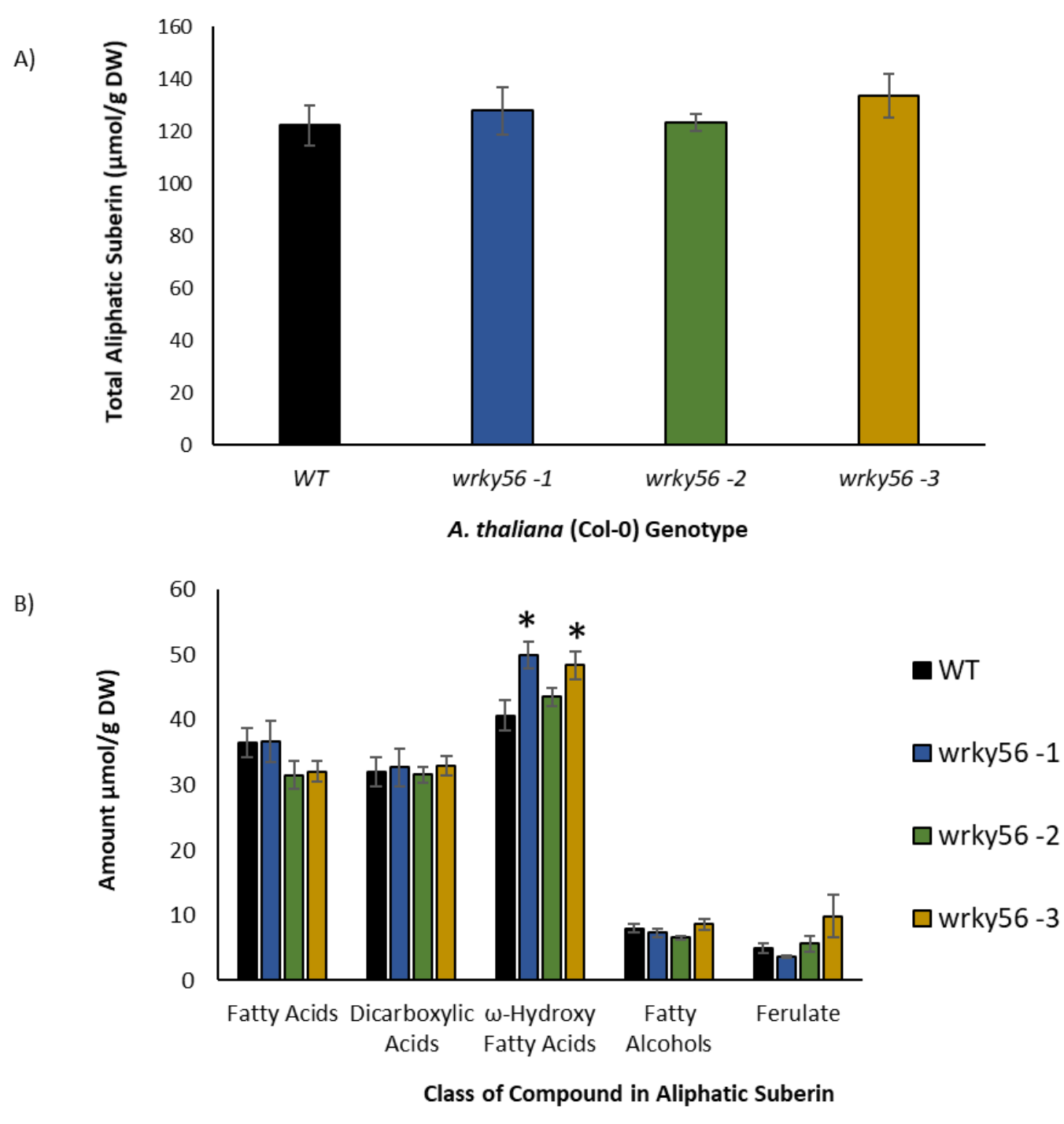

Figure 16: A) Total aliphatic suberin in roots of 12-day old Arabidopsis seedlings comparing wild-type to three different wrky56 T-DNA insertion alleles. No periderm expected in this young age of plants, and therefore suberin is from root endodermis B) Suberin monomer levels sorted into compound class, comparing wild-type to the three wrky56 T-DNA insertion alleles. Bars represent $\mu \mathrm{mol} / \mathrm{g}$ of DW (dryweight) \pm SE and asterisks are placed above bars that are statistically different (F-Test and two-tailed $t$ test) from the WT (wild-type) control. 


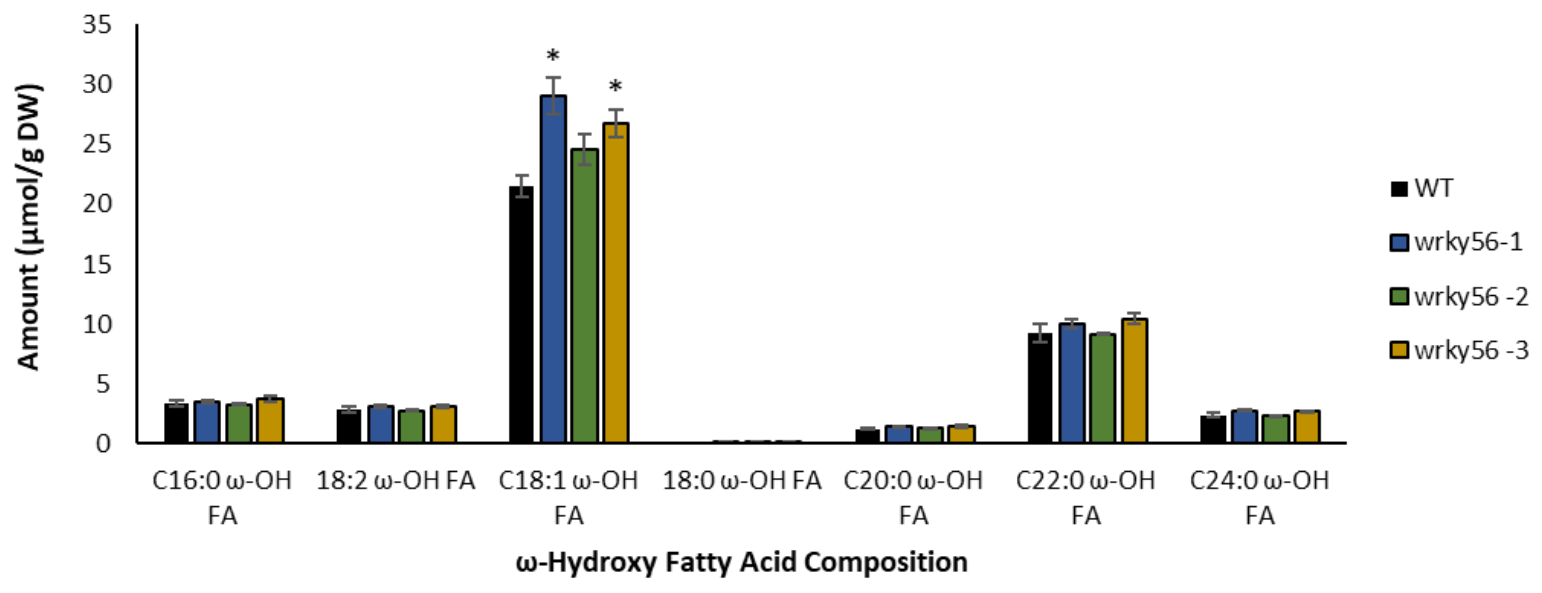

Figure 17: Amount of individual $\omega$-hydroxy fatty acids found in root suberin of wild-type and three wrky56 T-DNA insertion alleles of Arabidopsis. Bars represent $\mu \mathrm{mol} / \mathrm{g}$ of DW (dry-weight) $\pm \mathrm{SE}$ and asterisks are placed above the bars that are statistically different (F-test and two-tailed t-Test) from the WT (wild-type) control. 


\section{4- Discussion}

\section{1- Opening Statement}

The root endodermis of Arabidopsis contains aliphatic suberin and lignified Casparian strips in its cell walls. These are hydrophobic barriers that direct the movement of water and nutrients through the symplastic pathway and into the xylem (Barberon et al., 2016; Barbosa et al., 2019). SHORT-ROOT (SHR) is a GRAS-family transcription factor that is necessary for root endodermis identity throughout development. Expressed in the central root stele, SHR travels symplastically to the endodermis where it activates MYB36, although not directly, as part of stage I of root endodermis differentiation ( Li et al., 2018). MYB36, an R2R3-MYB transcription factor, directly induces the expression of CASP1, PER64, and ESB1, which encode enzymes responsible for the polymerization of Casparian strips (Kamiya et al., 2015). A second GRAS-family transcription factor SCARECROW (SCR), also regulated by SHR, regulates genes encoding receptor-like kinases (SNG1/SNG3) in the plasma membrane that trigger Casparian strip formation. The SCR pathway is mediated by stele-derived peptides CIF1/CIF2 (independent of SHR), that migrate to the endodermis through the apoplast and interact with SNG1/SNG3 to direct Casparian strip formation in a ring around the anticlinal cell wall of endodermal cells, thereby sealing the entire apoplast between adjacent endodermal cells (Kamiya et al., 2015; Li et al., 2018; Naseer et al., 2012). Once a Casparian strip is formed these peptides can no longer leave the stele, ensuring Casparian strip formation is specific to the endodermis ( Li et al., 2018).

While stage I of root endodermis differentiation involves blocking the apoplast with Casparian Strips, stage II involves the deposition of aliphatic suberin all around cells of the root endodermis to block the transmembrane movement of water and nutrients (Naseer et al., 2012). Interestingly, the overexpression of iSHR and iMYB36 eventually lead to the production of functional suberin in the root endodermis (C. Wang et al., 2020). Transcript analysis of iSHR and iMYB36 revealed that most suberin 
biosynthesis genes were upregulated along with suberin regulators MYB9, MY39, MYB41, MYB93, and MYB107, and MYB39. Mutant and overexpression line transcript analysis also provide evidence MYB39 functions downstream of SHR/MYB36 (Cohen et al., 2020; C. Wang et al., 2020). The regulation of suberin deposition being a downstream target of the SHR/MYB36 regulatory pathway makes sense for the timing and development of the root endodermis, but a lot is still unknown. With suberin having a complex biosynthetic pathway, transport, and cell wall assembly, plus having roles in lateral root development, abiotic and biotic stress responses, suberin production is likely controlled by an intricate regulatory network (Geldner, 2013; Vishwanath et al., 2015). While each enzyme that is involved in suberin biosynthesis can be regulated at various levels (transcriptional, post-transcriptional, translational, and post-translational), most research to date has focused on their transcriptional regulation. While MYB36 directly regulates Casparian Strip biosynthetic enzymes (Kamiya et al., 2015), it appears that other R2R3-MYB TF have a similar role in suberin biosynthesis. R2R3-MYB TFs of subgroup 10 (MYB9, MYB39, MYB107), subgroup 11 (MYB41, MYB74, MYB102), and subgroup 24 (MYB53, MYB92, MYB93) have all been implicated in positively regulating suberin biosynthesis in Arabidopsis. However, little work has been done to determine whether these transcription factors are direct or indirect transactivators of suberin biosynthesis genes or how they may work with other transcriptional regulators (Cohen et al., 2020; Kosma et al., 2014; Lashbrooke et al., 2016; Murmu et al., manuscript in preparation; To et al., 2020). My study was focused on these mechanistic gaps in our understanding of the regulated deposition of suberin.

\section{2- Suberin-associated MYB transcription factors trans-activate the promoter upstream regions of suberin biosynthetic genes}

Transcription factors that promote suberin biosynthesis in seeds coats (MYB9 and MYB107), the root endodermis under abiotic stress (MYB41), and the root endodermis throughout development (MYB39) have been reported, covering most of spatial-temporal occurrences of suberin in Arabidopsis (Cohen et 
al., 2020; Gou et al., 2017; Kosma et al., 2014; Lashbrooke et al., 2016). Loss of function mutants for MYB107 and MYB9 were used to demonstrate a decrease in seed coat suberin and associated suberin gene mRNA transcripts, as well as increased sensitivity of the mutants to osmotic stress, which is in line with the role of seed coat suberin (Gou et al., 2017; Lashbrooke et al., 2016). Ectopic over-expression of MYB41 in leaves was used to show its ability to induce the expression of suberin gene mRNA transcripts, individual suberin monomers, and suberin lamellae, but MYB41 is only expressed in the root endodermis in response to abiotic (salt) stress (Kosma et al., 2014). Cohen et al. (2020) used a loss-offunction mutant and over-expression lines to demonstrate that MYB39 induces suberin biosynthesis throughout root development, and they also demonstrated the trans-activation capabilities of MYB39 on suberin gene promoters. Specifically, MYB39 activated gene expression when a reporter gene (luciferase) was fused with the promoters (region $5^{\prime}$ of translation start site) of suberin biosynthetic genes FAR4, FAR1, GPAT5, ASFT, and CYP86B1, as well as the suberin transport gene ABCG6 (Cohen et al., 2020).

Similar to MYB39, Arabidopsis MYB53, MYB92 and MYB93 have also been implicated in regulating suberin biosynthesis in root endodermis through loss-of-function mutants, over-expression lines, and promoter: reporter gene expression experiments (Hu, 2018; Klein, 2019; Murmu et al., manuscript in preparation, Rowland Lab). My study here reproduced the finding by Cohen et al. (2020) that MYB39 can transactivate suberin gene promoters (Figure 4). I also demonstrated that MYB41, MYB53, MYB92, and MYB93 also transcriptionally activate suberin biosynthesis gene promoters (specifically, FAR4, GPAT5, CYP86A1, CYP86B1, and ASFT) (Figure 5). The next step would be to test the ability of each root suberin-associated MYB TF to transcriptionally activate genes encoding suberin transporters ( $A B C G 2$, ABCG6, ABCG20) and suberin polymerization enzymes (GELP22, GELP38, GELP49, GELP51, GELP96) genes, and even fatty acid synthesis genes, to see if each TF regulates every step or just parts suberin deposition. Also, MYB45 and MYB67 could not transcriptionally activate GPAT5 (Figure 6A), which is 
consistent with the findings of Kosma et al. (2014) who over-expressed MYB45 and MYB67 and observed no suberin monomer accumulation. R2R3-MYB and bHLH TF from Poplar also could not transactivate GPAT5 (Figure 6B), however, transcription factors that transcriptionally regulate similar surface lipid barriers (e.g. cuticle) or the closely associated lignified polymer that makes up Casparian Strips should be used to further evaluate the specificities of MYB-type TF that can trans-activate suberin biosynthetic genes. Further characterization of the expression patterns of MYB39, MYB41, MYB53, MYB92, and MYB93 during development and in response to all types of stress, and if they match the expression of suberin biosynthesis genes, needs to be analyzed to carve-out any unique roles for each TF. It should be noted that statistical significance throughout this study was determined using the F-test followed by a two-tailed student t-test, as done by Cohen et al. (2020), which can be prone to falsepositives.

\section{3- No evidence of Arabidopsis MYB53, MYB92, or MYB93 binding to the FAR4 promoter using yeast 1-hybrid analysis}

Although the root suberin-associated MYB TFs are transcription activators of suberin biosynthetic gene promoters, this does not necessarily mean they have a direct and physical interaction with the cognate promoters. There may be a transcriptional cascade where one or any combination of root suberinassociated MYB TFs activate each other, or another transcription factor, which then binds to promoter to activate the transcription of the suberin biosynthesis genes. Chromatin immunoprecipitation-qPCR and $\mathrm{Y} 1 \mathrm{H}$ revealed that MYB107 directly binds to the promoter of suberin biosynthesis genes (GPAT5, FAR1, and FACT) (Gou et al., 2017). Y1H experiments were done to test whether MYB39 could directly bind to promoter upstream regions of 10 suberin biosynthetic genes and it was only found to bind to the FAR5 promoter upstream region (C. Wang et al., 2020). Here, I attempted to determine if MYB53, MYB92, or MYB93 could directly bind to the promoter upstream region of suberin biosynthesis gene FAR4, through a $\mathrm{Y} 1 \mathrm{H}$, which I previously demonstrated was transcriptionally activated by these three 
R2R3-MYB transcription factors (Figure 5). $\mathrm{Y} 1 \mathrm{H}$ was used instead of CHiP-qPCR due to an inability to epitope tag the root suberin-associated R2R3-MYB TFs. Epitope tags on the N-terminus or C-terminus either caused a loss of activity or the epitope tags were removed by proteolysis in the cell (Rowland, personal communication). Also, antibodies specific to these transcription factors are not available.

The FAR4 promoter deletion series experiment indicated that the -545 bp to -1171 bp and -1594 to 2061 bp regions (Figure 9) contain important transcription factor binding sites for expression of FAR4 in root endodermis, which matches the sites of aliphatic suberin deposition in this tissue. These regions also contain numerous potential AC-rich MYB DNA-binding motifs (Figure 10 and 11), however only the 1594 to - 2061 bp region contained occurrences where two AC-rich MYB-DNA binding motifs were adjacent to each other as required by MYB92 to bind to the BCCP2 promoter (To et al., 2020). The bait fragments generated covered a majority of these two regions in the FAR4 promoter, however three (bait $\# 3$, \#9, and \#11) were not bound by MYB53, MYB92, and MYB93 using the Y1H assay, while more conclusive evidence is still needed for baits \#4 and \#10. As for bait \#12, no conclusion can be made due to autoactivation by the EV that occurred. While it is possible the root suberin-associated R2R3-MYB TFs may not bind the FAR4 promoter, other factors may be influencing this negative result. Arabidopsis MYB53, MYB92, and MYB93 having very high sequence similarity in their R2R3 DNA-binding domains and likely bind to DNA in a similar fashion. Genome-wide cistrome and epicistrome analysis of Arabidopsis TFs by O'Malley et al (2016) included the target genes of MYB93. Through DNA-affinity purification (DAP) of native gDNA, MYB93 was bound to the FAR4 promoter but was not bound to the FAR4 promoter when the native gDNA was PCR amplified before the DAP (amp-DAP). Native gDNA contains chemical modifications, such as methyl-cystosine, which are removed during PCR amplification. Comparing the binding of MYB93 in DAP vs. amp-DAP states indicates that an epigenetic chemical modification is needed for MYB93 to bind to the FAR4 promoter (Supp. Table 7). Interestingly, MYB93 was bound to the BCCP2 promoter region in the amp-DAP state but not in the DAP state (O'Malley et al., 
2016)(Suppl. Table 7). The methylation of cytosine is a major chemical modification made to DNA and AC-rich motifs being the preference for MYB53, MYB92, and MYB93 meaning very important cytosine residues may not be modified (i.e. methylated) thereby preventing binding to occur in the $\mathrm{Y} 1 \mathrm{H}$ assays. The full-length coding sequence of MYB92 and MYB53 appeared to be toxic when expressed in the yeast bait strains, although this was not the case for MYB93. For this reason, only the $\mathrm{N}$-terminal halves of MYB92 and MYB53, which contains the predicted R2R3 DNA-binding domain, were used for the Y1H assays and it is possible that the loss of the C-terminal portion affects the ability of the transcription factors to bind DNA despite lacking any obvious DNA binding domains (Millard et al., 2019).

There are other reasons that no binding was observed in the $\mathrm{Y} 1 \mathrm{H}$ assay. First, the $100 \mathrm{ng} / \mathrm{mL}$ of $\mathrm{AbA}$ used as the minimal concentration to eliminate auto-activation of the AUR1-C gene (Aba resistance gene) by endogenous yeast transcription factors may be high enough to prevent any activation caused by binding of any of the three R2R3-MYB TFs. Testing a concentration range from $50-100 \mathrm{ng} / \mathrm{mL}$ may reveal binding of these transcription factors, compared to the empty vector negative control. Second, the FAR4 promoter fragments tested in the $\mathrm{Y} 1 \mathrm{H}$ contain all the predicted AC-rich R2R3-MYB TF DNA binding sites from the manual analysis performed, but there could still be DNA-binding sites for MYB TFs not yet reported. Other regions of the FAR4 promoter may thus need to be tested. Third, the R2R3-MYB TFs may need one or more partner transcription factors to bind the FAR4 promoter. The binding of MYB92 to the BCCP2 promoter suggested dimerization (although not confirmed) due to the adjacent ACrich sites (To et al., 2020). However, FAR4 is not a fatty acid synthesis gene like BCCP2 and it is possible they are regulated differently such that a hetero-dimer and not a homo-dimer is required for binding to the FAR4 promoter. R2R3-MYB TFs have been shown to interact with bHLH and WRKY TFs to regulate transcription of some genes (Amato et al., 2019; Vannozzi et al., 2018), and recently it was shown that MYB92 and MYB93 interact with bHLH111 through a yeast 2-hybrid assay (Tapp, 2020 - Rowland Lab). 
Outside of the highly conserved N-terminal R2 and R3 DNA-binding domains (DBD) in R2R3-MYB TFs, little is known about the function of the rest of the protein which is highly variable. The motif ([DE]Lx2[RK]x3Lx6Lx3R within the R3 DBD is required for interactions with R/B-like bHLH TFs (Zhao et al., 2013). However, a second study found that subgroup 12 R2R3-MYB TFs and closely related MYB95 and MYB47 contain a [L/F]LN[K/R][V/L]A motif in the C-terminal non-MYB (or non-R2R3 DBD region) required for interactions with the bHLH TFs MYC2, MYC3, and MYC4. This has led to the idea that MYBbHLH interactions have evolved independently of each other, based on the specific needs of a sub-set of similar functioning R2R3-MYB TFs, making it difficult to predict MYB-bHLH interactions (Millard et al., 2019). As previously mentioned, R2R3-MYB TFs can also work with WRKY-family TFs to regulate gene expression. In soybeans, it was found through yeast 2-hybrid analysis that MYB174 and WRKY27 specifically interact with each other. Together, they bind and suppress the expression of NACO29, which in-turn activates SPOD1 to reduce intracellular ROS levels and improving stress tolerance in soybean (Wang et al., 2015). However, nothing is yet reported on how or if MYB174 and WRKY 27 physically interact. Therefore, the removal of the C-terminal half of MYB53 and MYB92 may affect their ability to homo or hetero-dimerize, thus preventing binding to the FAR4 promoter.

\section{4- Arabidopsis WRKY56 may have a role in regulating suberin deposition in response to abiotic stress}

WRKY56 is thought to be a down-stream target of suberin-associated R2R3-MYB TFs (Cohen et al., 2020; Klein, 2019; Lashbrooke et al., 2016). In this study, three independent wrky56 T-DNA mutants were obtained to determine if WRKY56 plays a role in regulating root suberin biosynthesis. None of the wrky56 T-DNA mutants had a significant difference in overall root suberin content when compared to WT (Figure 16A), but some individual compounds were altered. The wrky56-2 mutants had a small decrease in 16:0 and 18:0 fatty acids, but there were no changes to compounds more unique to suberin. In this allele, the T-DNA is outside the DNA-binding domain or any known functional domain of WRKY56, 
so it may not be a knock-out allele. The wrky56-3 mutant had a specific increase in 18:1 w-hydroxy fatty acids (Figure 17), which was accompanied by a decrease in 16:0 and 18:1 fatty acid (Suppl. Table 8 ). The wrky56-1 mutant also had an increase in 18:1 $\omega$-hydroxy fatty acids, but no compounds had a significant decrease. The increases in 18:1 $\omega$-hydroxy fatty acids indicated WRKY56 may be a negative regulator of suberin biosynthesis, and may specifically act on CYP86A1 (Höfer et al., 2008). The difference between wrky56-1 and wrky56-3 and the wrky9 and wrky33 mutants is that wrky56 only increased 18:1 $\omega$ hydroxy fatty acid, while wrky9 and wrky33 decreased 16:0 $\omega$-hydroxy fatty acids and altered $\alpha, \omega$ dicarboxylic acids and fatty alcohol content (Krishnamurthy et al., 2020, Krishnamurthy et al., 2021). In the wrky56-1 and wrky56-3 alleles the T-DNA is in the intron and exon 1, respectively. The wrky56-1 allele may be affecting intron splicing and the wrky56-3 allele is likely interfering the DNA-binding domain of WRKY56. However, it has yet to be confirmed whether the wrky56 mutants are knockdown or knockouts and so a complete picture of WRKY56's impact on suberin under non-stress conditions cannot be made. Another way to screen for WRKY56's potential role in regulating suberin deposition would be to overexpress MYB53 (or any other root suberin associated R2R3-MYB TF) with and without WRKY56, in $N$. benthamiana leaves, and see if suberin deposition is different between the two samples.

All of the suberin-associated R2R3-MYB TF tested here (MYB39, MYB41, MYB53, MYB92 and MYB93) could transcriptionally activate the WRKY56 promoter, although the amount of Luciferase Activity was significantly lower than what was observed with the suberin biosynthesis gene promoters (Figure 5). Since MYB41, which is abiotic stress induced, transcriptionally activates the WRKY56 promoter, it should be noted that the potential involvement of MYB53, MYB92, and MYB93 in abiotic stress responses are not known. Expression data from ePlant (https://bar.utoronto.ca/eplant/) shows that WRKY56 is highly upregulated in the roots in response to various abiotic stresses (i.e. cold, drought, salt, osmotic). Although direct binding studies still need to confirm if the suberin-associated R2R3-MYB TFs are direct regulators of WRKY56, it is likely that WRKY56 is down-stream in their regulatory pathway. The ability of 
WRKY56 to transcriptionally activate the promoter of suberin biosynthesis genes, specifically CYP86A1 which is responsible for 18:1 $\omega$-hydroxy fatty acid production, should be done to complement the suberin analysis in wrky56 roots. Also, performing the chemical and microscopic analysis of root suberin after applying abiotic stress to wrky56 mutant versus control wild type, may give a mor clear picture on the role of WRKY56 in regulating suberin biosynthesis.

\section{5- Conclusions}

I determined that Arabidopsis MYB53, MYB92, and MYB93, as well as MYB41, transcriptionally activate the promoter upstream regions of suberin biosynthesis genes. I also mapped two 500-600bp regions of the Arabidopsis FAR4 promoter that are important for directing specific gene expression in root endodermis. Although I found that MYB TF AC-rich motifs are enriched in the promoter upstream regions of suberin biosynthesis genes, including in the two regions of the FAR4 promoter required for root endodermis expression, there was no evidence that MYB53, MYB92, or MYB93 binds directly to the FAR4 promoter using yeast 1-hybrid assays. However, more research needs to be done with the yeast 1hybrid assay before any firm conclusions can be made, and ideally an alternate approach should be taken. Lastly, I found that Arabidopsis WRKY56 promoter to be transcriptionally activated by these same root suberin-associated R2R3-MYB transcription factors. Chemical root suberin analysis of wrky56 mutants indicated that WRKY56 is a negative regulator that specifically impacts $\omega$-hydroxy fatty acid production. However, the overall impact of WRKY56 on the suberin polymer under normal developmental conditions appears to be minimal, and further analysis should be done with a focus on the potential role of WRKY56 in regulating suberin deposition under abiotic stress conditions and through overexpression experiments. 


\section{5- References}

Amato, A., Cavallini, E., Walker, A. R., Pezzotti, M., Bliek, M., Quattrocchio, F., Koes, R., Ruperti, B., Bertini, E., Zenoni, S., \& Tornielli, G. B. (2019). The MYB5-driven MBW complex recruits a WRKY factor to enhance the expression of targets involved in vacuolar hyper-acidification and trafficking in grapevine. Plant Journal, 99(6), 1220-1241. https://doi.org/10.1111/tpj.14419

Atchley, W. R., \& Fitch, W. M. (1997). A natural classification of the basic helix-loop-helix class of transcription factors. Proceedings of the National Academy of Sciences of the United States of America, 94(10), 5172-5176. https://doi.org/10.1073/pnas.94.10.5172

Atkinson, J. A., Rasmussen, A., Traini, R., Voß, U., Sturrock, C., Mooney, S. J., Wells, D. M., \& Bennett, M. J. (2014). Branching out in roots: Uncovering form, function, and regulation. Plant Physiology, 166(2), 538-550. https://doi.org/10.1104/pp.114.245423

Ayaz, A., Saqib, S., Huang, H., Zaman, W., Lü, S., \& Zhao, H. (2021). Genome-wide comparative analysis of long-chain acyl-CoA synthetases (LACSs) gene family: A focus on identification, evolution and expression profiling related to lipid synthesis. Plant Physiology and Biochemistry, 161, 1-11. https://doi.org/10.1016/j.plaphy.2021.01.042

Barberon, M., Vermeer, J. E. M., De Bellis, D., Wang, P., Naseer, S., Andersen, T. G., Humbel, B. M., Nawrath, C., Takano, J., Salt, D. E., \& Geldner, N. (2016). Adaptation of Root Function by NutrientInduced Plasticity of Endodermal Differentiation. Cell, 164(3), 447-459. https://doi.org/10.1016/j.cell.2015.12.021

Barbosa, I. C. R., Rojas-Murcia, N., \& Geldner, N. (2019). The Casparian strip-one ring to bring cell biology to lignification? In Current Opinion in Biotechnology (Vol. 56, pp. 121-129). Elsevier Ltd. https://doi.org/10.1016/j.copbio.2018.10.004 
Baxter, I., Hosmani, P. S., Rus, A., Lahner, B., Borevitz, J. O., Muthukumar, B., Mickelbart, M. V., Schreiber, L., Franke, R. B., \& Salt, D. E. (2009). Root Suberin Forms an Extracellular Barrier That Affects Water Relations and Mineral Nutrition in Arabidopsis. PLoS Genetics, 5(5), e1000492. https://doi.org/10.1371/journal.pgen.1000492

Beisson, F., Li, Y., Bonaventure, G., Pollard, M., \& Ohlrogge, J. B. (2007). The Acyltransferase GPAT5 Is Required for the Synthesis of Suberin in Seed Coat and Root of Arabidopsis. THE PLANT CELL ONLINE, 19(1), 351-368. https://doi.org/10.1105/tpc.106.048033

Benveniste, I., Saito, T., Wang, Y., Kandel, S., Huang, H., Pinot, F., Kahn, R. A., Salaün, J. P., \& Shimoji, M. (2006). Evolutionary relationship and substrate specificity of Arabidopsis thaliana fatty acid omegahydroxylase. Plant Science, 170(2), 326-338. https://doi.org/10.1016/j.plantsci.2005.08.028

Bernards, M. A. (2002). Demystifying suberin. Canadian Journal of Botany, 80(3), 227-240. https://doi.org/10.1139/b02-017

The poly(phenolic) domain of potato suberin: a non-lignin cell wall bio-polymer, 57 Phytochemistry 1115 (2001). https://doi.org/10.1016/S0031-9422(01)00046-2

Bessire, M., Chassot, C., Jacquat, A.-C., Humphry, M., Borel, S., Petétot, J. M.-C., Métraux, J.-P., \& Nawrath, C. (2007). A permeable cuticle in Arabidopsis leads to a strong resistance to Botrytis cinerea. The EMBO Journal, 26(8), 2158-2168. https://doi.org/10.1038/sj.emboj.7601658

Bonacorsi, N. K., \& Seago, J. L. (2016). Root development and structure in seedlings of Ginkgo biloba. American Journal of Botany, 103(2), 355-363. https://doi.org/10.3732/ajb.1500312

Bonaventure, G., Beisson, F., Ohlrogge, J., \& Pollard, M. (2004). Analysis of the aliphatic monomer composition of polyesters associated with Arabidopsis epidermis: occurrence of octadeca-cis-6, cis9-diene-1,18-dioate as the major component. The Plant Journal, 40(6), 920-930. 
https://doi.org/10.1111/j.1365-313X.2004.02258.x

Elucidating the evolutionary conserved DNA-binding specificities of WRKY transcription factors by molecular dynamics and in vitro binding assays, 41 Nucleic Acids Research 9764 (2013). https://doi.org/10.1093/nar/gkt732

Chapple, C. C. S., \& Peterson, R. L. (1987). Root Structure in the Fern Platycerium bifurcatum (Cav.) C. Chr. (Polypodiaceae). Botanical Gazette, 148(2), 180-187. https://doi.org/10.1086/337646

Chow, C. N., Lee, T. Y., Hung, Y. C., Li, G. Z., Tseng, K. C., Liu, Y. H., Kuo, P. L., Zheng, H. Q., \& Chang, W. C. (2019). Plantpan3.0: A new and updated resource for reconstructing transcriptional regulatory networks from chip-seq experiments in plants. Nucleic Acids Research, 47(D1), D1155-D1163. https://doi.org/10.1093/nar/gky1081

Cohen, H., Fedyuk, V., Wang, C., Wu, S., \& Aharoni, A. (2020). SUBERMAN regulates developmental suberization of the Arabidopsis root endodermis. The Plant Journal, 102(3), 431-447. https://doi.org/10.1111/tpj.14711

Compagnon, V., Diehl, P., Benveniste, I., Meyer, D., Schaller, H., Schreiber, L., Franke, R., \& Pinot, F. (2009). CYP86B1 is required for very long chain $\omega$-hydroxyacid and $\alpha, \omega$-dicarboxylic acid synthesis in root and seed suberin polyester. Plant Physiology, 150(4), 1831-1843. https://doi.org/10.1104/pp.109.141408

Delude, C., Fouillen, L., Bhar, P., Cardinal, M.-J. J., Pascal, S., Santos, P., Kosma, D. K., Joubès, J., Rowland, O., \& Domergue, F. (2016). Primary Fatty Alcohols Are Major Components of Suberized Root Tissues of Arabidopsis in the Form of Alkyl Hydroxycinnamates. Plant Physiology, 171(3), 19341950. https://doi.org/10.1104/pp.16.00834

Domergue, F., Vishwanath, S. J., Joubès, J., Ono, J., Lee, J. A., Bourdon, M., Alhattab, R., Lowe, C., Pascal, 
S., Lessire, R., \& Rowland, O. (2010). Three Arabidopsis fatty Acyl-coenzyme a reductases, FAR1, FAR4, and FAR5, generate primary fatty alcohols associated with suberin deposition. Plant Physiology, 153(4), 1539-1554. https://doi.org/10.1104/pp.110.158238

Dubos, C., Kelemen, Z., Sebastian, A., Bülow, L., Huep, G., Xu, W., Grain, D., Salsac, F., Brousse, C., Lepiniec, L., Weisshaar, B., Contreras-Moreira, B., \& Hehl, R. (2014). Integrating bioinformatic resources to predict transcription factors interacting with cis-sequences conserved in co-regulated genes. BMC Genomics, 15(1). https://doi.org/10.1186/1471-2164-15-317

Enstone, D. E., Peterson, C. A., \& Ma, F. (2002). Root endodermis and exodermis: Structure, function, and responses to the environment. Journal of Plant Growth Regulation, 21(4), 335-351. https://doi.org/10.1007/s00344-003-0002-2

Franke, R., Briesen, I., Wojciechowski, T., Faust, A., Yephremov, A., Nawrath, C., \& Schreiber, L. (2005). Apoplastic polyesters in Arabidopsis surface tissues - A typical suberin and a particular cutin. Phytochemistry, 66(22), 2643-2658. https://doi.org/10.1016/J.PHYTOCHEM.2005.09.027

Franke, R., Höfer, R., Briesen, I., Emsermann, M., Efremova, N., Yephremov, A., \& Schreiber, L. (2009). The DAISY gene from Arabidopsis encodes a fatty acid elongase condensing enzyme involved in the biosynthesis of aliphatic suberin in roots and the chalaza-micropyle region of seeds. Plant Journal, 57(1), 80-95. https://doi.org/10.1111/j.1365-313X.2008.03674.x

Franke, R., \& Schreiber, L. (2007). Suberin - a biopolyester forming apoplastic plant interfaces. Current Opinion in Plant Biology, 10(3), 252-259. https://doi.org/10.1016/J.PBI.2007.04.004

Fraser, C. M., \& Chapple, C. (2011). The phenylpropanoid pathway in Arabidopsis. The Arabidopsis Book, 9, e0152. https://doi.org/10.1199/tab.0152

Geldner, N. (2013). The endodermis. In Annual Review of Plant Biology (Vol. 64, pp. 531-558). 
https://doi.org/10.1146/annurev-arplant-050312-120050

Gibbs, D. J., Voß, U., Harding, S. A., Fannon, J., Moody, L. A., Yamada, E., Swarup, K., Nibau, C., Bassel, G. W., Choudhary, A., Lavenus, J., Bradshaw, S. J., Stekel, D. J., Bennett, M. J., \& Coates, J. C. (2014). AtMYB93 is a novel negative regulator of lateral root development in Arabidopsis. New Phytologist, 203(4). https://doi.org/10.1111/nph.12879

Gil-Muñoz, F., Sánchez-Navarro, J. A., Besada, C., Salvador, A., Badenes, M. L., Naval, M. del M., \& Ríos, G. (2020). MBW complexes impinge on anthocyanidin reductase gene regulation for proanthocyanidin biosynthesis in persimmon fruit. Scientific Reports, 10(1), 1-11. https://doi.org/10.1038/s41598-020-60635-w

Gou, J.-Y. J.-Y., Yu, X.-H. X.-H., \& Liu, C.-J. C.-J. (2009). A hydroxycinnamoyltransferase responsible for synthesizing suberin aromatics in Arabidopsis. PNAS, 106(44). https://doi.org/10.1073/pnas.0905555106

Gou, M., Hou, G., Yang, H., Zhang, X., Cai, Y., Kai, G., \& Liu, C.-J. (2017). The MYB107 Transcription Factor Positively Regulates Suberin Biosynthesis. Plant Physiology, 173(2), 1045-1058. https://doi.org/10.1104/pp.16.01614

Graça, J. (2015). Suberin: the biopolyester at the frontier of plants. Frontiers in Chemistry, 3, 62. https://doi.org/10.3389/fchem.2015.00062

Graça, J., \& Santos, S. (2006). Linear aliphatic dimeric esters from cork suberin. Biomacromolecules, 7(6), 2003-2010. https://doi.org/10.1021/bm060174u

Hartmann, U., Sagasser, M., Mehrtens, F., Stracke, R., \& Weisshaar, B. (2005). Differential combinatorial interactions of cis-acting elements recognized by R2R3-MYB, BZIP, and BHLH factors control lightresponsive and tissue-specific activation of phenylpropanoid biosynthesis genes. Plant Molecular 
Biology, 57(2), 155-171. https://doi.org/10.1007/s11103-004-6910-0

Hatton, D., Sablowski, R., Yung, M.-H., Smith, C., Schuch, W., \& Bevan, M. (1995). Two classes of cis sequences contribute to tissue-specific expression of a PAL2 promoter in transgenic tobacco. The Plant Journal, 7(6), 859-876. https://doi.org/10.1046/j.1365-313X.1995.07060859.x

Hellens, R. P., Allan, A. C., Friel, E. N., Bolitho, K., Grafton, K., Templeton, M. D., Karunairetnam, S., Gleave, A. P., \& Laing, W. A. (2005). Transient expression vectors for functional genomics, quantification of promoter activity and RNA silencing in plants. Plant Methods, 1(1), 13. https://doi.org/10.1186/1746-4811-1-13

Higo, K., Ugawa, Y., Iwamoto, M., \& Korenaga, T. (1999). Plant cis-acting regulatory DNA elements (PLACE) database: 1999. In Nucleic Acids Research (Vol. 27, Issue 1, pp. 297-300). Oxford Academic. https://doi.org/10.1093/nar/27.1.297

Höfer, R., Briesen, I., Beck, M., Pinot, F., Schreiber, L., \& Franke, R. (2008). The Arabidopsis cytochrome P450 CYP86A1 encodes a fatty acid v-hydroxylase involved in suberin monomer biosynthesis. Journal of Experimental Botany, 59(9), 2347-2360. https://doi.org/10.1093/jxb/ern101

$\mathrm{Hu}, \mathrm{H}$. (2018). The role of transcription factor MYB53 from Arabidopsis thaliana in the regulated production of suberin. https://curve.carleton.ca/9a4f95f7-f6ba-436c-af66-cb49a0a5c865

James, A. M., Ma, D., Mellway, R., Gesell, A., Yoshida, K., Walker, V., Tran, L., Stewart, D., Reichelt, M., Suvanto, J., Salminen, J.-P., Gershenzon, J., Séguin, A., \& Constabel, C. P. (2017). Poplar MYB115 and MYB134 Transcription Factors Regulate Proanthocyanidin Synthesis and Structure. Plant Physiology, 174(1), 154-171. https://doi.org/10.1104/pp.16.01962

Kamiya, T., Borghi, M., Wang, P., Danku, J. M. C. C., Kalmbach, L., Hosmani, P. S., Naseer, S., Fujiwara, T., Geldner, N., \& Salt, D. E. (2015). The MYB36 transcription factor orchestrates Casparian strip 
formation. Proceedings of the National Academy of Sciences of the United States of America, 112(33), 10533-10538. https://doi.org/10.1073/pnas.1507691112

Kanofsky, K., Bahlmann, A. K., Hehl, R., \& Dong, D. X. (2017). Combinatorial requirement of W- and WTboxes in microbe-associated molecular pattern-responsive synthetic promoters. Plant Cell Reports, 36(6), 971-986. https://doi.org/10.1007/s00299-017-2130-3

Kelemen, Z., Sebastian, A., Xu, W., Grain, D., Salsac, F., Avon, A., Berger, N., Tran, J., Dubreucq, B., Lurin, C., Lepiniec, L., Contreras-Moreira, B., \& Dubos, C. (2015). Analysis of the DNA-Binding Activities of the Arabidopsis R2R3-MYB Transcription Factor Family by One-Hybrid Experiments in Yeast. PLOS ONE, 10(10), e0141044. https://doi.org/10.1371/journal.pone.0141044

Kim, J., Jung, J. H., Lee, S. B., Go, Y. S., Kim, H. J., Cahoon, R., Markham, J. E., Cahoon, E. B., \& Suh, M. C. (2013). Arabidopsis 3-ketoacyl-coenzyme a synthase9 is involved in the synthesis of tetracosanoic acids as precursors of cuticular waxes, suberins, sphingolipids, and phospholipids. Plant Physiology, 162(2), 567-580. https://doi.org/10.1104/pp.112.210450

Klein, D. (2019). The downstream targets of MYB-type transcription factors involved in suberin biosynthesis. https://curve.carleton.ca/e656b9e8-31ba-44b2-8696-e0d5359703d4

Koornneef, M., \& Meinke, D. (2010). The development of Arabidopsis as a model plant. Plant Journal, 61(6), 909-921. https://doi.org/10.1111/j.1365-313X.2009.04086.x

Kosma, D. K., Murmu, J., Razeq, F. M., Santos, P., Bourgault, R., Molina, I., \& Rowland, O. (2014). AtMYB41 activates ectopic suberin synthesis and assembly in multiple plant species and cell types. Plant Journal, 80(2), 216-229. https://doi.org/10.1111/tpj.12624

Kosma, D. K., Rice, A., \& Pollard, M. (2015). Analysis of aliphatic waxes associated with root periderm or exodermis from eleven plant species. Phytochemistry, 117, 351-362. 
https://doi.org/10.1016/J.PHYTOCHEM.2015.06.011

Krishnamurthy, P., Vishal, B., Bhal, A., \& Kumar, P. P. (2021). WRKY9 transcription factor regulates cytochrome P450 genes CYP94B3 and CYP86B1, leading to increased root suberin and salt tolerance in Arabidopsis. Physiologia Plantarum, ppl.13371. https://doi.org/10.1111/ppl.13371

Krishnamurthy, P., Vishal, B., Ho, W. J., Lok, F. C. J., Lee, F. S. M., \& Kumar, P. P. (2020). Regulation of a cytochrome P450 gene CYP94B1 by WRKY33 transcription factor controls apoplastic barrier formation in roots to confer salt tolerance. Plant Physiology, 184(4), 2199-2215. https://doi.org/10.1104/pp.20.01054

Lashbrooke, J., Cohen, H., Levy-Samocha, D., Tzfadia, O., Panizel, I., Zeisler, V., Massalha, H., Stern, A., Trainotti, L., Schreiber, L., Costa, F., \& Aharoni, A. (2016). MYB107 and MYB9 Homologs Regulate Suberin Deposition in Angiosperms. The Plant Cell, 28(9), 2097-2116. https://doi.org/10.1105/TPC.16.00490

Lee, S. B., Jung, S. J., Go, Y. S., Kim, H. U., Kim, J. K., Cho, H. J., Park, O. K., \& Suh, M. C. (2009). Two Arabidopsis 3-ketoacyl CoA synthase genes, KCS20 and KCS2/DAISY, are functionally redundant in cuticular wax and root suberin biosynthesis, but differentially controlled by osmotic stress. Plant Journal, 60(3), 462-475. https://doi.org/10.1111/j.1365-313X.2009.03973.x

Legay, S., Guerriero, G., André, C., Guignard, C., Cocco, E., Charton, S., Boutry, M., Rowland, O., \& Hausman, J.-F. (2016). MdMyb93 is a regulator of suberin deposition in russeted apple fruit skins. New Phytologist, 212(4), 977-991. https://doi.org/10.1111/nph.14170

Li, P., Yu, Q., Gu, X., Xu, C., Qi, S., Wang, H., Zhong, F., Baskin, T. I., Rahman, A., \& Wu, S. (2018). Construction of a Functional Casparian Strip in Non-endodermal Lineages Is Orchestrated by Two Parallel Signaling Systems in Arabidopsis thaliana. Current Biology, 28, 2777-2786.e2. 
https://doi.org/10.1016/j.cub.2018.07.028

Li, S. (2014). Transcriptional control of flavonoid biosynthesis: Fine-tuning of the MYB-bHLH-WD40 (MBW) complex. In Plant Signaling and Behavior (Vol. 9, Issue JAN). Landes Bioscience. https://doi.org/10.4161/psb.27522

Lindemose, S., Jensen, M. K., De Velde, J. Van, O’Shea, C., Heyndrickx, K. S., Workman, C. T., Vandepoele, K., Skriver, K., \& Masi, F. De. (2014). A DNA-binding-site landscape and regulatory network analysis for NAC transcription factors in Arabidopsis thaliana. Nucleic Acids Research, 42(12), 7681-7693. https://doi.org/10.1093/nar/gku502

Mahmood, K., Zeisler-Diehl, V. V., Schreiber, L., Bi, Y.-M., Rothstein, S. J., \& Ranathunge, K. (2019). Overexpression of ANAC046 Promotes Suberin Biosynthesis in Roots of Arabidopsis thaliana. International Journal of Molecular Sciences, 20(24), 6117. https://doi.org/10.3390/ijms20246117

McFarlane, H. E., Watanabe, Y., Yang, W., Huang, Y., Ohlrogge, J., \& Samuels, A. L. (2014). Golgi- and Trans-Golgi Network-Mediated Vesicle Trafficking Is Required for Wax Secretion from Epidermal Cells. Plant Physiology, 164(3), 1250-1260. https://doi.org/10.1104/pp.113.234583

Millard, P. S., Kragelund, B. B., \& Burow, M. (2019). R2R3 MYB Transcription Factors-Functions outside the DNA-Binding Domain Trends in Plant Science. Trends in Plant Science, 24(10). https://doi.org/10.1016/j.tplants.2019.07.003

Moire, L., Schmutz, A., Buchala, A., Yan, B., Stark, R. E., Ryser, U., Salaun, J. P., \& Pinot, F. (1999). Glycerol Is a Suberin Monomer. New Experimental Evidence for an Old Hypothesis. Plant Physiology, 119(3), 1137-1146. https://doi.org/10.1104/pp.119.3.1137

Molina, I., Li-Beisson, Y., Beisson, F., Ohlrogge, J. B., \& Pollard, M. (2009). Identification of an Arabidopsis feruloyl-coenzyme A transferase required for suberin synthesis. Plant Physiology, 151(3), 1317- 
1328. https://doi.org/10.1104/pp.109.144907

Naseer, S., Lee, Y., Lapierre, C., Franke, R., Nawrath, C., \& Geldner, N. (2012). Casparian strip diffusion barrier in Arabidopsis is made of a lignin polymer without suberin. Proceedings of the National Academy of Sciences of the United States of America, 109(25), 10101-10106. https://doi.org/10.1073/pnas.1205726109

Nawrath, C., Schreiber, L., Franke, R. B., Geldner, N., Reina-Pinto, J. J., \& Kunst, L. (2013). Apoplastic diffusion barriers in Arabidopsis. The Arabidopsis Book, 11, e0167. https://doi.org/10.1199/tab.0167

O’Malley, R. C., Huang, S. S. C., Song, L., Lewsey, M. G., Bartlett, A., Nery, J. R., Galli, M., Gallavotti, A., \& Ecker, J. R. (2016). Cistrome and Epicistrome Features Shape the Regulatory DNA Landscape. Cell, 165(5), 1280-1292. https://doi.org/10.1016/j.cell.2016.04.038

Oda-Yamamizo, C., Mitsuda, N., Sakamoto, S., Ogawa, D., Ohme-Takagi, M., \& Ohmiya, A. (2016). The NAC transcription factor ANAC046 is a positive regulator of chlorophyll degradation and senescence in Arabidopsis leaves. Scientific Reports, 6(1), 1-13. https://doi.org/10.1038/srep23609

Prouse, M. B., \& Campbell, M. M. (2012). The interaction between MYB proteins and their target DNA binding sites. Biochimica et Biophysica Acta (BBA) - Gene Regulatory Mechanisms, 1819(1), 67-77. https://doi.org/10.1016/J.BBAGRM.2011.10.010

Raskin, I., Ribnicky, D. M., Komarnytsky, S., llic, N., Poulev, A., Borisjuk, N., Brinker, A., Moreno, D. A., Ripoll, C., Yakoby, N., O’Neal, J. M., Cornwell, T., Pastor, I., \& Fridlender, B. (2002). Plants and human health in the twenty-first century. In Trends in Biotechnology (Vol. 20, Issue 12, pp. 522531). Elsevier Current Trends. https://doi.org/10.1016/S0167-7799(02)02080-2

Schnurr, J., Shockey, J., \& Browse, J. (2004). The Acyl-CoA synthetase encoded by LACS2 is essential for 
normal cuticle development in arabidopsis. Plant Cell, 16(3), 629-642.

https://doi.org/10.1105/tpc.017608

Transport barriers made of cutin, suberin and associated waxes, 15 Trends in Plant Science 546 (2010). http://www.cell.com/article/S1360138510001500/fulltext

Seago, J. L., \& Fernando, D. D. (2013). Anatomical aspects of angiosperm root evolution. Annals of Botany, 112(2), 223-238. https://doi.org/10.1093/aob/mcs266

Shockey, J. M., Fulda, M. S., \& Browse, J. A. (2002). Arabidopsis contains nine long-chain acyl-coenzyme A synthetase genes that participate in fatty acid and glycerolipid metabolism. Plant Physiology, 129(4), 1710-1722. https://doi.org/10.1104/pp.003269

Stracke, R., Werber, M., \& Weisshaar, B. (2001). The R2R3-MYB gene family in Arabidopsis thaliana. Current Opinion in Plant Biology, 4(5), 447-456. https://doi.org/10.1016/S1369-5266(00)00199-0

To, A., Joubès, J., Thueux, J., Kazaz, S., Lepiniec, L., \& Baud, S. (2020). AtMYB92 enhances fatty acid synthesis and suberin deposition in leaves of Nicotiana benthamiana. The Plant Journal, 103(2), 660-676. https://doi.org/10.1111/tpj.14759

Ursache, R., De Jesus Vieira Teixeira, C., Dénervaud Tendon, V., Gully, K., De Bellis, D., Schmid-Siegert, E., Grube Andersen, T., Shekhar, V., Calderon, S., Pradervand, S., Nawrath, C., Geldner, N., \& Vermeer, J. E. M. (2021). GDSL-domain proteins have key roles in suberin polymerization and degradation. Nature Plants, 7(3), 353-364. https://doi.org/10.1038/s41477-021-00862-9

Van Verk, M. C., Pappaioannou, D., Neeleman, L., Bol, J. F., \& Linthorst, H. J. M. (2008). A novel WRKY transcription factor is required for induction of PR-1a gene expression by salicylic acid and bacterial elicitors. Plant Physiology, 146(4), 1983-1995. https://doi.org/10.1104/pp.107.112789

Vannozzi, A., Wong, D. C. J., Höll, J., Hmmam, I., Matus, J. T., Bogs, J., Ziegler, T., Dry, I., Barcaccia, G., \& 
Lucchin, M. (2018). Combinatorial Regulation of Stilbene Synthase Genes by WRKY and MYB Transcription Factors in Grapevine (Vitis vinifera L.). Plant and Cell Physiology, 59(5), 1043-1059. https://doi.org/10.1093/pcp/pcy045

Vishwanath, S. J., Delude, C., Domergue, F., \& Rowland, O. (2015). Suberin: biosynthesis, regulation, and polymer assembly of a protective extracellular barrier. Plant Cell Reports, 34(4), 573-586. https://doi.org/10.1007/s00299-014-1727-z

Vishwanath, S. J., Kosma, D. K., Pulsifer, I. P., Scandola, S., Pascal, S., Joubès, J., Dittrich-Domergue, F., Lessire, R., Rowland, O., \& Domergue, F. (2013). Suberin-associated fatty alcohols in Arabidopsis: distributions in roots and contributions to seed coat barrier properties. Plant Physiology, 163(3), 1118-1132. https://doi.org/10.1104/pp.113.224410

Wang, C., Wang, H., Li, P., Li, H., Xu, C., Cohen, H., Aharoni, A., \& Wu, S. (2020). Developmental programs interact with abscisic acid to coordinate root suberization in Arabidopsis. The Plant Journal, 104(1), 241-251. https://doi.org/10.1111/tpj.14920

Wang, F., Chen, H. W., Li, Q. T., Wei, W., Li, W., Zhang, W. K., Ma, B., Bi, Y. D., Lai, Y. C., Liu, X. L., Man, W. Q., Zhang, J. S., \& Chen, S. Y. (2015). GmWRKY27 interacts with GmMYB174 to reduce expression of GmNAC29 for stress tolerance in soybean plants. Plant Journal, 83(2), 224-236. https://doi.org/10.1111/tpj.12879

Winter, D., Vinegar, B., Nahal, H., Ammar, R., Wilson, G. V., \& Provart, N. J. (2007). An “Electronic Fluorescent Pictograph" Browser for Exploring and Analyzing Large-Scale Biological Data Sets. PLoS ONE, 2(8), e718. https://doi.org/10.1371/journal.pone.0000718

Yadav, V., Molina, I., Ranathunge, K., Castillo, I. Q., Rothstein, S. J., \& Reed, J. W. (2014). ABCG transporters are required for suberin and pollen wall extracellular barriers in Arabidopsis. The Plant 
Cell, 26(9), 3569-3588. https://doi.org/10.1105/tpc.114.129049

Yang, W., Pollard, M., Li-Beisson, Y., \& Ohlrogge, J. (2016). Quantitative analysis of glycerol in dicarboxylic acid-rich cutins provides insights into Arabidopsis cutin structure. Phytochemistry, 130, 159-169. https://doi.org/10.1016/j.phytochem.2016.03.017

Yang, W., Simpson, J. P., Li-Beisson, Y., Beisson, F., Pollard, M., \& Ohlrogge, J. B. (2012a). A land-plantspecific glycerol-3-phosphate acyltransferase family in Arabidopsis: substrate specificity, sn-2 preference, and evolution. Plant Physiology, 160(2), 638-652. https://doi.org/10.1104/pp.112.201996

Yang, W., Simpson, J. P., Li-Beisson, Y., Beisson, F., Pollard, M., \& Ohlrogge, J. B. (2012b). A land-plantspecific glycerol-3-phosphate acyltransferase family in arabidopsis: Substrate specificity, sn-2 preference, and evolution. Plant Physiology, 160(2), 638-652. https://doi.org/10.1104/pp.112.201996

Yilmaz, A., Mejia-Guerra, M. K., Kurz, K., Liang, X., Welch, L., \& Grotewold, E. (2011). AGRIS: The arabidopsis gene regulatory information server, an update. Nucleic Acids Research, 39(SUPPL. 1), D1118-D1122. https://doi.org/10.1093/nar/gkq1120

Zeier, J., Ruel, K., Ryser, U., \& Schreiber, L. (1999). Chemical analysis and immunolocalisation of lignin and suberin in endodermal and hypodermal/rhizodermal cell walls of developing maize (Zea mays L.) primary roots. Planta, 209(1), 1-12. https://doi.org/10.1007/s004250050601

Zhao, Lei, Gao, L., Wang, H., Chen, X., Wang, Y., Yang, H., Wei, C., Wan, X., \& Xia, T. (2013). The R2R3MYB, bHLH, WD40, and related transcription factors in flavonoid biosynthesis. Functional \& Integrative Genomics, 13(1), 75-98. https://doi.org/10.1007/s10142-012-0301-4

Zhao, Lifang, Haslam, T. M., Sonntag, A., Molina, I., \& Kunst, L. (2019). Functional Overlap of Long-Chain 
Acyl-CoA Synthetases in Arabidopsis. Plant and Cell Physiology, 60(5), 1041-1054.

https://doi.org/10.1093/pcp/pcz019

Zhong, R., Lee, C., \& Ye, Z. H. (2010). Global analysis of direct targets of secondary wall NAC master switches in arabidopsis. Molecular Plant, 3(6), 1087-1103. https://doi.org/10.1093/mp/ssq062 


\section{6- Supplemental Material}

Supplemental Table 1: Seed lines

\begin{tabular}{|c|c|c|}
\hline Species & Genotype & \# of independent lines \\
\hline Nicotiana benthamiana & Wild type & N/A \\
\hline Arabidopsis thaliana (Col-0) & Wild type & N/A \\
\hline Arabidopsis thaliana (Col-0) & FAR4promoter(-2300bp): GUS & 16 \\
\hline Arabidopsis thaliana (Col-0) & FAR4promoter(-2061bp): GUS & 9 \\
\hline Arabidopsis thaliana (Col-0) & FAR4promoter(-1594bo): GUS & 14 \\
\hline Arabidopsis thaliana (Col-0) & FAR4promoter(-1171bp): GUS & 16 \\
\hline Arabidopsis thaliana (Col-0) & FAR4promoter(-545bp): GUS & 14 \\
\hline Arabidopsis thaliana (Col-0) & FAR4promoter(-245b): GUS & N/A \\
\hline Arabidopsis thaliana (Col-0) & wrky56-1 T-DNA mutant & N/A \\
\hline Arabidopsis thaliana (Col-0) & (SALK_201886C) & \\
\hline Arabidopsis thaliana (Col-0) & (SAIL_1287_G04) & N/A \\
\hline
\end{tabular}


Supplemental Table 2: DNA vectors, host strains, and required antibiotics

\begin{tabular}{|c|c|c|}
\hline Vector & Host Species & Selection $(\mu \mathrm{g} / \mathrm{mL})$ \\
\hline \multirow[t]{2}{*}{ pMDC32 } & E. coli $(\mathrm{DH} 5 \alpha)$ & Kanamycin (50) \\
\hline & $\begin{array}{l}\text { A. tumefaciens } \\
\text { (GV3101: pMP90) }\end{array}$ & $\begin{array}{l}\text { Rifampicin (100), Gentamycin (40), } \\
\text { Kanamycin (50) }\end{array}$ \\
\hline \multirow[t]{2}{*}{ pK7WG2D } & E. coli $(\mathrm{DH} 5 \alpha)$ & Spectinomycin (80) \\
\hline & $\begin{array}{l}\text { A. tumefaciens } \\
\text { (GV3101: pMP90) }\end{array}$ & $\begin{array}{l}\text { Rifampicin (100), Gentamycin (40), } \\
\text { Spectinomycin (100) }\end{array}$ \\
\hline \multirow[t]{3}{*}{ pKGWFS7 } & E. coli $(\mathrm{DH} 5 \alpha)$ & Spectinomycin (80) \\
\hline & $\begin{array}{c}\text { A. tumefaciens } \\
\text { (GV3101: pMP90) }\end{array}$ & $\begin{array}{c}\text { Rifampicin (100), Gentamycin (40), } \\
\text { Spectinomycin (100) }\end{array}$ \\
\hline & A. thaliana (Col-0) & Kanamycin (50) \\
\hline pGREENII 0800-LUC & E. coli $(\mathrm{DH} 5 \alpha)$ & Kanamycin (50) \\
\hline pSOUP & E. coli $(\mathrm{DH} 5 \alpha)$ & Tetracycline (5) \\
\hline pGREENII 0800-LUC + pSOUP & $\begin{array}{l}\text { A. tumefaciens } \\
\text { (GV3101: pMP90) }\end{array}$ & $\begin{array}{l}\text { Rifampicin (100), Gentamycin (40), } \\
\text { Kanamycin (50), Tetracycline (2.5) }\end{array}$ \\
\hline pBIN19-p19 & $\begin{array}{l}\text { A. tumefaciens } \\
\text { (C58C1+pCH32) }\end{array}$ & Kanamycin (50), Tetracycline (2.5) \\
\hline \multirow[t]{2}{*}{ pGADT7-AD } & E. coli $(\mathrm{DH} 5 \alpha)$ & Ampicillin (100) \\
\hline & S. cerevisiae (Y1HGold) & -Leucine \\
\hline \multirow[t]{2}{*}{ pAbAi } & E. coli $(\mathrm{DH} 5 \alpha)$ & Ampicillin (100) \\
\hline & S. cerevisiae (Y1HGold) & - Uracil \\
\hline
\end{tabular}


Supplemental Table 3: Primer list

\begin{tabular}{|c|c|c|c|}
\hline Stock \# & Primer Name & Primer Sequence ( $5^{\prime}$--> 3') & Use \\
\hline 210 & $\begin{array}{c}\text { FAR4Prom- } \\
\text { Forward-attaB1 }\end{array}$ & $\begin{array}{l}\text { GGGGACAAGTTTGTACAAAAAAGCAGGCTG } \\
\text { GAACCTATGTCCGAACTCC }\end{array}$ & $\begin{array}{c}\text { FAR4 promoter } \\
\text { Gateway } \\
\text { Cloning }\end{array}$ \\
\hline 211 & $\begin{array}{c}\text { FAR4Prom- } \\
\text { Reverse-attaB2 }\end{array}$ & $\begin{array}{l}\text { GGGGACCACTTTGTACAAGAAAGCTGGGTG } \\
\text { AAGAAACTTATATCTATCC }\end{array}$ & $\begin{array}{c}\text { FAR4 promoter } \\
\text { Gateway } \\
\text { Cloning }\end{array}$ \\
\hline 213 & $\begin{array}{c}\text { FAR4_Forward_ } \\
1\end{array}$ & $\begin{array}{l}\text { GGGGACAAGTTTGTACAAAAAAGCAGGCTCT } \\
\text { CCGAGATTTCAGAGCATG }\end{array}$ & $\begin{array}{c}\text { FAR4 promoter } \\
\text { Gateway } \\
\text { Cloning }\end{array}$ \\
\hline 214 & $\begin{array}{c}\text { FAR4_Forward_ } \\
2\end{array}$ & $\begin{array}{l}\text { GGGGACAAGTTTGTACAAAAAAGCAGGCTAT } \\
\text { TAGAACGCCAACCTTCCA }\end{array}$ & $\begin{array}{c}\text { FAR4 promoter } \\
\text { Gateway } \\
\text { Cloning }\end{array}$ \\
\hline 215 & $\begin{array}{c}\text { FAR4_Forward_ } \\
3\end{array}$ & $\begin{array}{l}\text { GGGGACAAGTTTGTACAAAAAAGCAGGCTTT } \\
\text { GTCAAACATCTGCATTGT }\end{array}$ & $\begin{array}{c}\text { FAR4 promoter } \\
\text { Gateway } \\
\text { Cloning }\end{array}$ \\
\hline 216 & $\begin{array}{c}\text { FAR4_Forward_ } \\
4\end{array}$ & $\begin{array}{l}\text { GGGGACAAGTTTGTACAAAAAAGCAGGCTG } \\
\text { ACTTGTACTTCTAAAACTC }\end{array}$ & $\begin{array}{c}\text { FAR4 promoter } \\
\text { Gateway } \\
\text { Cloning }\end{array}$ \\
\hline 217 & $\begin{array}{c}\text { FAR4_Forward_ } \\
5\end{array}$ & $\begin{array}{l}\text { GGGGACAAGTTTGTACAAAAAAGCAGGCTA } \\
\text { GCAGTTCTAACCCCGACAT }\end{array}$ & $\begin{array}{c}\text { FAR4 promoter } \\
\text { Gateway } \\
\text { Cloning }\end{array}$ \\
\hline 237 & $\begin{array}{l}\text { pKGWFS7- } \\
\text { SeqFor }\end{array}$ & ATCCTCTAGAGTCGACCTGCA & $\begin{array}{c}\text { Colony } \\
\text { PCR/Sequencing } \\
\text { for pKGWFS7 }\end{array}$ \\
\hline 238 & $\begin{array}{l}\text { pKGWFS7- } \\
\text { SeqRev }\end{array}$ & GAACTTGTGGCCGTTTACGTC & $\begin{array}{c}\text { Colony } \\
\text { PCR/Sequencing } \\
\text { for pKGWFS7 }\end{array}$ \\
\hline 1406 & $\begin{array}{c}\text { AtFAR4 } \\
\text { promoter LUC } \\
\text { FW (HindIII) }\end{array}$ & $\begin{array}{l}\text { CGGTATCGATAAGCTTGGAACCTATGTCCGA } \\
\text { AC TC }\end{array}$ & $\begin{array}{c}\text { Infusion cloning } \\
\text { into pGREENII } \\
\text { 0800-LUC }\end{array}$ \\
\hline 1407 & $\begin{array}{c}\text { AtFAR4 } \\
\text { promoter LUC } \\
\text { RV (BamHI) }\end{array}$ & $\begin{array}{l}\text { TAGAACTAGTGGATCCTGAAGAAACTTATAT } \\
\text { CTATCCAA TT }\end{array}$ & $\begin{array}{c}\text { Infusion cloning } \\
\text { into pGREENII } \\
\text { 0800-LUC }\end{array}$ \\
\hline 1410 & $\begin{array}{c}\text { AtGPAT5 } \\
\text { promoter LUC } \\
\text { FW (HindIII) }\end{array}$ & $\begin{array}{l}\text { CGGTATCGATAAGCTTTGATCGCAAACGTCA } \\
\text { ATGGT }\end{array}$ & $\begin{array}{c}\text { Infusion cloning } \\
\text { into pGREENII } \\
\text { 0800-LUC }\end{array}$ \\
\hline
\end{tabular}




\begin{tabular}{|c|c|c|c|}
\hline 1411 & $\begin{array}{c}\text { AtGPAT5 } \\
\text { promoter LUC } \\
\text { RV (BamHI) }\end{array}$ & $\begin{array}{l}\text { TAGAACTAGTGGATCCTTCTTTTGTTTTTTGGT } \\
\text { CGAATA TT }\end{array}$ & $\begin{array}{l}\text { Infusion cloning } \\
\text { into pGREENII } \\
\text { 0800-LUC }\end{array}$ \\
\hline 1609 & & 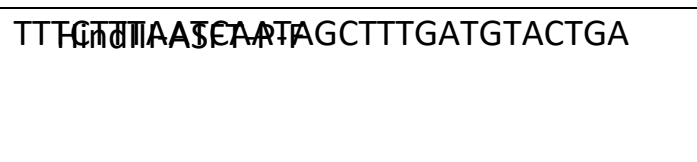 & $\begin{array}{l}\text { Infusion cloning } \\
\text { into pGREENII } \\
\text { 0800-LUC }\end{array}$ \\
\hline 1610 & BamHI-ASFT-P-R & TTTGATCCAAATGGAGAAAACAGCAC & $\begin{array}{c}\text { Infusion cloning } \\
\text { into pGREENII } \\
\text { 0800-LUC }\end{array}$ \\
\hline 1611 & $\begin{array}{l}\text { HindIII-RALPH- } \\
\text { P-F }\end{array}$ & AGTACTTTACTTACTCGGTAGCACACC & $\begin{array}{c}\text { Infusion cloning } \\
\text { into pGREENII } \\
\text { 0800-LUC }\end{array}$ \\
\hline 1612 & $\begin{array}{l}\text { BamHI-RALPH- } \\
\text { P-R }\end{array}$ & TGTGACAAAGAGAAGAGAGAGCGATG & $\begin{array}{c}\text { Infusion cloning } \\
\text { into pGREENII } \\
\text { 0800-LUC }\end{array}$ \\
\hline 1613 & $\begin{array}{l}\text { HindIII-HORST- } \\
\text { P-F }\end{array}$ & TGCCAAAACCATGCACGATCTTGT & $\begin{array}{c}\text { Infusion cloning } \\
\text { into pGREENII } \\
\text { 0800-LUC }\end{array}$ \\
\hline 1614 & $\begin{array}{l}\text { BamHI-HORST- } \\
\text { P-R }\end{array}$ & TATCCCGGTTTAGGCTTTTTGCTTTTGT & $\begin{array}{c}\text { Infusion cloning } \\
\text { into pGREENII } \\
\text { 0800-LUC }\end{array}$ \\
\hline 1615 & $\begin{array}{l}\text { HindIII-WRKY56- } \\
\text { P-F }\end{array}$ & TTCGAGCGGTCAAAGAGATTCTTAAC & $\begin{array}{c}\text { Infusion cloning } \\
\text { into pGREENII } \\
\text { 0800-LUC }\end{array}$ \\
\hline 1616 & $\begin{array}{l}\text { BamHI- } \\
\text { WRKY56-P-R }\end{array}$ & TGATTATGAAGCTTTCACTATCTTGCTAG & $\begin{array}{c}\text { Infusion cloning } \\
\text { into pGREENII } \\
\text { 0800-LUC }\end{array}$ \\
\hline 1528 & $\begin{array}{l}\text { PGREENIIO800L } \\
\text { UC_SeqFW }\end{array}$ & CCAGTCACGACGTTGTAA & $\begin{array}{c}\text { Colony } \\
\text { PCR/sequencing } \\
\text { for pGREENII } \\
\text { 0800-LUC }\end{array}$ \\
\hline 1529 & $\begin{array}{l}\text { PGREENIIO800L } \\
\text { UC_SeqRV }\end{array}$ & CCTCGATATGTGCATCTG & $\begin{array}{l}\text { Sequencing for } \\
\text { pGREENII 0800- } \\
\text { LUC }\end{array}$ \\
\hline 1525 & GPAT5pRV & CATCCTCGGCACCATCC & $\begin{array}{l}\text { Colony PCR for } \\
\text { pGREENII 0800- } \\
\text { LUC }\end{array}$ \\
\hline
\end{tabular}




\begin{tabular}{|c|c|c|c|}
\hline 1526 & FAR4pRV & TGCATCGGACATATCAAGCC & $\begin{array}{l}\text { Colony PCR for } \\
\text { pGREENII 0800- } \\
\text { LUC }\end{array}$ \\
\hline 1617 & ASFT-Pro-R1 & CTTCAAAATTCAAATCCACACTG & $\begin{array}{l}\text { Colony PCR for } \\
\text { pGREENII 0800- } \\
\text { LUC }\end{array}$ \\
\hline 1618 & RALPH-Pro-R1 & TGAGGATTGTCCTAAGTTTGGAA & $\begin{array}{l}\text { Colony PCR for } \\
\text { pGREENII 0800- } \\
\text { LUC }\end{array}$ \\
\hline 1619 & HORST-Pro-R1 & TCAGATCACCCAATCCTAAAAAAT & $\begin{array}{c}\text { Colony PCR for } \\
\text { pGREENII 0800- } \\
\text { LUC }\end{array}$ \\
\hline 1620 & WRKY56-Pro-R1 & GTCGGTTTGAGAACTAGCTAAAATT & $\begin{array}{l}\text { Colony PCR for } \\
\text { pGREENII 0800- } \\
\text { LUC }\end{array}$ \\
\hline 1625 & MYB39-CDS-F & & $\begin{array}{l}\text { Cloning into } \\
\text { pDONR221 }\end{array}$ \\
\hline 1626 & MYB39-CDS-R & & $\begin{array}{l}\text { Cloning into } \\
\text { pDONR221 }\end{array}$ \\
\hline 578 & $\begin{array}{l}\text { 35S:Promo-F- } \\
\text { pK7WG2D }\end{array}$ & GAGGACTCCGGTATTTTTACAAC & $\begin{array}{c}\text { Colony } \\
\text { PCR/Sequencing } \\
\text { for pK7WG2D }\end{array}$ \\
\hline 579 & $\begin{array}{l}\text { 35S:Term-R- } \\
\text { pK7WG2D }\end{array}$ & СССТАATTCCСTTATCTGGGAAC & $\begin{array}{c}\text { Colony } \\
\text { PCR/Sequencing } \\
\text { for pK7WG2D }\end{array}$ \\
\hline 1627 & $\begin{array}{c}\text { FAR4proY1H\#3 } \\
\text { FW }\end{array}$ & $\begin{array}{l}\text { ATGAATTGAAAAGCTTGATAGGGCAGCGGT } \\
\text { GTATGG }\end{array}$ & $\begin{array}{l}\text { Cloning into } \\
\text { pAbAi }\end{array}$ \\
\hline 1628 & $\begin{array}{c}\text { FAR4proY1H\#3 } \\
\text { RV }\end{array}$ & $\begin{array}{l}\text { GAGCACATGCCTCGAGCAACTGTAAAAAGAG } \\
\text { CCTTAGGG }\end{array}$ & $\begin{array}{c}\text { Colony PCR } \\
\text { /Cloning into } \\
\text { pAbAi }\end{array}$ \\
\hline 1629 & $\begin{array}{c}\text { FAR4proY1H\#4 } \\
\text { FW }\end{array}$ & $\begin{array}{l}\text { ATGAATTGAAAAGCTTTCAGTTCGCTATTGAA } \\
\text { GTATACATG }\end{array}$ & $\begin{array}{l}\text { Cloning into } \\
\text { pAbAi }\end{array}$ \\
\hline 1630 & $\begin{array}{c}\text { FAR4proY1H\#4 } \\
\text { RV }\end{array}$ & $\begin{array}{l}\text { GAGCACATGCCTCGAGGCAAAGTTACACAGA } \\
\text { TGGTAACAG }\end{array}$ & $\begin{array}{c}\text { Colony } \\
\text { PCR/Cloning } \\
\text { into pAbAi }\end{array}$ \\
\hline 1631 & $\begin{array}{c}\text { FAR4proY1H\#9 } \\
\text { FW }\end{array}$ & $\begin{array}{l}\text { ATGAATTGAAAAGCTTGCTATTATTTAAGTAA } \\
\text { CACTAACAA }\end{array}$ & $\begin{array}{l}\text { Cloning into } \\
\text { pAbAi }\end{array}$ \\
\hline 1632 & $\begin{array}{c}\text { FAR4proY1H\#9 } \\
\text { RV }\end{array}$ & $\begin{array}{l}\text { GAGCACATGCCTCGAGAAAAGAACAAGATG } \\
\text { ATAACGTGA }\end{array}$ & $\begin{array}{c}\text { Colony } \\
\text { PCR/Cloning } \\
\text { into pAbAi }\end{array}$ \\
\hline
\end{tabular}




\begin{tabular}{|c|c|c|c|}
\hline 1633 & $\begin{array}{l}\text { FAR4proY1H\#10 } \\
\text { FW }\end{array}$ & $\begin{array}{l}\text { ATGAATTGAAAAGCTTTCACGTTATCATCTTG } \\
\text { TTCTTTT }\end{array}$ & $\begin{array}{c}\text { Cloning into } \\
\text { pAbAi }\end{array}$ \\
\hline 1634 & $\begin{array}{l}\text { FAR4proY1H\#10 } \\
\text { RV }\end{array}$ & $\begin{array}{l}\text { GAGCACATGCCTCGAGAGTCAACAAAAAGCA } \\
\text { GGGGAA }\end{array}$ & $\begin{array}{c}\text { Colony } \\
\text { PCR/Cloning } \\
\text { into pAbAi }\end{array}$ \\
\hline 1635 & $\begin{array}{l}\text { FAR4proY1H\#11 } \\
\text { FW }\end{array}$ & $\begin{array}{l}\text { ATGAATTGAAAAGCTTTAATGTTCCCCTGCTT } \\
\text { TTTGTTGA }\end{array}$ & $\begin{array}{l}\text { Cloning into } \\
\text { pAbAi }\end{array}$ \\
\hline 1636 & $\begin{array}{l}\text { FAR4proY1H\#11 } \\
\text { RV }\end{array}$ & $\begin{array}{l}\text { GAGCACATGCCTCGAGATACCTAAGTGTTTT } \\
\text { GGTTAAACGC }\end{array}$ & $\begin{array}{c}\text { Colony } \\
\text { PCR/Cloning } \\
\text { into pAbAi }\end{array}$ \\
\hline 1637 & $\begin{array}{l}\text { FAR4proY1H\#12 } \\
\text { FW }\end{array}$ & $\begin{array}{l}\text { ATGAATTGAAAAGCTTCTAAAATTAGAACGC } \\
\text { CAACCTTCC }\end{array}$ & $\begin{array}{l}\text { Cloning into } \\
\text { pAbAi }\end{array}$ \\
\hline 1638 & $\begin{array}{l}\text { FAR4proY1H\#12 } \\
\text { RV }\end{array}$ & $\begin{array}{l}\text { GAGCACATGCCTCGAGCTCTAGGTAGAGCAA } \\
\text { TACGAGAG }\end{array}$ & $\begin{array}{l}\text { Cloning into } \\
\text { pAbAi }\end{array}$ \\
\hline 1639 & $\begin{array}{c}\text { pGADT7- } \\
\text { AD(EcoR1) } \\
\text { MYB53 FW }\end{array}$ & $\begin{array}{l}\text { GGAGGCCAGTGAATTCATGGGAAGATCTCCT } \\
\text { AGCTCA }\end{array}$ & $\begin{array}{c}\text { Colony } \\
\text { PCR/Cloning } \\
\text { into pGADT7-AD }\end{array}$ \\
\hline 1640 & $\begin{array}{c}\text { pGADT7- } \\
\text { ADMYB53(Bam } \\
\text { H1) RV }\end{array}$ & $\begin{array}{l}\text { CGAGCTCGATGGATCCTTAAGATTGATAAGA } \\
\text { AATGTCTGGA }\end{array}$ & $\begin{array}{l}\text { Cloning into } \\
\text { pGADT7-AD }\end{array}$ \\
\hline 1641 & $\begin{array}{l}\text { pGADT7- } \\
\text { AD(EcoR1) } \\
\text { MYB92 FW }\end{array}$ & $\begin{array}{l}\text { GGAGGCCAGTGAATTCATGGGAAGATCTCCT } \\
\text { ATCTCTGA }\end{array}$ & $\begin{array}{c}\text { Colony } \\
\text { PCR/Cloning } \\
\text { into pGADT7-AD }\end{array}$ \\
\hline 1642 & $\begin{array}{c}\text { pGADT7- } \\
\text { ADMYB92(Bam } \\
\text { H1) RV }\end{array}$ & $\begin{array}{l}\text { CGAGCTCGATGGATCCCTAAGGAATGTCGGA } \\
\text { AAATATAGAA }\end{array}$ & $\begin{array}{l}\text { Cloning into } \\
\text { pGADT7-AD }\end{array}$ \\
\hline 1643 & $\begin{array}{c}\text { pGADT7- } \\
\text { AD(EcoR1) } \\
\text { MYB593 FW }\end{array}$ & $\begin{array}{l}\text { GGAGGCCAGTGAATTCATGGGGAGGTCGCC } \\
\text { TTGT }\end{array}$ & $\begin{array}{c}\text { Colony } \\
\text { PCR/Cloning } \\
\text { into pGADT7-AD }\end{array}$ \\
\hline 1644 & $\begin{array}{c}\text { pGADT7- } \\
\text { ADMYB93(Bam } \\
\text { H1) RV }\end{array}$ & $\begin{array}{l}\text { CGAGCTCGATGGATCCCTAAGATATAACGTT } \\
\text { CATGAGGCTT }\end{array}$ & $\begin{array}{l}\text { Cloning into } \\
\text { pGADT7-AD }\end{array}$ \\
\hline 1645 & $\begin{array}{c}\text { pGADT7- } \\
\text { ADMYB53- } \\
\text { Nterm(BamH1) } \\
\text { RV }\end{array}$ & $\begin{array}{l}\text { CGAGCTCGATGGATCCTTAAGAAGGTTGAAG } \\
\text { AAGGTATTGG }\end{array}$ & $\begin{array}{l}\text { Cloning into } \\
\text { pGADT7-AD }\end{array}$ \\
\hline 1646 & $\begin{array}{l}\text { pGADT7- } \\
\text { ADMYB92- }\end{array}$ & $\begin{array}{l}\text { CGAGCTCGATGGATCCCTAGGAAGACGGTTG } \\
\text { AAGAAGG }\end{array}$ & $\begin{array}{l}\text { Cloning into } \\
\text { pGADT7-AD }\end{array}$ \\
\hline
\end{tabular}




\begin{tabular}{|c|c|c|c|}
\hline & $\begin{array}{l}\text { Nterm(BamH1) } \\
\text { RV }\end{array}$ & & \\
\hline 1647 & $\begin{array}{c}\text { pGADT7- } \\
\text { ADMYB93- } \\
\text { Nterm(BamH1) } \\
\text { RV }\end{array}$ & $\begin{array}{l}\text { CGAGCTCGATGGATCCCTAACGTTGGAGATA } \\
\text { TTGTAGATTG }\end{array}$ & $\begin{array}{l}\text { Cloning into } \\
\text { pGADT7-AD }\end{array}$ \\
\hline 1648 & 3' AD RV Seq & AGATGGTGCACGATGCACAG & $\begin{array}{l}\text { Sequencing } \\
\text { pGADT7-AD }\end{array}$ \\
\hline 1648 & pAbAi FW Seq & GTTCCTTATATGTAGCTTTCGACAT & $\begin{array}{l}\text { Sequencing } \\
\text { pAbAi }\end{array}$ \\
\hline 1501 & LP_CS876373 & GCAACAACCAAACCATATTCG & $\begin{array}{l}\text { Genotyping T- } \\
\text { DNA mutant }\end{array}$ \\
\hline 1502 & RP_CS876373 & ТТСТССТСТТСТССТТСТТССТС & $\begin{array}{l}\text { Genotyping T- } \\
\text { DNA mutant }\end{array}$ \\
\hline 1503 & LP_SALK201886 & TTAATGATGATGGCTCCTTCG & $\begin{array}{l}\text { Genotyping T- } \\
\text { DNA mutant }\end{array}$ \\
\hline 1504 & RP_SALK201886 & CGACTTCACGAGGTATAATTGG & $\begin{array}{l}\text { Genotyping T- } \\
\text { DNA mutant }\end{array}$ \\
\hline 1505 & LP_CS848035 & TTGCTTGTTTCTTGGAATTGG & $\begin{array}{l}\text { Genotyping T- } \\
\text { DNA mutant }\end{array}$ \\
\hline 1506 & RP_CS848035 & AATCCACTCAAACCCGAAATC & $\begin{array}{l}\text { Genotyping T- } \\
\text { DNA mutant }\end{array}$ \\
\hline 1486 & SALK LB-1.3 BP & ATTTTGCCGATTTCGGAAC & $\begin{array}{l}\text { Genotyping T- } \\
\text { DNA mutant }\end{array}$ \\
\hline 1487 & SAIL LB-1 BP & $\begin{array}{l}\text { TAGCATCTGAATTTCATAACCAATCTCGATAC } \\
\text { AC }\end{array}$ & $\begin{array}{l}\text { Genotyping T- } \\
\text { DNA mutant }\end{array}$ \\
\hline
\end{tabular}


Supplemental Table 4: Constructed vector DNA glycerol stocks

\begin{tabular}{|c|c|c|c|}
\hline Stock \# & Vector & Strain & Use \\
\hline 833 & pVKH18-35S:MYB93 CDS & $\begin{array}{c}\text { A. tumefaciens } \\
\text { (GV3103::pMP90) }\end{array}$ & $\begin{array}{c}\text { Promoter Activation } \\
\text { Assay }\end{array}$ \\
\hline 1105 & pK7WG2D-35S:MYB53 CDS & $\begin{array}{c}\text { A. tumefaciens } \\
\text { (GV3103::pMP90) }\end{array}$ & $\begin{array}{c}\text { Promoter Activation } \\
\text { Assay }\end{array}$ \\
\hline 1124 & pK7WG2D-35S:MYB41 CDS & $\begin{array}{c}\text { A. tumefaciens } \\
\text { (GV3103::pMP90) }\end{array}$ & $\begin{array}{c}\text { Promoter Activation } \\
\text { Assay }\end{array}$ \\
\hline 1170 & pMDC32-35S:MYB92 CDS & $\begin{array}{c}\text { A. tumefaciens } \\
\text { (GV3103::pMP90) }\end{array}$ & $\begin{array}{c}\text { Promoter Activation } \\
\text { Assay }\end{array}$ \\
\hline 960 & pDONR221: FAR4 promoter full (2300 bp) & E. coli $(\mathrm{DH} 5 \alpha)$ & $\begin{array}{l}\text { Promoter:Gus } \\
\text { Expression }\end{array}$ \\
\hline 964 & pDONR221: FAR4 promoter del_1 (245 bp) & E. coli $(\mathrm{DH} 5 \alpha)$ & $\begin{array}{l}\text { Promoter:Gus } \\
\text { Expression }\end{array}$ \\
\hline 966 & pDONR221: FAR4 promoter del_2 (546 bp) & E. coli $(\mathrm{DH} 5 \alpha)$ & $\begin{array}{l}\text { Promoter:Gus } \\
\text { Expression }\end{array}$ \\
\hline 969 & pDONR221: FAR4 promoter del_3 (1171 bp) & E. coli $(\mathrm{DH} 5 \alpha)$ & $\begin{array}{l}\text { Promoter:Gus } \\
\text { Expression }\end{array}$ \\
\hline 970 & pDONR221: FAR4 promoter del_4 (1594 bp) & E. coli $(\mathrm{DH} 5 \alpha)$ & $\begin{array}{l}\text { Promoter:Gus } \\
\text { Expression }\end{array}$ \\
\hline 971 & pDONR221: FAR4 promoter del_5 (2061 bp) & E. coli $(\mathrm{DH} 5 \alpha)$ & $\begin{array}{l}\text { Promoter:Gus } \\
\text { Expression }\end{array}$ \\
\hline 1767 & pKGWFS7: FAR4 promoter full (2300 bp) & $\begin{array}{c}\text { A. tumefaciens } \\
\text { (GV3103::pMP90) }\end{array}$ & $\begin{array}{l}\text { Promoter:Gus } \\
\text { Expression }\end{array}$ \\
\hline 1768 & pKGWFS7: FAR4 promoter del_1 (245 bp) & $\begin{array}{c}\text { A. tumefaciens } \\
\text { (GV3103::pMP90 }\end{array}$ & $\begin{array}{c}\text { Promoter:Gus } \\
\text { Expression }\end{array}$ \\
\hline 1769 & pKGWFS7: FAR4 promoter del_2 (546 bp) & $\begin{array}{c}\text { A. tumefaciens } \\
\text { (GV3103::pMP90 }\end{array}$ & $\begin{array}{l}\text { Promoter:Gus } \\
\text { Expression }\end{array}$ \\
\hline 1770 & pKGWFS7: FAR4 promoter del_3 (1171 bp) & $\begin{array}{l}\text { A. tumefaciens } \\
\text { (GV3103::pMP90 }\end{array}$ & $\begin{array}{l}\text { Promoter:Gus } \\
\text { Expression }\end{array}$ \\
\hline 1771 & pKGWFS7: FAR4 promoter del_4 (1594 bp) & $\begin{array}{c}\text { A. tumefaciens } \\
\text { (GV3103::pMP90 }\end{array}$ & $\begin{array}{l}\text { Promoter:Gus } \\
\text { Expression }\end{array}$ \\
\hline 1772 & pKGWFS7: FAR4 promoter del_5 (2061 bp) & $\begin{array}{c}\text { A. tumefaciens } \\
\text { (GV3103::pMP90) }\end{array}$ & $\begin{array}{l}\text { Promoter:Gus } \\
\text { Expression }\end{array}$ \\
\hline 1784 & pGREENII0800-PtANR1promoter:LUC & $\begin{array}{c}\text { A. tumefaciens } \\
\text { (GV3103::pMP90) }\end{array}$ & $\begin{array}{c}\text { Promoter Activation } \\
\text { Assay }\end{array}$ \\
\hline 1785 & pMDC32-35S:PtMYB134 & $\begin{array}{c}\text { A. tumefaciens } \\
\text { (GV3103::pMP90) }\end{array}$ & $\begin{array}{c}\text { Promoter Activation } \\
\text { Assay }\end{array}$ \\
\hline 1786 & pMDC32-35S:PtbHLH131 & $\begin{array}{c}\text { A. tumefaciens } \\
\text { (GV3103::pMP90) }\end{array}$ & $\begin{array}{c}\text { Promoter Activation } \\
\text { Assay }\end{array}$ \\
\hline
\end{tabular}




\begin{tabular}{|c|c|c|c|}
\hline 1816 & $\begin{array}{l}\text { pGREENII0800-FAR4promoter(2300bp):LUC + } \\
\text { pSOUP }\end{array}$ & $\begin{array}{l}\text { A. tumefaciens } \\
\text { (GV3103::pMP90) }\end{array}$ & $\begin{array}{c}\text { Promoter Activation } \\
\text { Assay }\end{array}$ \\
\hline 1817 & $\begin{array}{l}\text { pGREENII0800-GPAT5promoter(2165 } \\
\text { bp):LUC + pSOUP }\end{array}$ & $\begin{array}{l}\text { A. tumefaciens } \\
\text { (GV3103::pMP90) }\end{array}$ & $\begin{array}{l}\text { Promoter Activation } \\
\text { Assay }\end{array}$ \\
\hline 1906 & $\begin{array}{c}\text { ASFT promoter in pGREENII0800 } \\
\text { (@HindIII/BamH1) + pSOUP }\end{array}$ & $\begin{array}{l}\text { A. tumefaciens } \\
\text { (GV3103::pMP90) }\end{array}$ & $\begin{array}{c}\text { Promoter Activation } \\
\text { Assay }\end{array}$ \\
\hline 1907 & $\begin{array}{l}\text { RALPH promoter in pGREENII0800 } \\
\text { (@HindIII/BamH1) + pSOUP }\end{array}$ & $\begin{array}{l}\text { A. tumefaciens } \\
\text { (GV3103::pMP90) }\end{array}$ & $\begin{array}{c}\text { Promoter Activation } \\
\text { Assay }\end{array}$ \\
\hline 1908 & $\begin{array}{l}\text { HORST promoter in pGREENII0800 } \\
(@ \text { HindIII/BamH1) + pSOUP }\end{array}$ & $\begin{array}{l}\text { A. tumefaciens } \\
\text { (GV3103::pMP90) }\end{array}$ & $\begin{array}{l}\text { Promoter Activation } \\
\text { Assay }\end{array}$ \\
\hline 1909 & $\begin{array}{l}\text { WRKY56 promoter in pGREENII0800 } \\
\text { (@HindIII/BamH1) + pSOUP }\end{array}$ & $\begin{array}{l}\text { A. tumefaciens } \\
\text { (GV3103::pMP90) }\end{array}$ & $\begin{array}{c}\text { Promoter Activation } \\
\text { Assay }\end{array}$ \\
\hline 1915 & pKGWDIIG-35S:AtMYB39 CDS & $\begin{array}{l}\text { A. tumefaciens } \\
\text { (GV3103::pMP90) }\end{array}$ & $\begin{array}{c}\text { Promoter Activation } \\
\text { Assay }\end{array}$ \\
\hline 1917 & pGADT7-AD: MYB53 full-length CDS (933 bp) & E. coli $(\mathrm{DH} 5 \alpha)$ & Y1H Assay (prey) \\
\hline 1918 & pGADT7-AD:MYB92 full-length CDS (1037 bp) & E. coli $(\mathrm{DH} 5 \alpha)$ & Y1H Assay (prey) \\
\hline 1919 & pGADT7-AD:MYB93 full-length CDS (1098 bp) & E. coli $(\mathrm{DH} 5 \alpha)$ & Y1H Assay (prey) \\
\hline 1920 & pGADT7-AD:MYB53 N-terminal CDS (581 bp) & E. coli $(\mathrm{DH} 5 \alpha)$ & Y1H Assay (prey) \\
\hline 1921 & pGADT7-AD:MYB92 N-terminal CDS (587 bp) & E. coli $(\mathrm{DH} 5 \alpha)$ & Y1H Assay (prey) \\
\hline 1922 & pGADT7-AD:MYB93 N-terminal CDS (551 bp) & E. coli $(\mathrm{DH} 5 \alpha)$ & Y1H Assay (prey) \\
\hline 1923 & $\begin{array}{l}\text { pAbAi-FAR4pro\#3 (-2037 bp to }-1838 \text { bp } \\
\text { from ATG start site) }\end{array}$ & E. coli $(\mathrm{DH} 5 \alpha)$ & Y1H Assay (prey) \\
\hline 1924 & $\begin{array}{l}\text { pAbAi-FAR4pro\#4 (-1825 bp to }-1826 \text { bp } \\
\text { from ATG start site) }\end{array}$ & E. coli $(\mathrm{DH} 5 \alpha)$ & Y1H Assay (bait) \\
\hline 1925 & $\begin{array}{l}\text { pAbAi-FAR4pro\#9 (-965 bp to }-774 \text { bp from } \\
\text { ATG start site) }\end{array}$ & E. coli $(\mathrm{DH} 5 \alpha)$ & Y1H Assay (bait) \\
\hline 1926 & $\begin{array}{l}\text { pAbAi-FAR4pro\#10 (-797 bp to }-632 \text { bp from } \\
\text { ATG start site) }\end{array}$ & E. coli $(\mathrm{DH} 5 \alpha)$ & Y1H Assay (bait) \\
\hline
\end{tabular}




\begin{tabular}{|c|l|c|c|}
\hline 1927 & $\begin{array}{l}\text { pAbAi-FAR4pro\#11 (-658 bp to -563 bp from } \\
\text { ATG start site) }\end{array}$ & E. coli (DH5 $\alpha$ ) & Y1H Assay (bait) \\
\hline 1928 & $\begin{array}{l}\text { pAbAi-FAR4pro\#12 (-551 bp to -401 bp from } \\
\text { ATG start site) }\end{array}$ & E. coli (DH5a) & Y1H Assay (bait) \\
\hline 1929 & $\begin{array}{l}\text { pAbAi-FAR4pro\#3 (-2037 bp to -1838 bp } \\
\text { from ATG start site) - integrated in ura3-52 } \\
\text { locus }\end{array}$ & $\begin{array}{l}\text { Saccharomyces } \\
\text { cerevisiae (Y1H } \\
\text { GOLD) }\end{array}$ & Y1H Assay (bait) \\
\hline 1930 & $\begin{array}{l}\text { pAbAi-FAR4pro\#4 (-1825 bp to -1826 bp } \\
\text { from ATG start site) - integrated in ura3-52 } \\
\text { locus }\end{array}$ & $\begin{array}{l}\text { Saccharomyces } \\
\text { cerevisiae (Y1H } \\
\text { GOLD) }\end{array}$ & Y1H Assay (bait) \\
\hline 1931 & $\begin{array}{l}\text { pAbAi-FAR4pro\#9 (-965 bp to -774 bp from } \\
\text { ATG start site) - integrated in ura3-52 locus }\end{array}$ & $\begin{array}{l}\text { Saccharomyces } \\
\text { cerevisiae (Y1H } \\
\text { GOLD) }\end{array}$ & Y1H Assay (bait) \\
\hline 1932 & $\begin{array}{l}\text { pAbAi-FAR4pro\#10 (-797 bp to -632 bp from } \\
\text { ATG start site) - integrated in ura3-52 locus }\end{array}$ & $\begin{array}{l}\text { Saccharomyces } \\
\text { cerevisiae (Y1H } \\
\text { GOLD) }\end{array}$ & Y1H Assay (bait) \\
\hline 1933 & $\begin{array}{l}\text { pAbAi-FAR4pro\#11 (-658 bp to -563 bp from } \\
\text { ATG start site) - integrated in ura3-52 locus }\end{array}$ & $\begin{array}{l}\text { Saccharomyces } \\
\text { cerevisiae (Y1H } \\
\text { GOLD) }\end{array}$ & Y1H Assay (bait) \\
\hline 1934 & $\begin{array}{l}\text { Saccharomyces } \\
\text { cerevisiae (Y1H } \\
\text { GOLD) }\end{array}$ & Y1H Assay (bait) \\
\hline
\end{tabular}


Supplemental Table 5: FAR4pro: GUS deletion series images after GUS staining

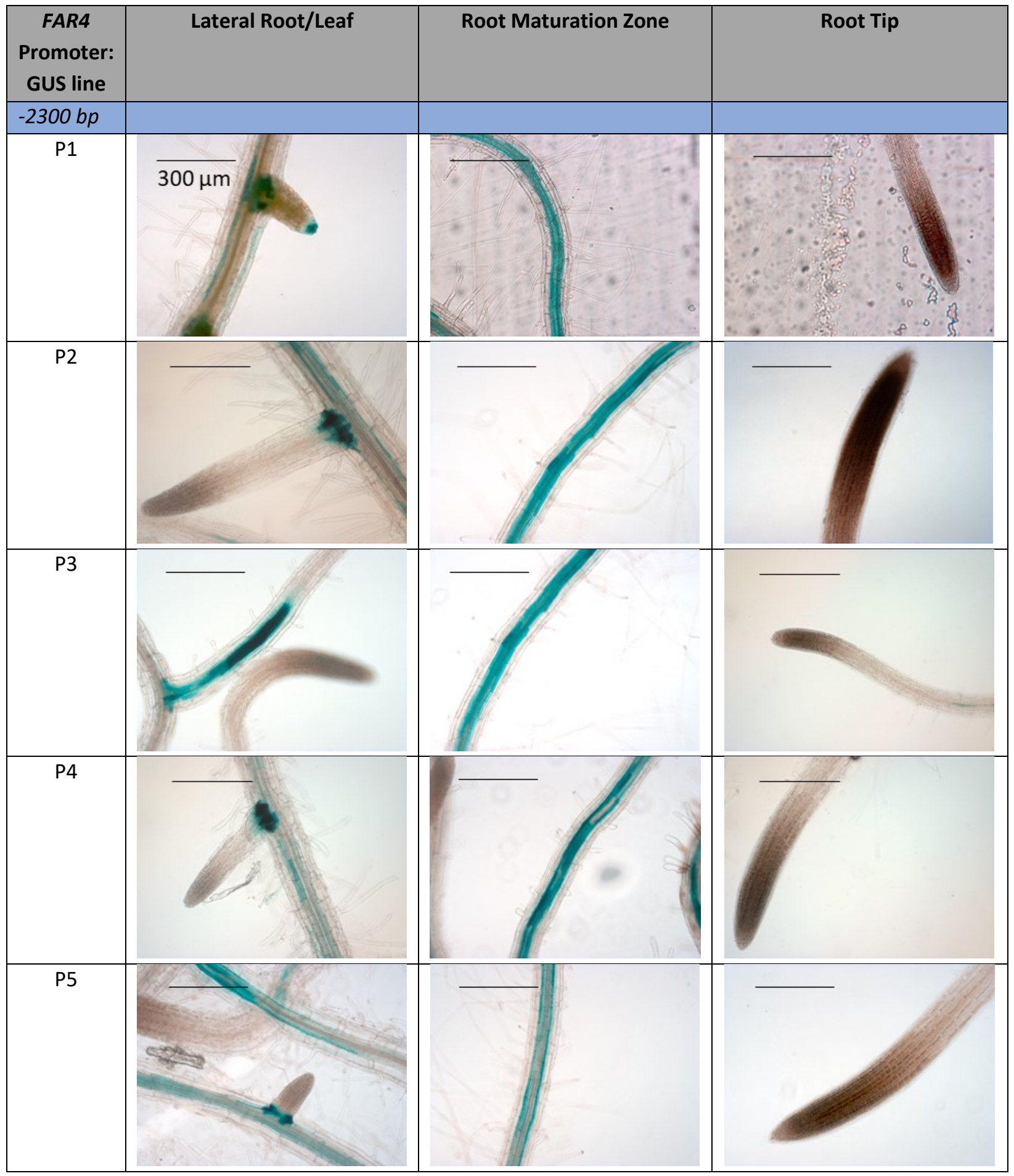




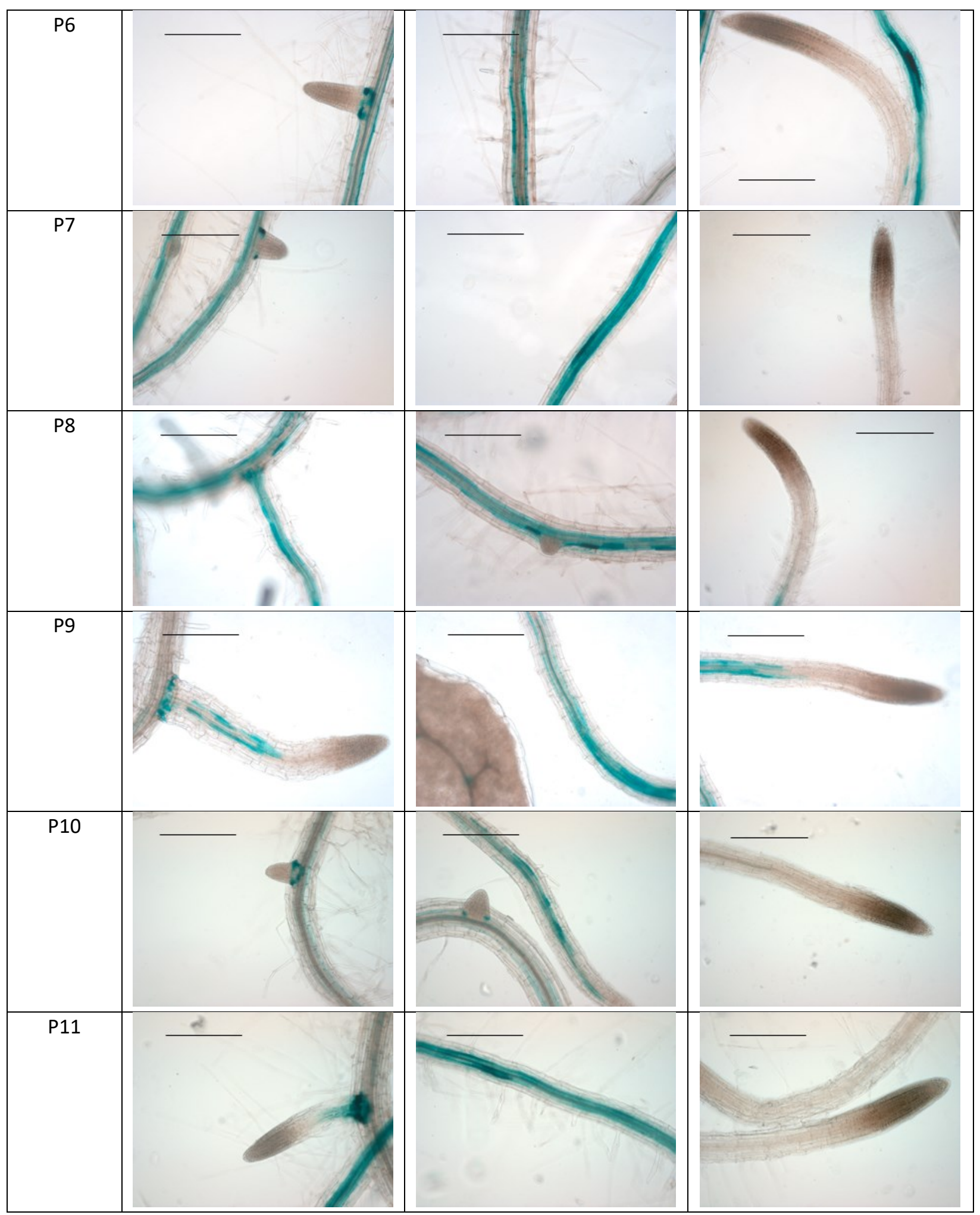




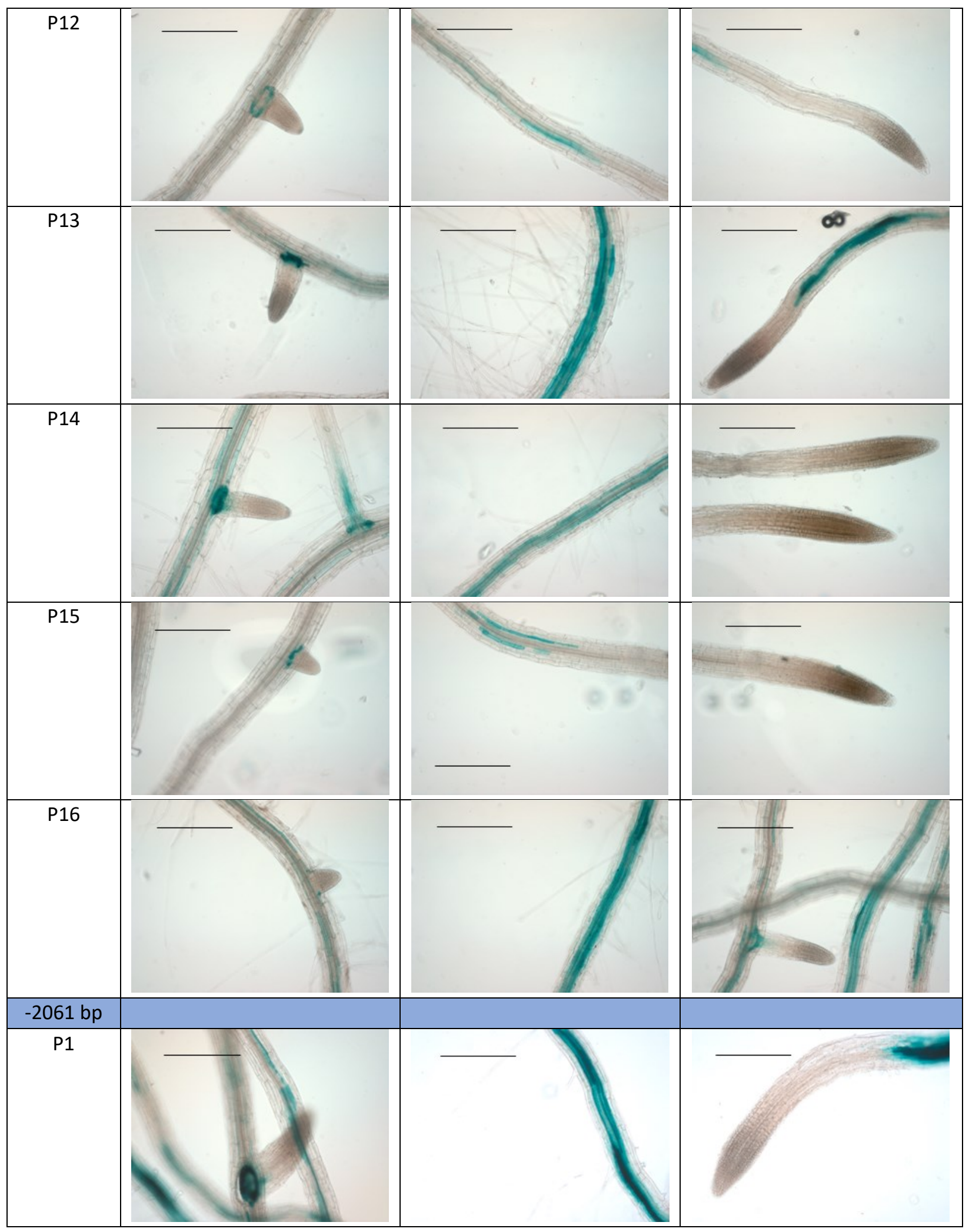




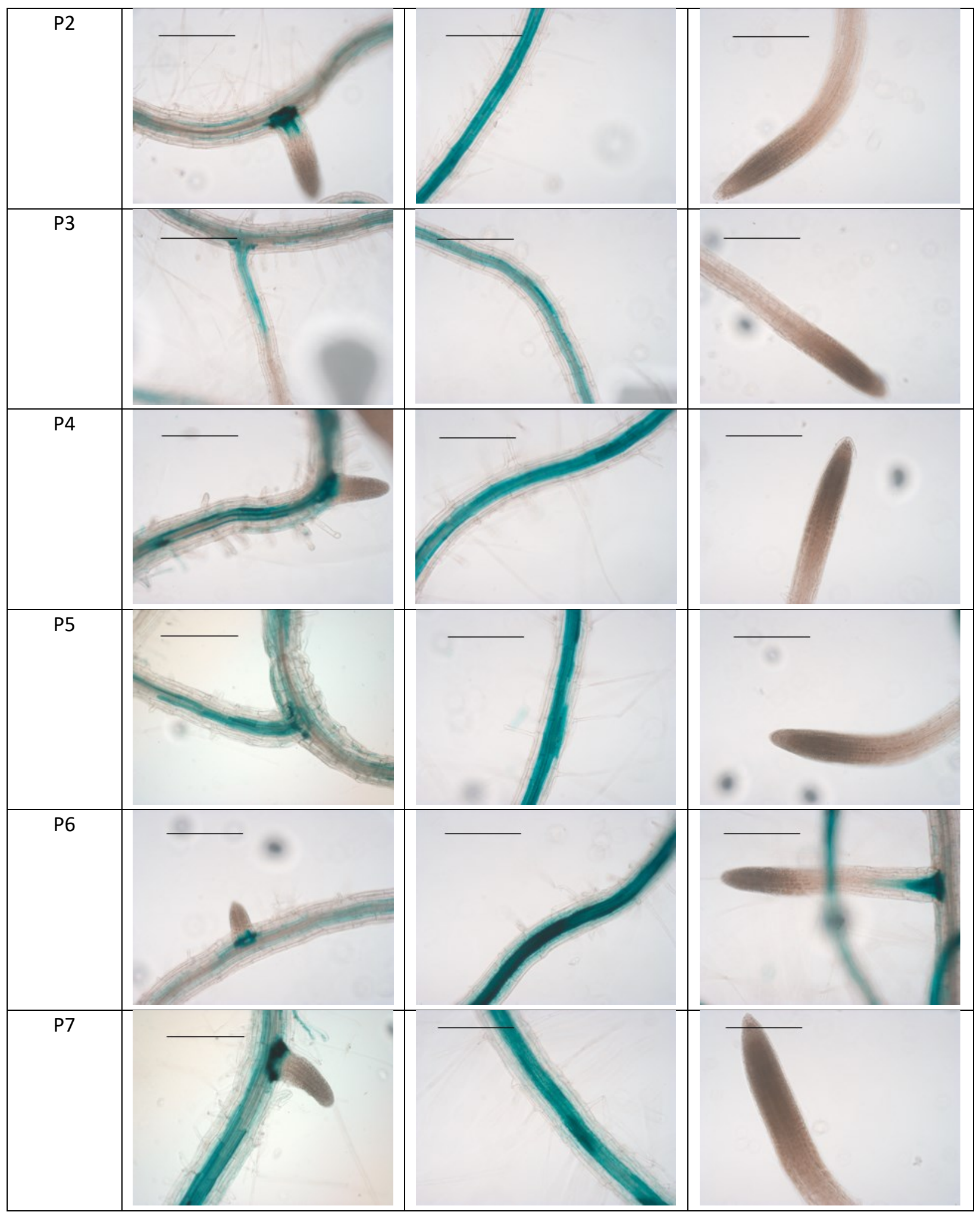




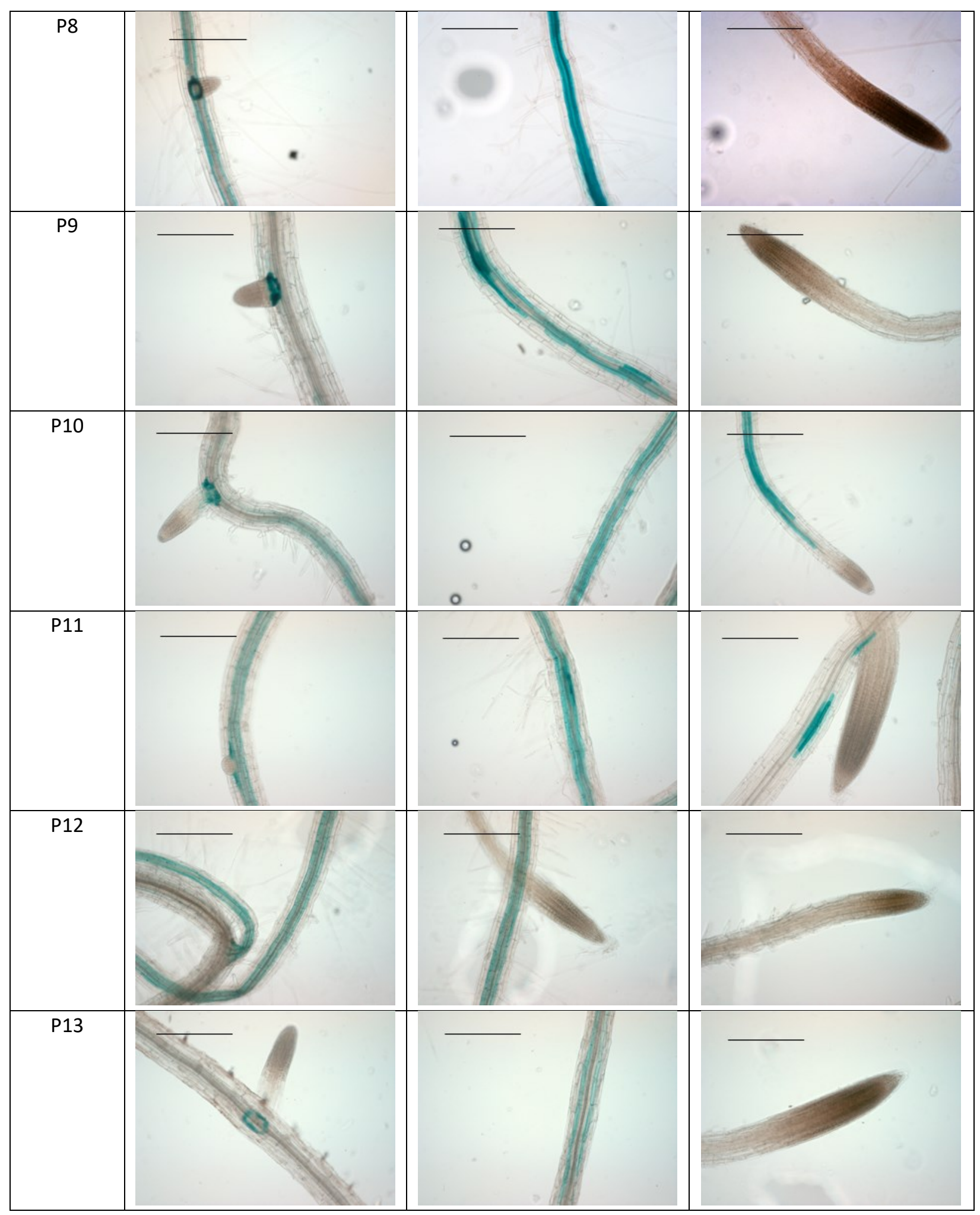




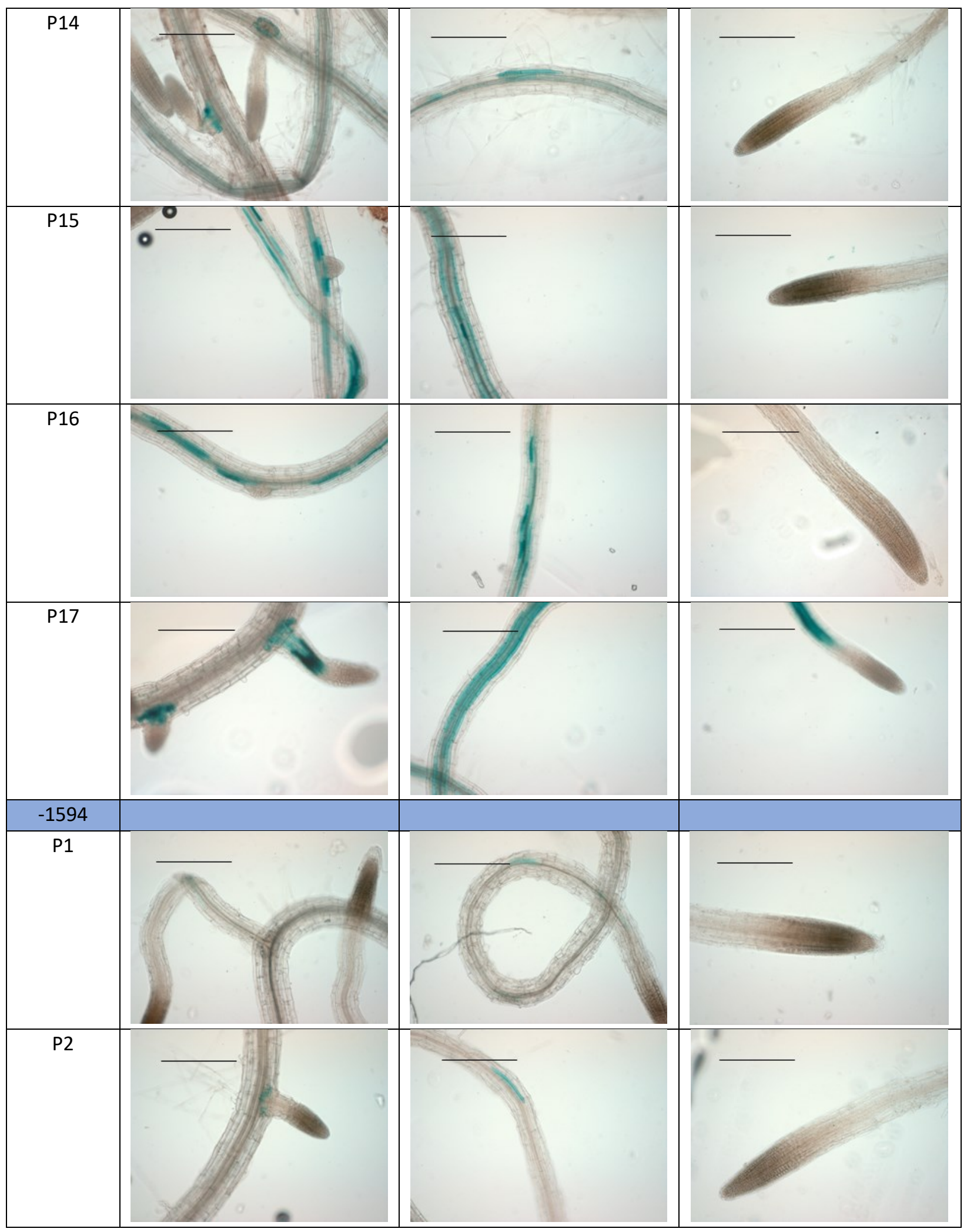




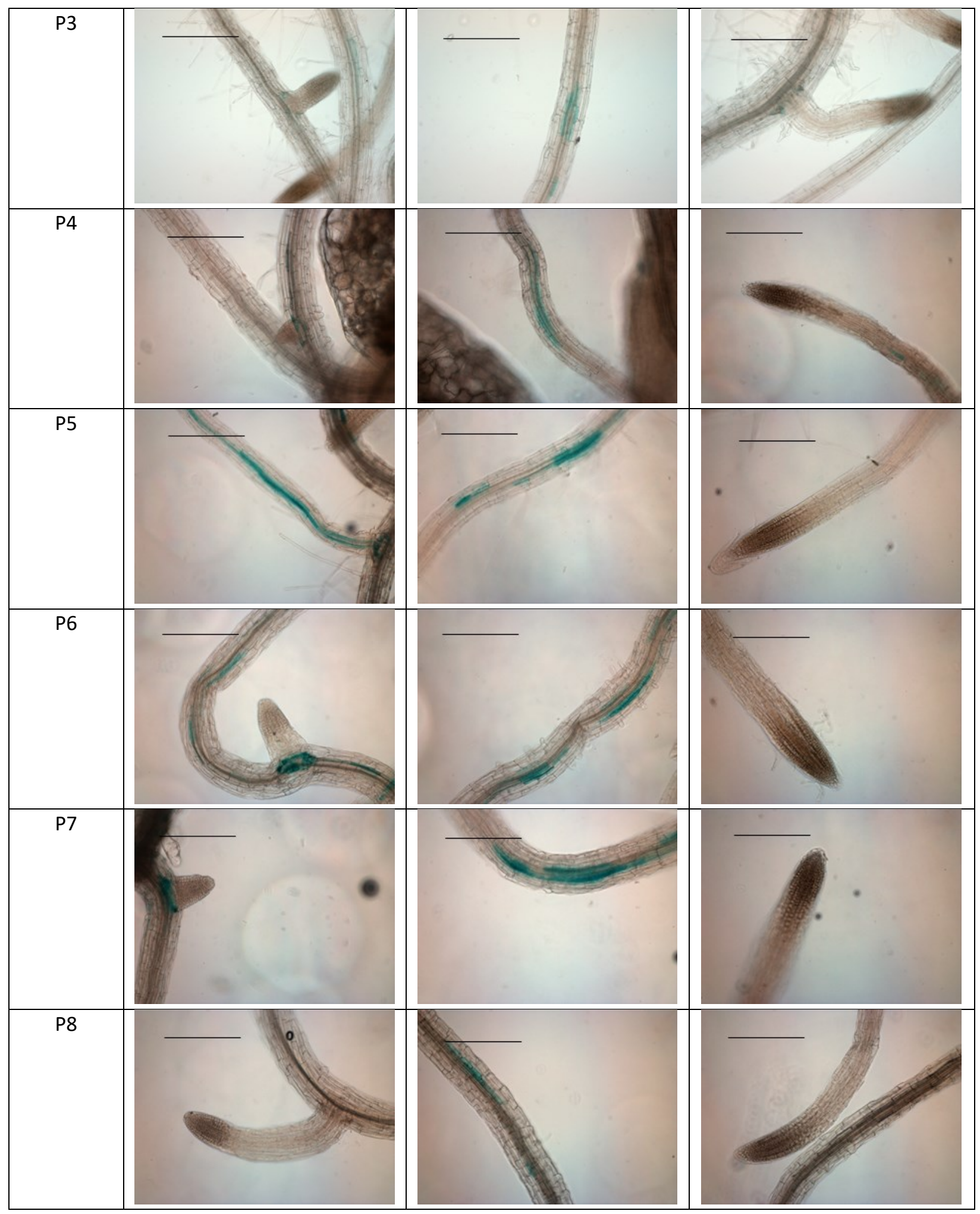




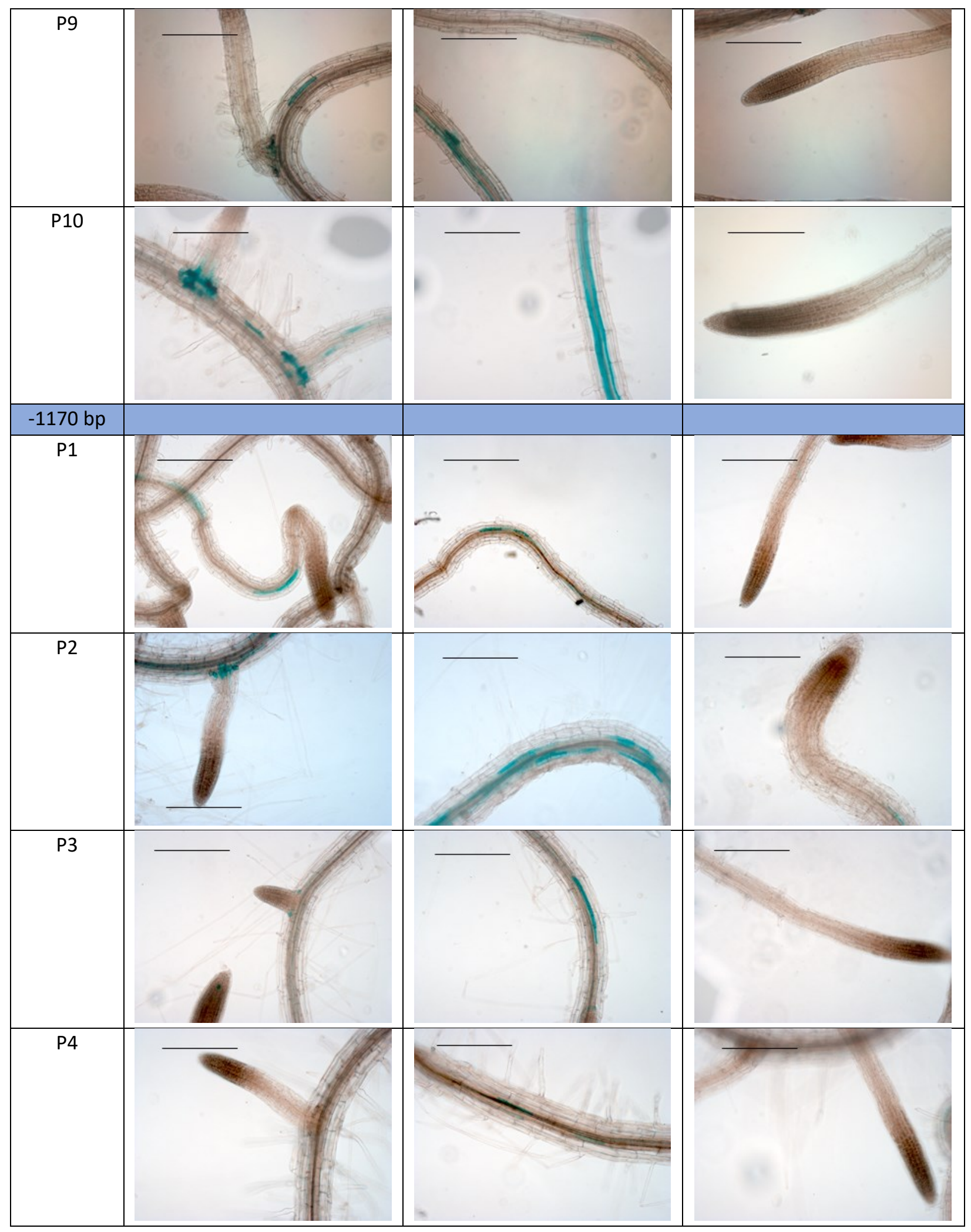




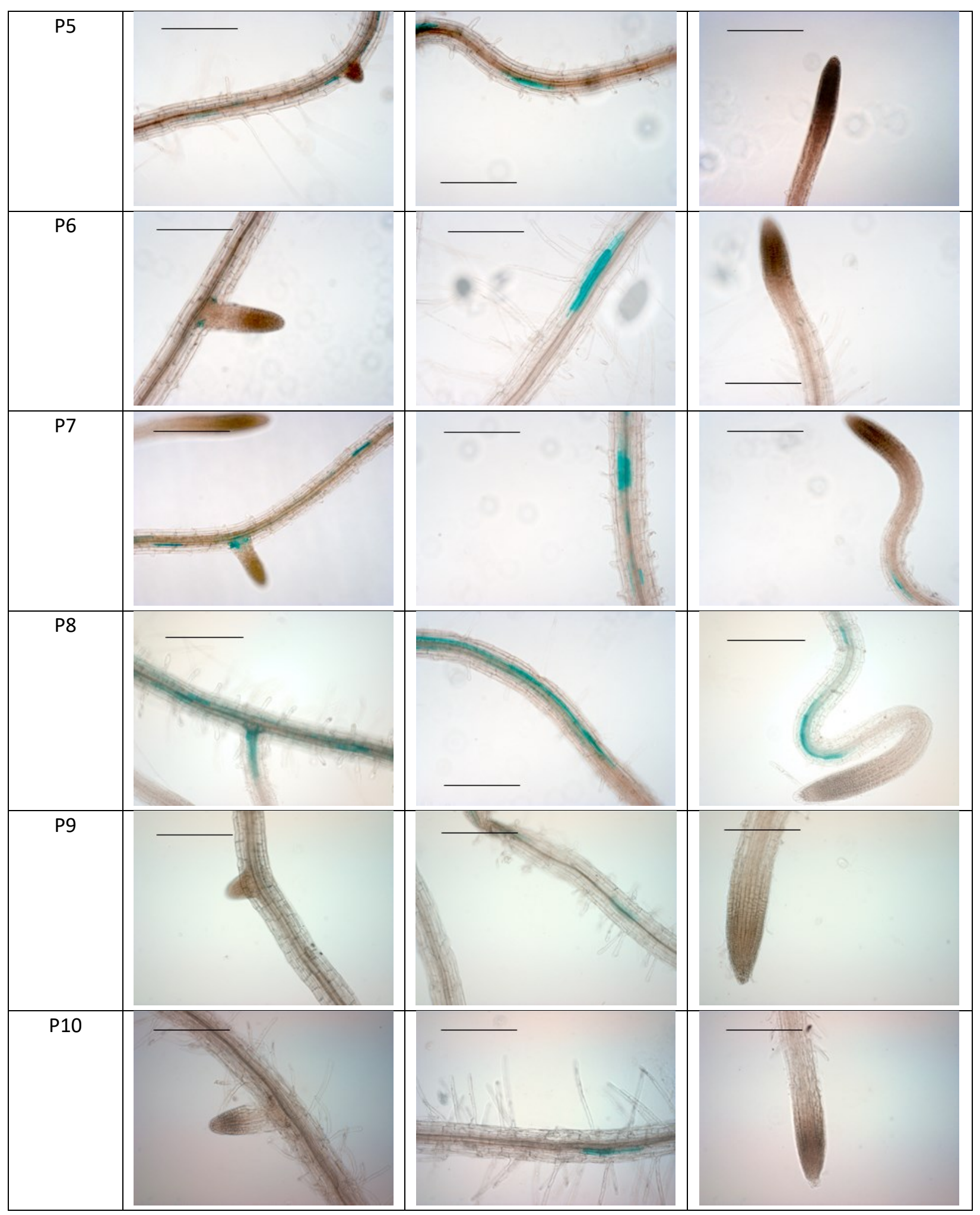




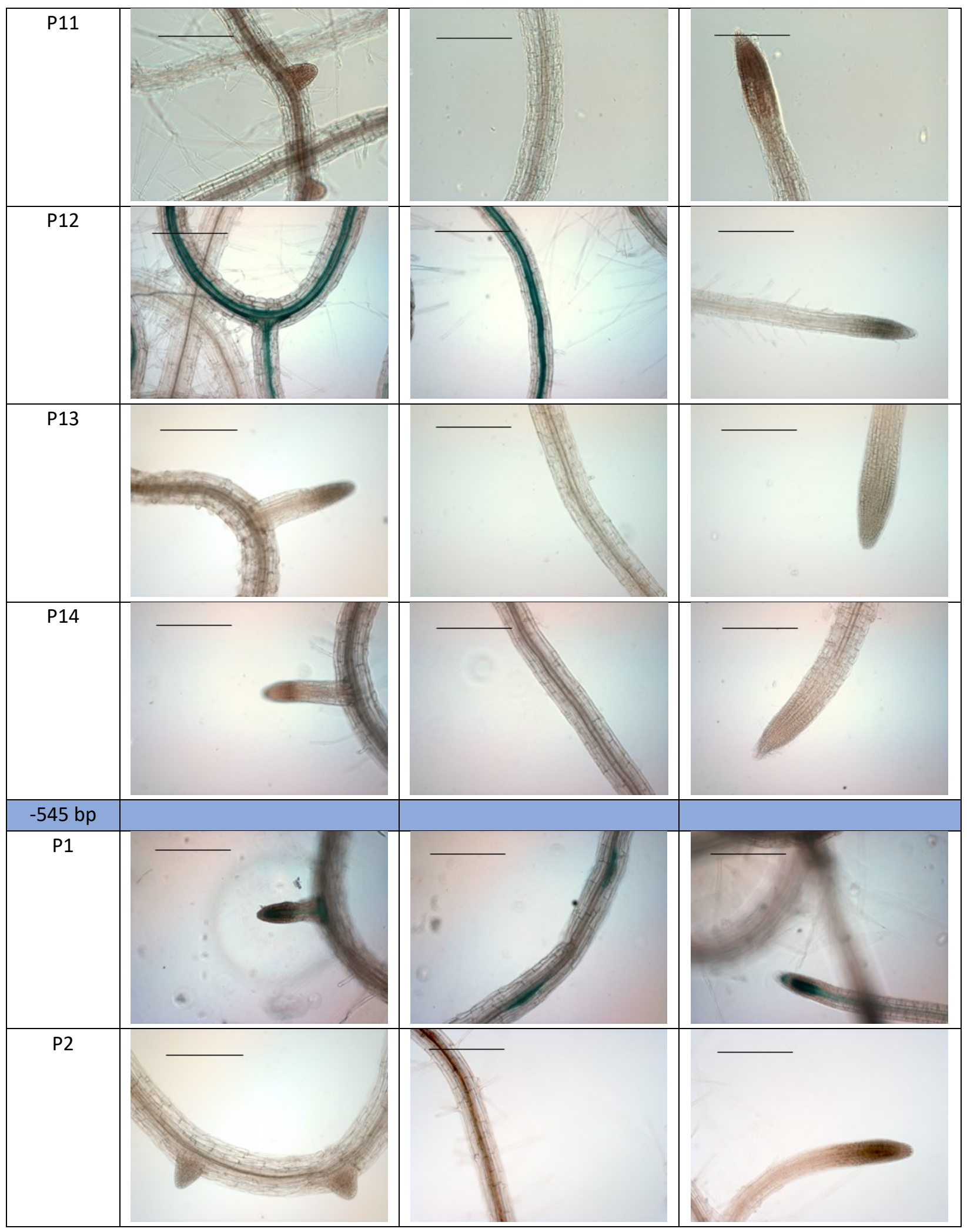




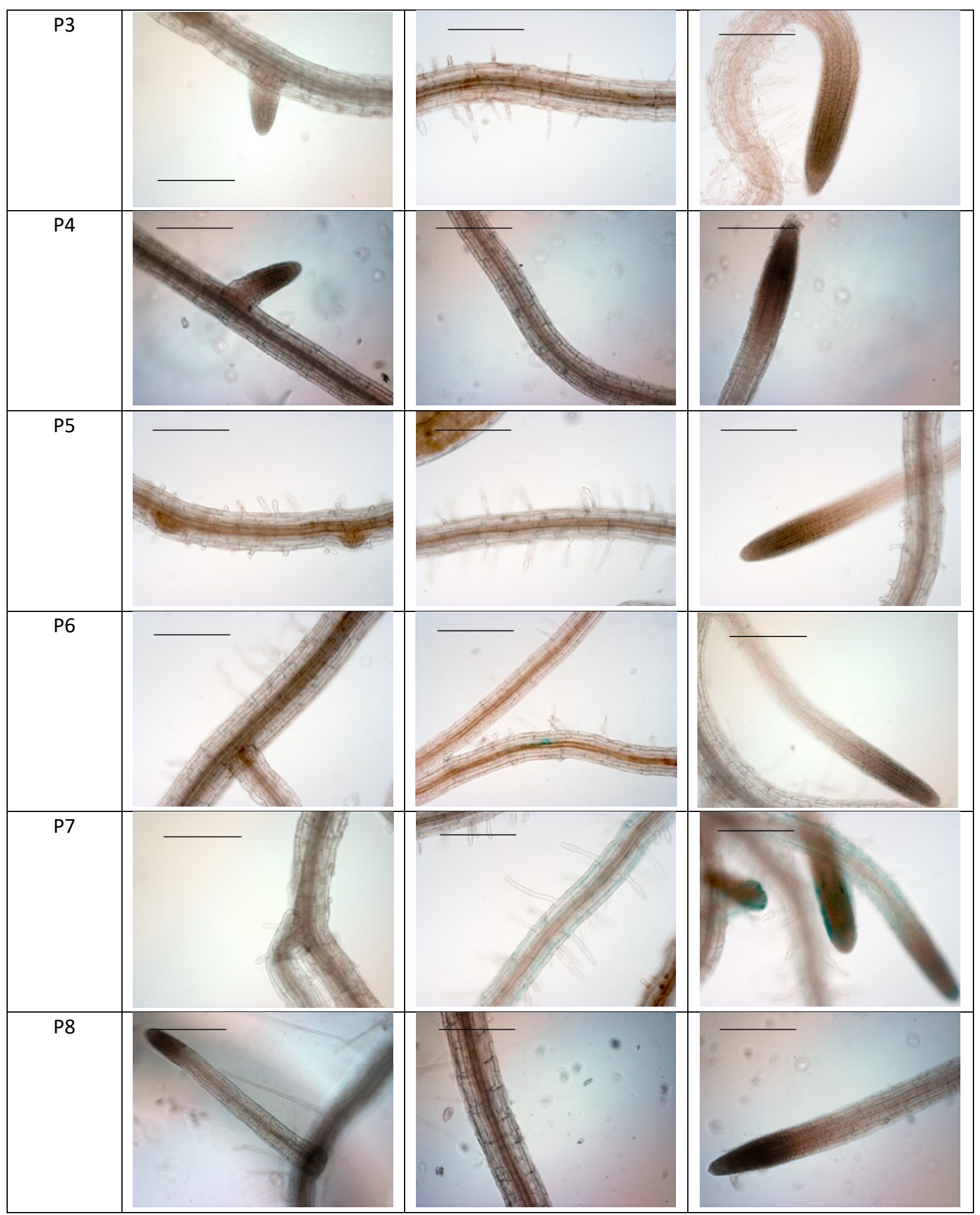




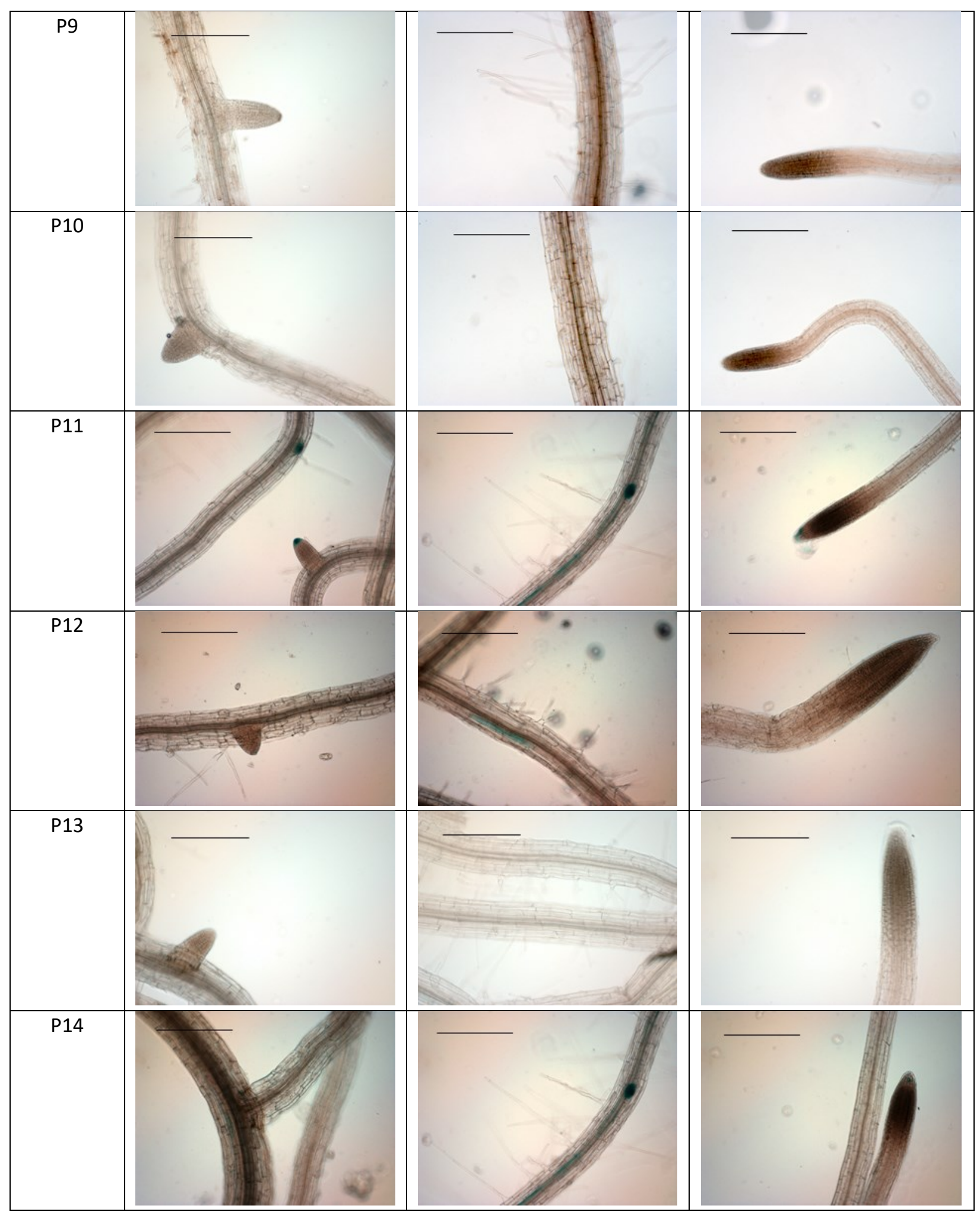




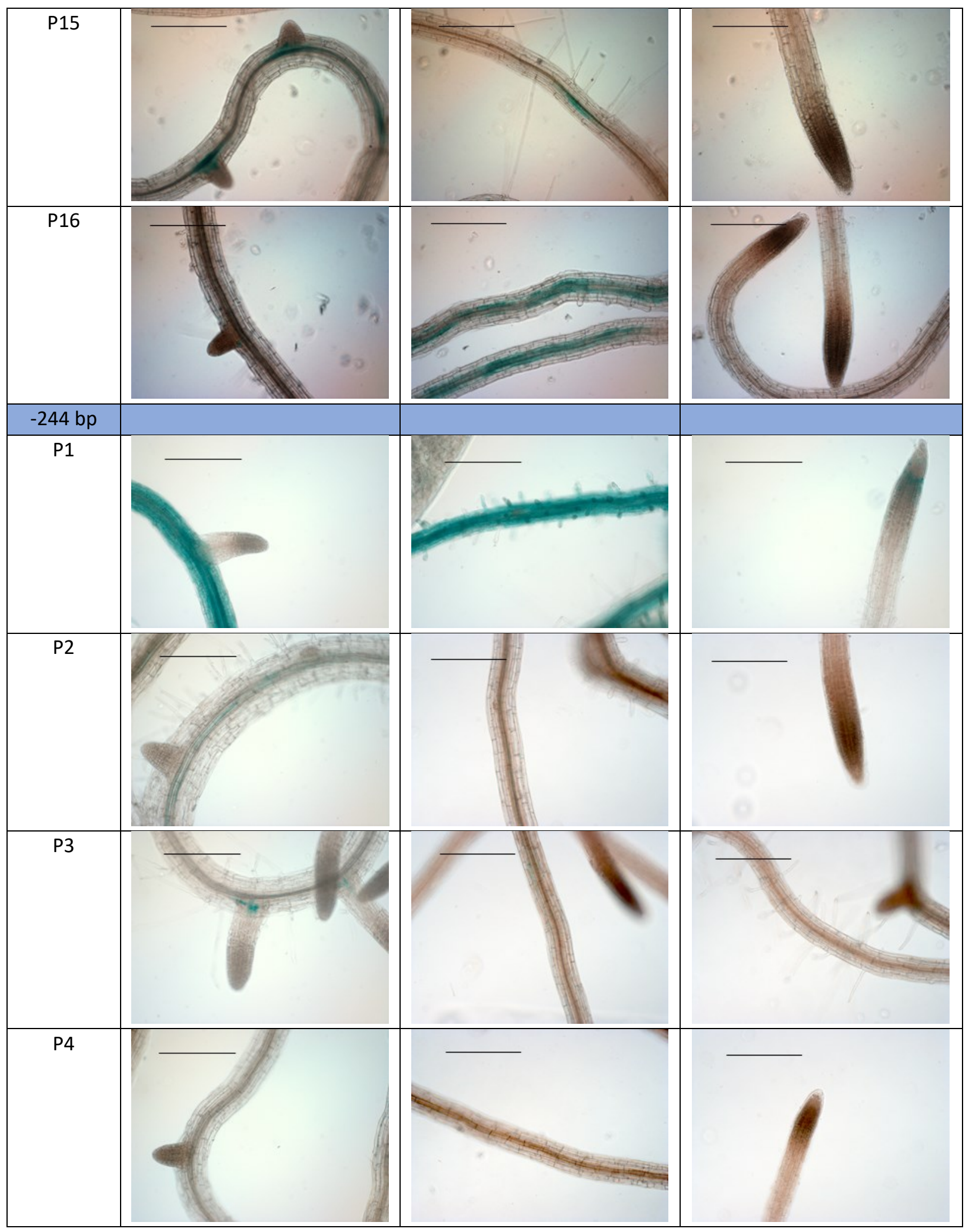




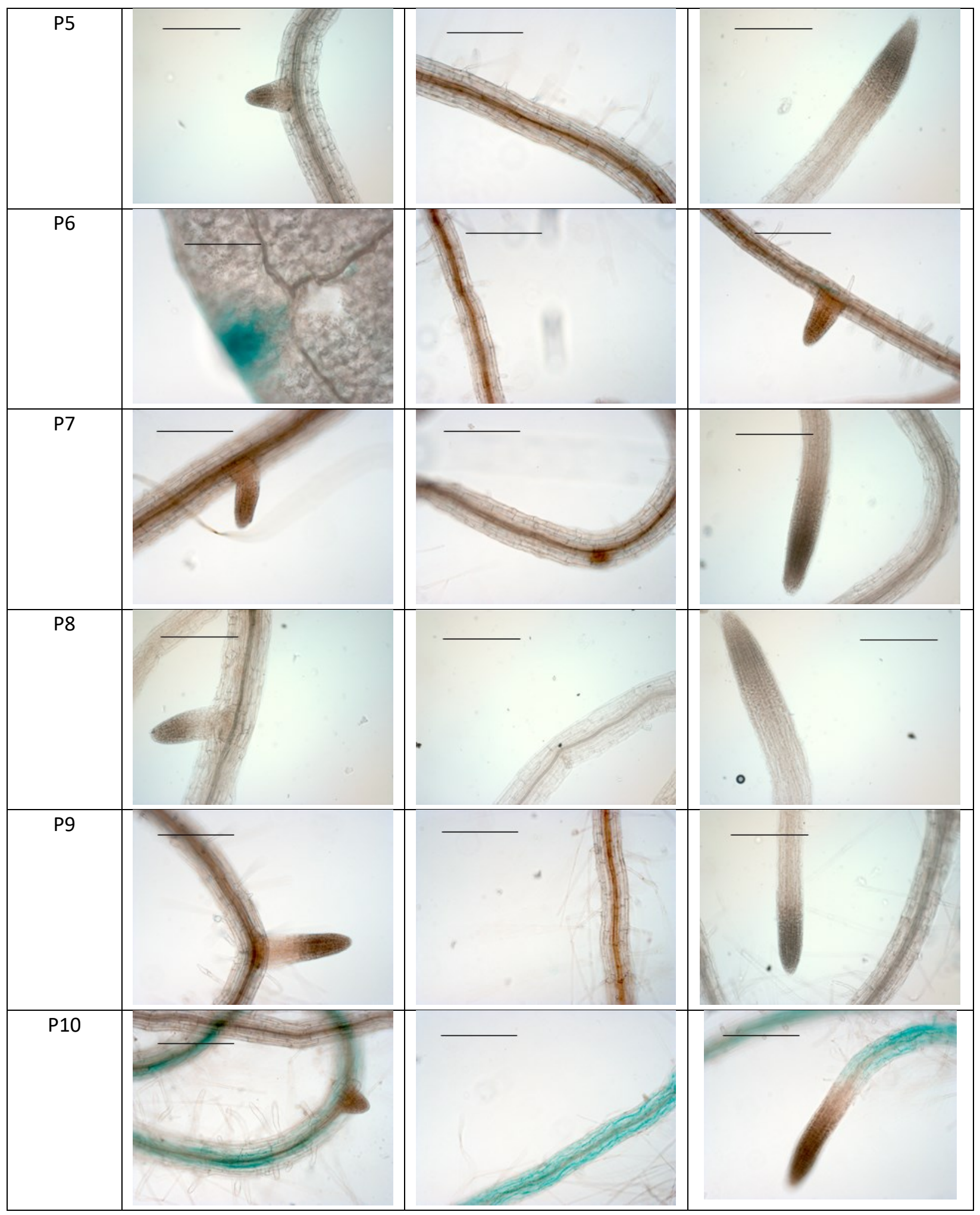




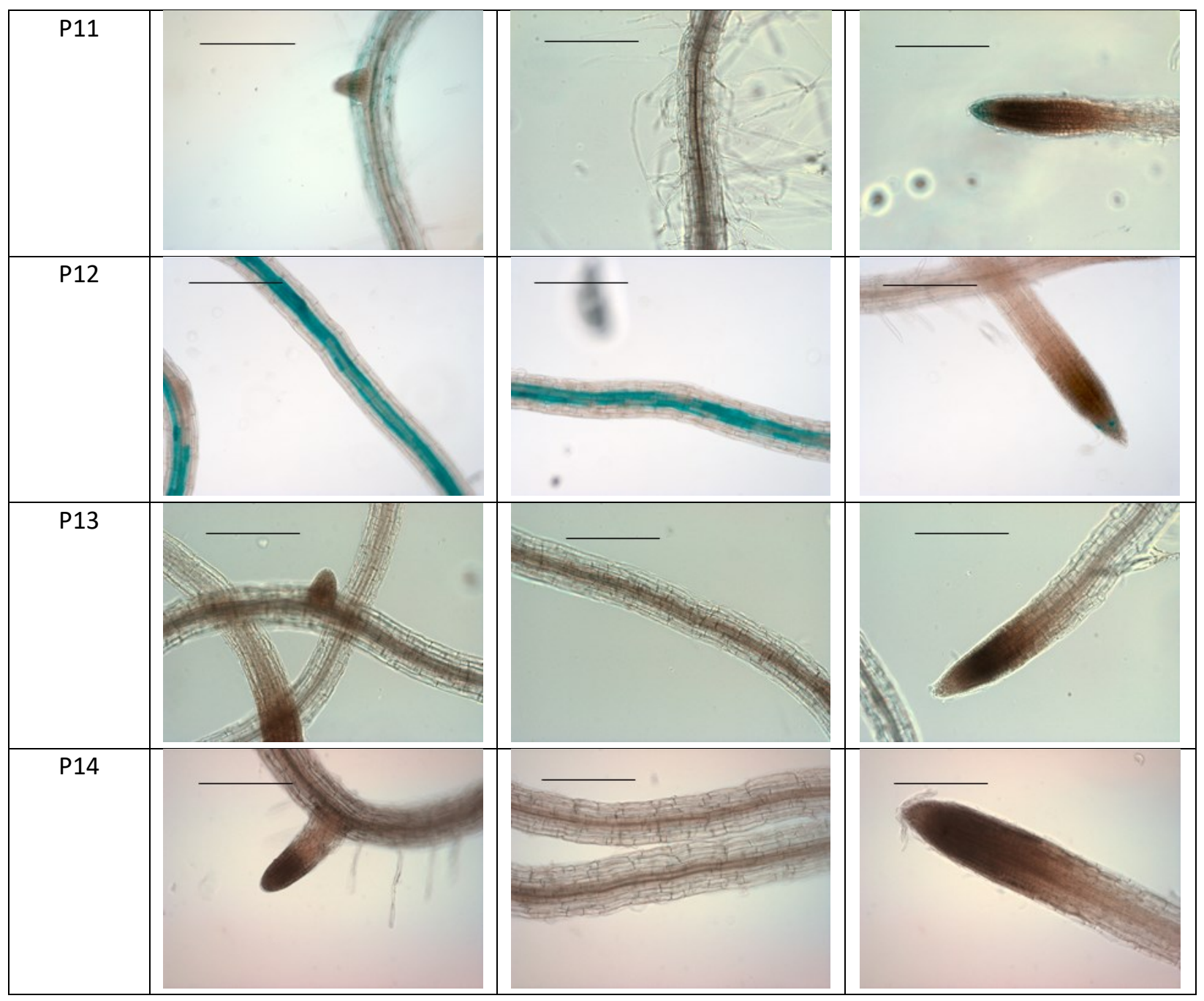


Supplemental Table 6: Genes involved in suberin deposition.

\begin{tabular}{|c|c|c|}
\hline Role & Gene Name & Accession Number \\
\hline \multirow[t]{3}{*}{ Transport } & $A B C G 2$ & At2g37360 \\
\hline & $A B C G 6$ & At5g13580 \\
\hline & $A B C G 20$ & At3g53510 \\
\hline \multirow[t]{12}{*}{ Biosynthesis } & $F A C T$ & At5g63560 \\
\hline & ASFT1 & At5g41040 \\
\hline & CYP86A1 & At5g58860 \\
\hline & CYP86B1 & At5g23190 \\
\hline & FAR1 & At5g22500 \\
\hline & FAR4 & At3G44540 \\
\hline & FAR5 & At3g44550 \\
\hline & GPAT5 & At3g11430 \\
\hline & GPAT7 & At5g06090 \\
\hline & KCS2 & At1g04220 \\
\hline & KCS9 & At2g16280 \\
\hline & KCS20 & At5g43760 \\
\hline \multirow[t]{8}{*}{ Regulation } & MYB9 & At5g16770 \\
\hline & MYB41 & At4g28110 \\
\hline & MYB53 & At5g65230 \\
\hline & MYB92 & At5g10280 \\
\hline & МУВ93 & At1g34670 \\
\hline & MYB107 & At3g02940 \\
\hline & MYB39 & At4g17785 \\
\hline & NAC046 & At3g04060 \\
\hline
\end{tabular}


Supplemental Table 7: Binding of suberin-associated transcription factors to genes involved in suberin deposition.

\begin{tabular}{|c|c|c|c|c|c|c|c|}
\hline$\frac{\text { Target }}{\text { Gene }}$ & $\begin{array}{l}\text { Accessio } \\
\text { n Number }\end{array}$ & $\begin{array}{l}\text { MYB9 } \\
\text { 3 DAP } \\
\end{array}$ & $\begin{array}{c}\text { MYB93 } \\
\text { amp-DAP } \\
\end{array}$ & $\begin{array}{l}\text { NAC04 } \\
6 \text { DAP } \\
\end{array}$ & $\begin{array}{r}\text { NAC046 } \\
\text { amp-DAP } \\
\end{array}$ & $\frac{\text { MYB107 }}{\text { DAP }}$ & $\frac{\text { MYB107 }}{\text { amp-DAP }}$ \\
\hline ABCG2 & At2g37360 & yes & yes & yes & yes & yes & yes \\
\hline ABCG6 & At5g13580 & yes & no & no & no & yes & no \\
\hline ABCG20 & At3g53510 & yes & yes & no & yes & yes & yes \\
\hline FACT & At5g63560 & no & no & yes & yes & no & no \\
\hline ASFT1 & At5g41040 & yes & yes & yes & yes & yes & yes \\
\hline $\begin{array}{c}\text { CYP86A } \\
1\end{array}$ & At5g58860 & no & no & yes & yes & no & no \\
\hline $\begin{array}{c}\text { CYP86B } \\
1\end{array}$ & At5g23190 & yes & yes & no & yes & yes & no \\
\hline FAR1 & At5g22500 & no & no & yes & yes & yes & yes \\
\hline FAR4 & $\begin{array}{c}\text { At3g4454 } \\
0\end{array}$ & yes & no & no & yes & no & yes \\
\hline FAR5 & At3g44550 & yes & yes & yes & yes & yes & yes \\
\hline GPAT5 & At3g11430 & no & yes & no & yes & yes & yes \\
\hline GPAT7 & At5g06090 & yes & yes & yes & yes & yes & yes \\
\hline KCS2 & At1g04220 & yes & yes & yes & yes & yes & yes \\
\hline KCS9 & At2g16280 & no & no & no & no & no & no \\
\hline KCS20 & At5g43760 & yes & yes & no & no & yes & no \\
\hline MYB9 & At5g16770 & no & no & no & yes & no & no \\
\hline MYB41 & At4g28110 & no & no & no & yes & yes & no \\
\hline MYB53 & At5g65230 & no & no & no & yes & no & no \\
\hline MYB92 & At5g10280 & no & no & no & yes & no & no \\
\hline MYB93 & At1g34670 & yes & yes & no & yes & yes & yes \\
\hline MYB107 & At3g02940 & no & no & yes & yes & yes & no \\
\hline MYB39 & At4g17785 & no & no & no & no & no & no \\
\hline NAC046 & At3g04060 & yes & no & no & no & yes & no \\
\hline bHLH112 & At1g61660 & no & no & yes & yes & no & no \\
\hline bHLH111 & At1g31050 & no & yes & no & yes & no & no \\
\hline bHLH27 & At4g29930 & no & no & no & no & yes & no \\
\hline WRKY56 & At1g64000 & yes & yes & no & no & yes & yes \\
\hline BCCP2 & $\begin{array}{c}\text { At5g1553 } \\
0\end{array}$ & no & yes & yes & yes & yes & yes \\
\hline
\end{tabular}


Supplemental Table 8: Total aliphatic suberin from 12-day old roots of various Arabidopsis genotypes

\begin{tabular}{|l|l|l|l|l|l|l|l|}
\hline Genotype & \multicolumn{4}{|l|}{ Amount (umols/g DW) } & \multicolumn{4}{l|}{ Descriptive Stats } \\
\hline & $\mathbf{1}$ & $\mathbf{2}$ & $\mathbf{3}$ & $\mathbf{4}$ & $\mathbf{A V G}$ & SD & SE \\
\hline Wild-type & 135.4851 & 110.256 & 135.0588 & 108.0627 & 122.2157 & 15.1037 & 7.55185 \\
\hline wrky56-1 & 138.0475 & 147.402 & 109.0651 & 116.6497 & 127.791 & 17.93112 & 8.96556 \\
\hline wrky56-2 & 125.6982 & 115.6235 & 121.599 & 130.5749 & 123.3739 & 6.337064 & 3.168532 \\
\hline wrky56-3 & 147.968 & 127.3929 & 146.5292 & 112.7744 & 133.6662 & 16.79107 & 8.395533 \\
\hline
\end{tabular}

Supplemental Table 9: Aliphatic suberin compounds of 12-day old roots from various Arabidopsis genotypes

\begin{tabular}{|l|l|l|l|l|l|l|l|l|}
\hline Genotype & \multicolumn{7}{|c|}{ Amount (umols/g DW) } \\
\hline & $\mathbf{1}$ & $\mathbf{2}$ & $\mathbf{3}$ & $\mathbf{4}$ & Average & SD & SE \\
\hline & \multicolumn{7}{|c|}{ Fatty acids } \\
\hline Wild-type & 40.05805 & 35.19074 & 40.21737 & 30.88326 & 36.58735 & 4.461311 & 2.230655 \\
\hline wrky56-1 & 40.10494 & 42.42527 & 27.62512 & 36.63505 & 36.69759 & 6.499484 & 3.249742 \\
\hline wrky56-2 & 34.47179 & 25.67284 & 31.21961 & 34.82699 & 31.54781 & 4.239722 & 2.119861 \\
\hline wrky56-3 & 33.41222 & 30.63161 & 35.66651 & 28.50859 & 32.05473 & 3.135183 & 1.567591 \\
\hline & \multicolumn{7}{|c|}{ Dicarboxylic fatty acids } \\
\hline Wild-type & 33.88699 & 28.27555 & 37.75631 & 28.17979 & 32.02466 & 4.660435 & 2.330217 \\
\hline wrky56-1 & 36.50888 & 36.91379 & 24.50081 & 33.04844 & 32.74298 & 5.76207 & 2.881035 \\
\hline wrky56-2 & 34.66045 & 28.43988 & 31.37269 & 31.83965 & 31.57817 & 2.546889 & 1.273445 \\
\hline wrky56-3 & 34.02537 & 31.72053 & 36.51602 & 29.4541 & 32.929 & 3.033374 & 1.516687 \\
\hline & \multicolumn{7}{|c|}{ w-hydroxy fatty acids } \\
\hline Wild-type & 45.43541 & 35.36471 & 43.5411 & 38.28031 & 40.65538 & 4.647877 & 2.323938 \\
\hline wrky56-1 & 50.46328 & 55.40454 & 47.90528 & 46.22129 & 49.9986 & 4.003754 & 2.001877 \\
\hline wrky56-2 & 40.79879 & 41.98128 & 44.60124 & 46.83396 & 43.55382 & 2.703053 & 1.351527 \\
\hline wrky56-3 & 52.30945 & 47.35669 & 50.90661 & 43.00105 & 48.39345 & 4.155474 & 2.077737 \\
\hline & \multicolumn{7}{|c|}{ Fatty alcohols } \\
\hline Wild-type & 9.004422 & 6.660086 & 9.189354 & 7.073674 & 7.981884 & 1.300713 & 0.650356 \\
\hline wrky56-1 & 7.682106 & 8.86068 & 6.362956 & 6.301549 & 7.301669 & 1.218573 & 0.609287 \\
\hline wrky56-2 & 6.837364 & 5.597236 & 6.903145 & 6.88476 & 6.555626 & 0.639528 & 0.319764 \\
\hline wrky56-3 & 9.913942 & 7.135468 & 10.16468 & 7.289245 & 8.625833 & 1.636553 & 0.818277 \\
\hline & \multicolumn{7}{|c|}{ Ferulate } \\
\hline Wild-type & 7.10028 & 4.764895 & 4.354657 & 3.64568 & 4.966378 & 1.495836 & 0.747918 \\
\hline wrky56-1 & 3.288271 & 3.798284 & 3.805565 & 3.499936 & 3.598014 & 0.250829 & 0.125414 \\
\hline wrky56-2 & 4.174559 & 8.949454 & 3.202337 & 6.102895 & 5.607311 & 2.533259 & 1.266629 \\
\hline wrky56-3 & 17.32927 & 3.773134 & 13.49141 & 4.808553 & 9.850592 & 6.621777 & 3.310889 \\
\hline
\end{tabular}


Cis-element Map

< FAR4 Promoter (2300 bp) - 2300 nucleotides

MYB AC-rich = blue (ACCWAMY and ACCWHH)

MYB-core = baby blue (YAACNG or YNGTTR)

WRKY $\mathrm{W}$-box $=$ pink (TGAC or TTGACY)

WRKY WT-box $=$ purple (GGACTTTC)

WRKY WK-box = purple (TTTTCCAC)

bHLH $E-b o x=y e l l o w ~(C A N N T G$ or specific G-box CACGTG)

$\overline{\mathrm{bHLH}}$ non $\mathrm{E}-\mathrm{box}=\operatorname{red}(\overline{\mathrm{NRCGTG}})$

$\mathrm{bHLH} \mathrm{N}-\mathrm{box}=\operatorname{red}(\mathrm{CAC} \overline{\mathrm{GRG}})$

$\mathrm{bHLH}$ CGC-box = red (GGKCCKRWC)

NAC-core $=$ green $($ CGTR $) \rightarrow$ palindromic $\left(\right.$ CTTN $\left._{7} A A G\right)$ and $\left(\right.$ CGTN $\left._{7} A C G\right) \ldots$ manual check

NAC-ZF = dark green (CCGCC)

NAC cluster $3=$ dark green (TTVCTT)

CAAT-box $=$ teal (CCAAT)

$\overline{\text { TATA-box }}=$ gold (TATAWAW)

* $=$ nucleotides shared between adjacent motifs

Top strand $=+=5^{\prime} \rightarrow 3^{\prime}$

Bottom strand $=-3^{\prime} \rightarrow 5^{\prime}$

$-2300 \mathrm{bp}$

FL

ggalcctatgtccgaactccgaattggcttgatatgtccgatgcatttagacaaaatcaaattgttttgaatat ccttggatacaggcttgaggcttaaccgaactatacaggctacgtaaatctgtttttagtttaacaaacttata

catcgctggcttcttcatattttgttgttcaaaagaaaagttgtttgttgtacagtgaatatttgtatggccaca gtagcgaccgaagaagtataaacaacaagttttcttttcaacaaacaacatgtcacttataaacataccggtgt

$-2150 \mathrm{bp}$

atcagatttagtttgatattatcaattattcaaatttatgcagaattttcttcaagttacatacatggcttgtat tagtctaaatcaactataatagttaataagtttaaatacgtcttaaagaagttcaatgtatgtaccgaacata

del 5

gcatattcttcç̄tagcagttctaaccccgacataagggatagggcagcggtgtatggectcatatttaatatt cgtataagaaggcatcgtcaagattggggctgtattccctatcccgtcgccacatacctggagtataaattataa

$-2000 \mathrm{bp}$

aaaaattataaaaaattgttagtggtataaatactctcgaaaatataaatacatttttttttgtcacaataa ttttttaatattttttaacaatcaccatattttatgagagctttatatttatgtaaaaaaacagtgttatt

tacatatttatatttgcaaatatagaattttatttaaataacaagactaaaatcttctttttttccctaaggct atgtataaatataaacgtttatatcttaaataaatttattgttctgattttagaagaaaaaaagggattccga

ctttttacagttgggccggggctgatcagttcgctattgaagtatacatgtcaaagaaaatgaaggagaat gaaaatgtcaacccggccccgactagtcaagcgataacttcatatgtacagtttcttttacttcctcttatttg

gtattaattaaatcgatttgactaatgagacaacttaattcagctttaatatagtttaaatttcgtacatg gtagcataattaatttagctaaactgattactctgttgaattaagtcgaaattatatcaaatttaaagcatgtac

$-1700 \mathrm{bp}$

AC-rich (x2)

accaggtaatcaaattttctaaacaaatggaacaatatcagatagggtaaactgttaccatctgtgtaactttgc tggtccattagtttaaagatttgtttaccttgttatagtctatcccatttgacaatggtagacacattgaaacg 
$\operatorname{Del} 4$

aaattagtaagtctaaattataagaaacgatgacttgtacttctaaactccagcatatcatataaattttgag tttaatcattcagatttaatattctttgctactgaacatgaagattttgaggtcgtatagtatattttaaa

$-1550 \mathrm{bp}$ gtttgagacatttctataagttcagatttaattcttcctaacgtatgaggttaggtattttctgtcgct aactctgtaaagatattcaagtctaaattaagaaggattgcatactccaatccataaagacagcgaaatggt AC-rich (x2)

$\operatorname{AC}-r i c h(x 5)$

aaatttgacgtttcccatacgttttagcttgttatgtcattgttgcataatttatgaccaaccaacctaaga tttttaaactgcaaagggtatgcaaaatcgaacaatacagtaacaacgtattaaatactggttggtttggattct

tcaggtttttagatagtcctttttcctttgaaattataagatgttttggttgtattggcatagattaca ggtttagtccaaaatctatcaggaaaaaggaactttaatattctacalaaccaacataaccgtatctaatgt

aaattactccccccattttagattagctgtcgttgaagatttttacagaataataaaaaacattcaatttttc ttttaatgaggggggtaaaatctaatcgacagcaacttctaaaatgtcttattatttttttgtaagttaaaaag

$-1250 \mathrm{bp}$

tgttttaccctaattaatgtattgttatatttgatatcatcaataaatacgtttaaaatgttgataaaattgga acaaatgggattaattacataacaatataactatagtagttatttatgcaaattttacaactattttaacc

del 3

aacttĔgtcaaacatctgcattgtaatatataatctaaaaaaatgatttcttatattctatcaaatatggctaa tgaacagtttgtagacgtaacattatatattagatttttttactaaagaatataagatagtttataccgatt

$-1100 \mathrm{bp}$

ctatacacatataatttgggctgagctgtcatctttcgacatgaaattactccgaattatacataatttgccaga gatatgtgtatattaaacccgactcgacagtagaaagctgtactttaatgaggcttaatatgtattaaacggtct

gaagttatgttacataacaacactcatattcaaagaaaactagatgtataatgtattagctattatttaagtaa cttcaatacaatgtattgttgtgagtataagttttctttgatctacatattacataatcgataataaatcatt

$-950 \mathrm{bp}$

TSS?

cactaacaactaaataaatagaatggatgaactataaaaattaagaattattattgaatgagtatatttttt gtgattgttgatttatttatcttacctadttgatatttttaattcttaataataacttactcatataaaaa

tctattttggtcaaacgtcgaggtggagtttaagaaaatcgtgattctaaaatagtgcaataatgaaatattaaa agataaaccagtttgcagctccacctcaattctttagcactaagatttatcacgttattactttataattt

$-800 \mathrm{bp}$

aatcacgttatcatcttgttcttttatttccactattttctcttgaaatttaaatgaaatatgttat

tttagtgcaatagtagaacaagaaataaaggtgataaagagaactttaaatttactttatacaataaaggt

CDNA end

aaatgttgttacaaccgatttactatctcataaatatgttcttttgtgattttaatttttgtattattaatgttc tttacaacaatgttggctaaatgatagagtatttatacaagaaacactaaattaaaacataataattacaag 
-650 bp MYBcore (x2)/E-box

ccctgctttttgttgactaaacaactcgttactcgttagatatatattcacgttgagaaaaaagcgtttaaccaa gggacgaaaacaactgatttgttgagcaatgagcaatctatatataagtgcaactcttttttcgcaaattggtt

Del 2

aacacttaggtatattgaagagttctaaaātagaacgccaaccttccaatcaacacacctacgacaattctag ttgtgaatccatataacttctcaagattttaatcttgcggttggaaggtttagttgtgtggatgctgttaagatc

$-500 \mathrm{bp}$

tcctacaacatagatccttctagcaaaccacalaggaaacttcttgtggaaaacactaacactatcctcactcagt aggatgttgtatctaggaagatcgtttggtgttcctttgaagaacaccttttgtgattgtgataggagtgagtca

tactctcgtattgctctacctagagtttctaattctgctatgttataaaattcttacatacttattcttttttt atgagagcataacgagatggatctcaaagattaagacgatacaatatttttaagaatgtatgaataagaaaaaa

$-350 \mathrm{bp}$

tctttctaaacattccattcgttttaaaagctaggcccacgattagtagttaaaatattttaatttttaaaata agaaagatttgtaaggtaagcaaaattttcgatccgggtgctaatcatcaattttataaattaaaatttttat

del 1

tgggttacatattttttāttctttttagagctccgagatttcagagcatgttctaattggatatgtgatatttaa acccaatgtataaaaataagaaaatctcgaggctctaaagtctcgtacaagattaacctatacactataaatt

$-200 \mathrm{bp}$

tcagaagtagttttaatattgttttttttttataaagaaaatgtaggtaggtttacgtacaagtagtagatatg agtcttcatcaaaattataacaaaaaaaatattttcttttacatccatccaaatgcatgttcatcatctatac

5' UTR/flcDNA start atggctcaacaaaacgggtcaacatttacgggtctatatatattcgtgcctcatcgccgaaggtgttatggttca taccgagttgttttgcccagttgtaaatgcccagatatatataagcacggagtagcggettccacalaccaagt $-50 \mathrm{bp}$ aaacaatctatcgtacttagttattaattggatagatataagtttcttcaATG tttgttagatagcatgaatcaataattaacctatctatattcaaagaagtTAC

$50 \mathrm{bp}$ last line, $75 \mathrm{bp}$ all other lines

0 tandem repeats and 0 CPNPG islands.

Supplemental Figure 1: Map of the FAR4 5' promoter upstream region with specific motifs 


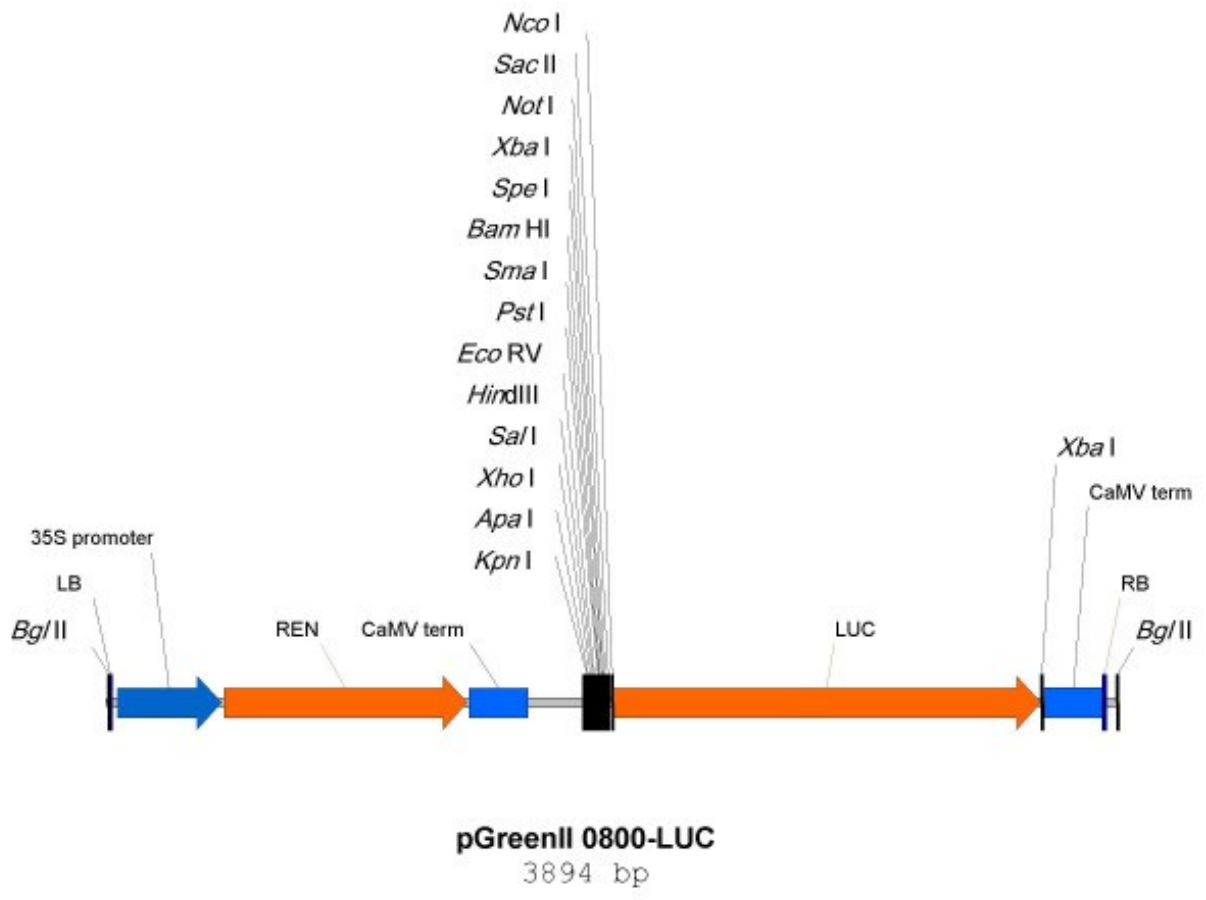

Supplemental Figure 2: Map of the T-DNA region in pGREENII 0800-LUC

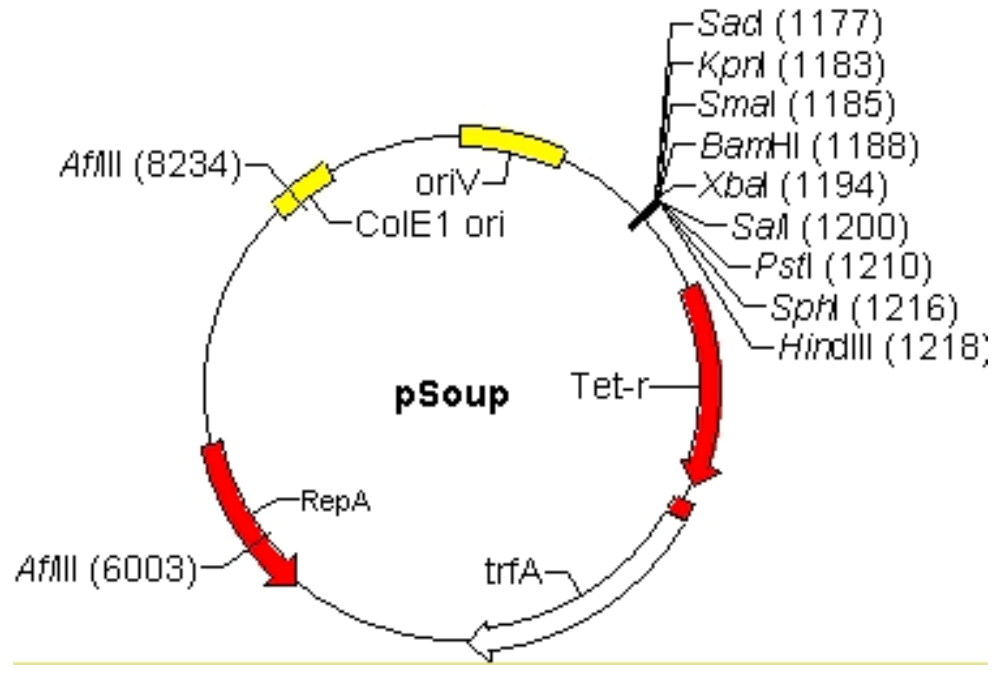

Supplemental Figure 3: Vector map of pSOUP 


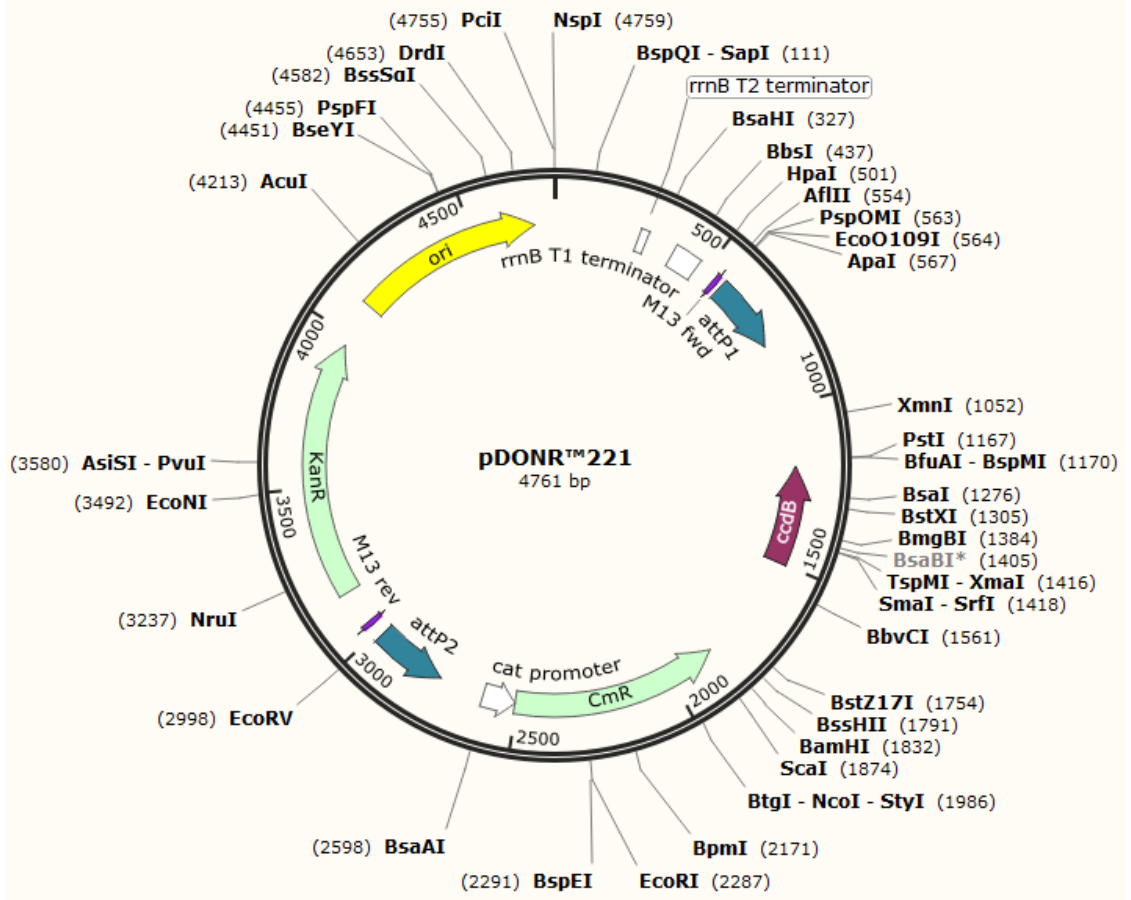

Supplemental Figure 4: Vector map of pDONR221

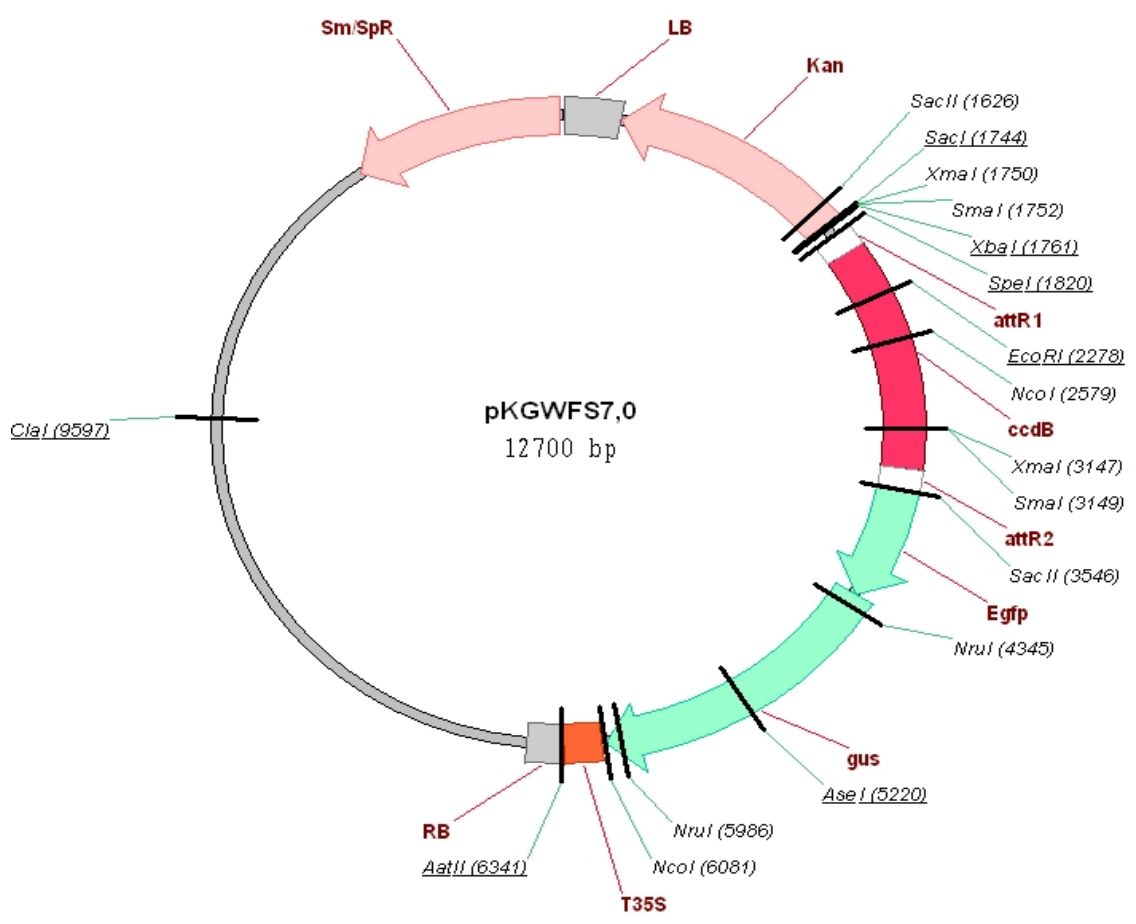

Supplemental Figure 5: Vector map of pKGWFS7 


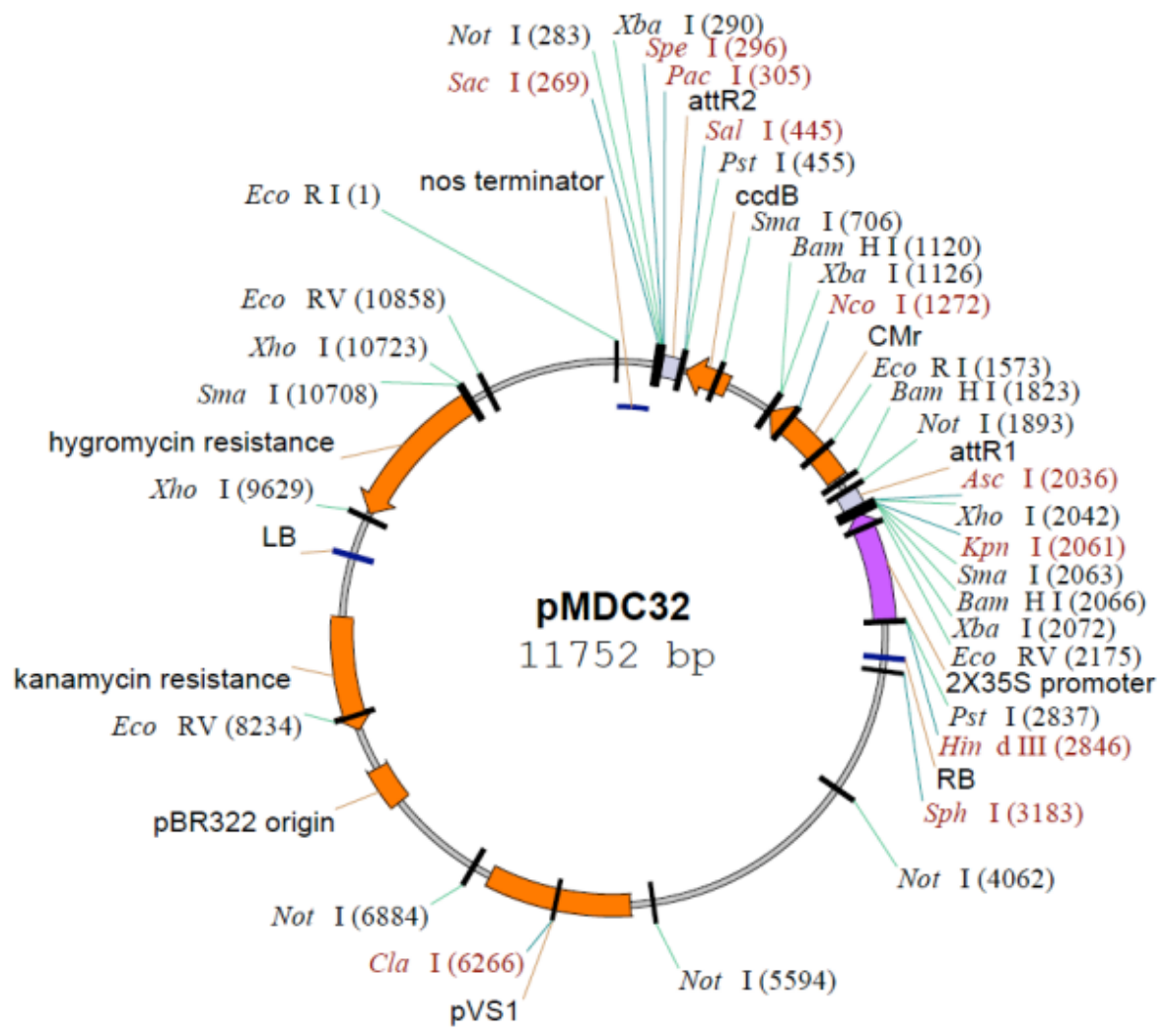

Supplemental Figure 6: Vector map of pMDC32

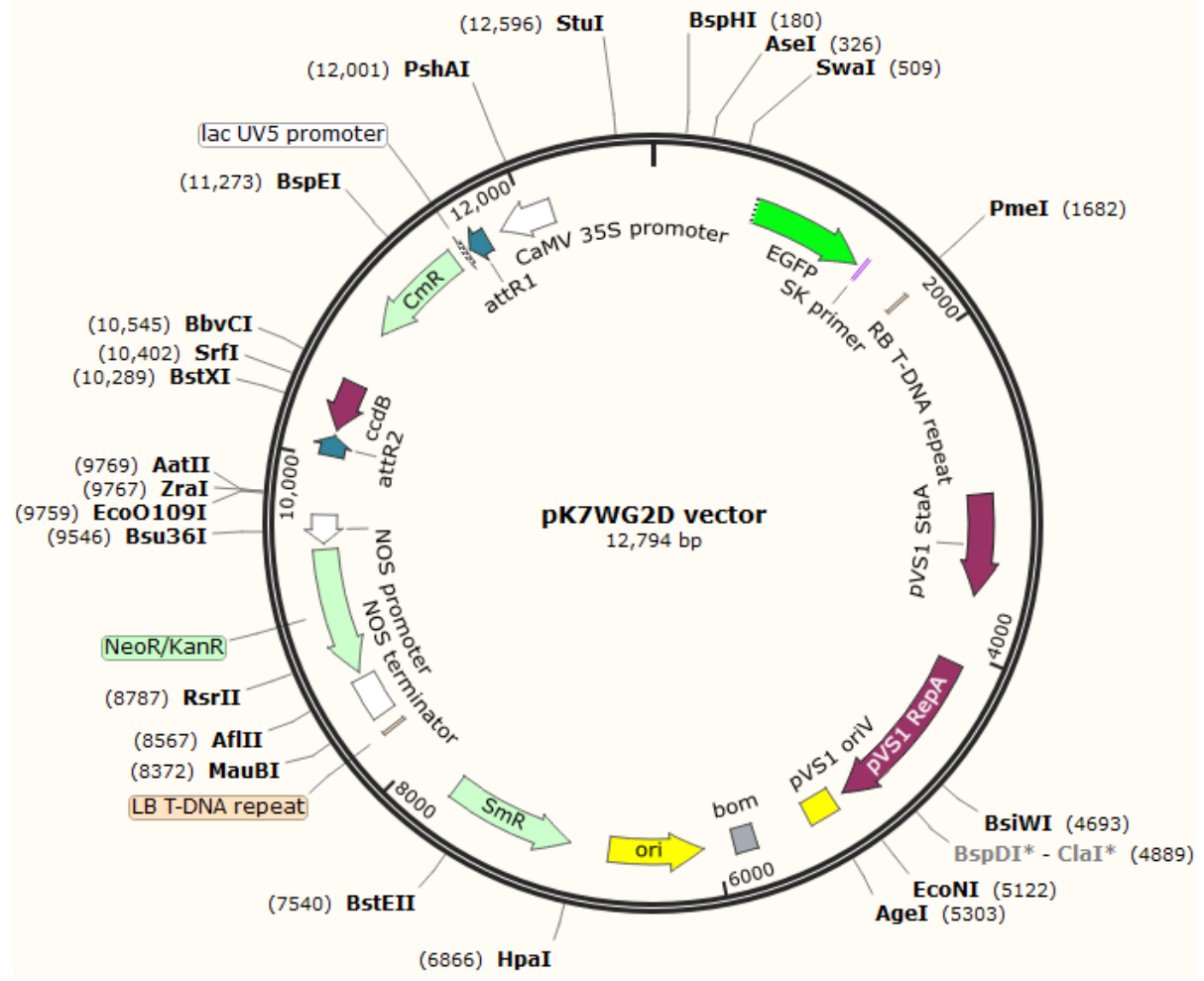

Supplemental Figure 7: Vector map of pK7WG2D 


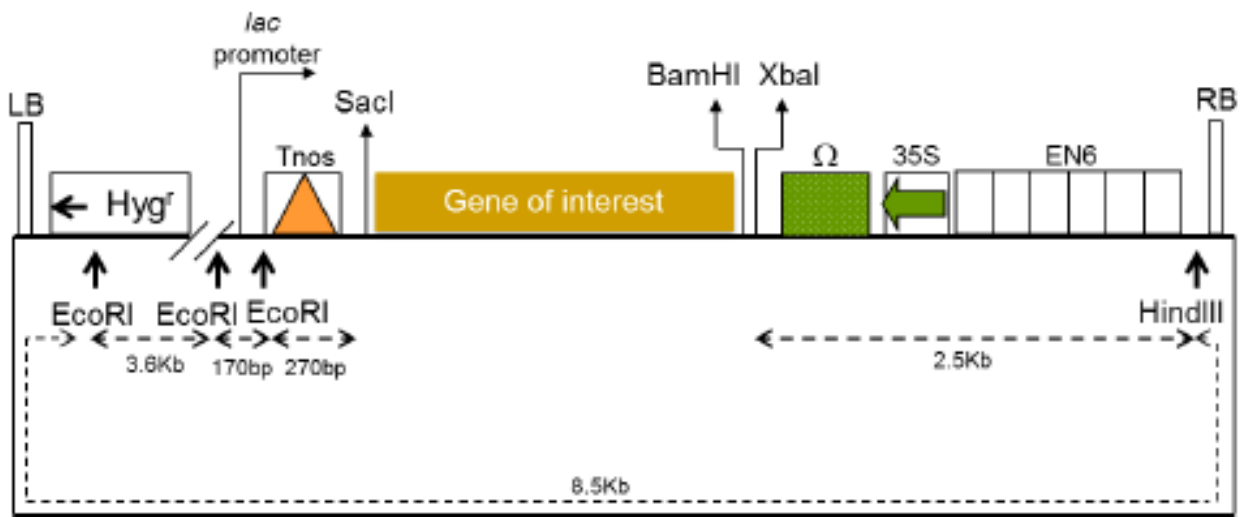

Figure 3.1 Schematic representation of pVKH18-EN6 binary vector, used for transient expression of cardosin A and its mutated versions in tobacco leaves. En 6 - 35S CaMV promoter $+6 x$ enhancer; Hygr - hygromycin resistance gene; LB - left border, RB - right border, Tnos - nopaline synthase terminator. Adapted from Batoko et al. (2000).

Supplemental Figure 8: Vector map of pVKH18

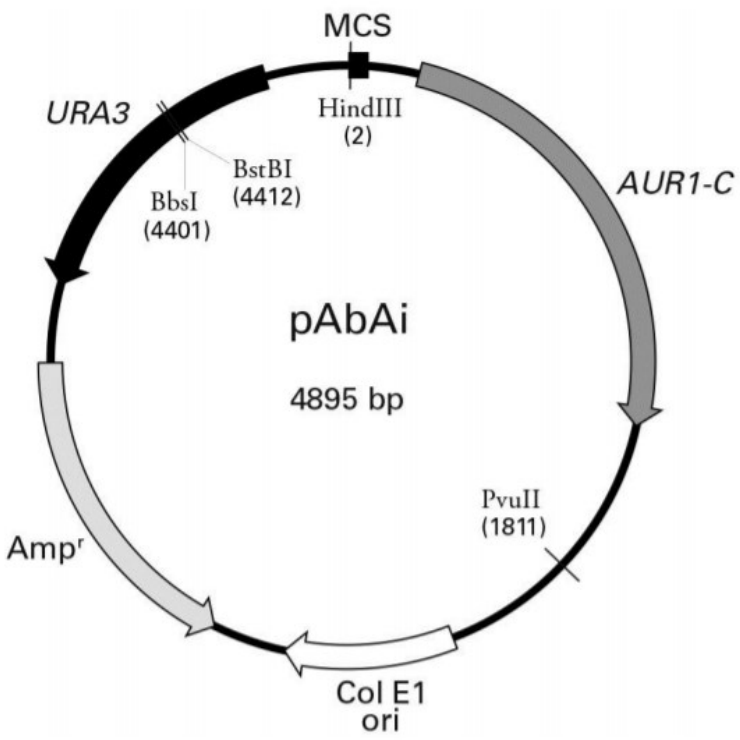

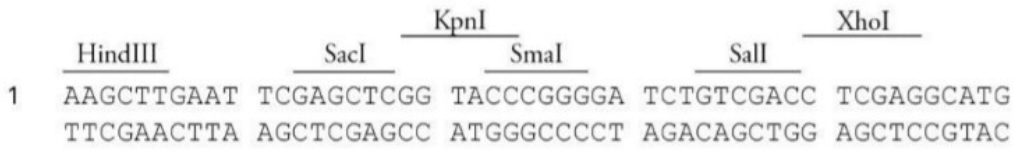

Supplemental Figure 9: Vector map of pAbAi 

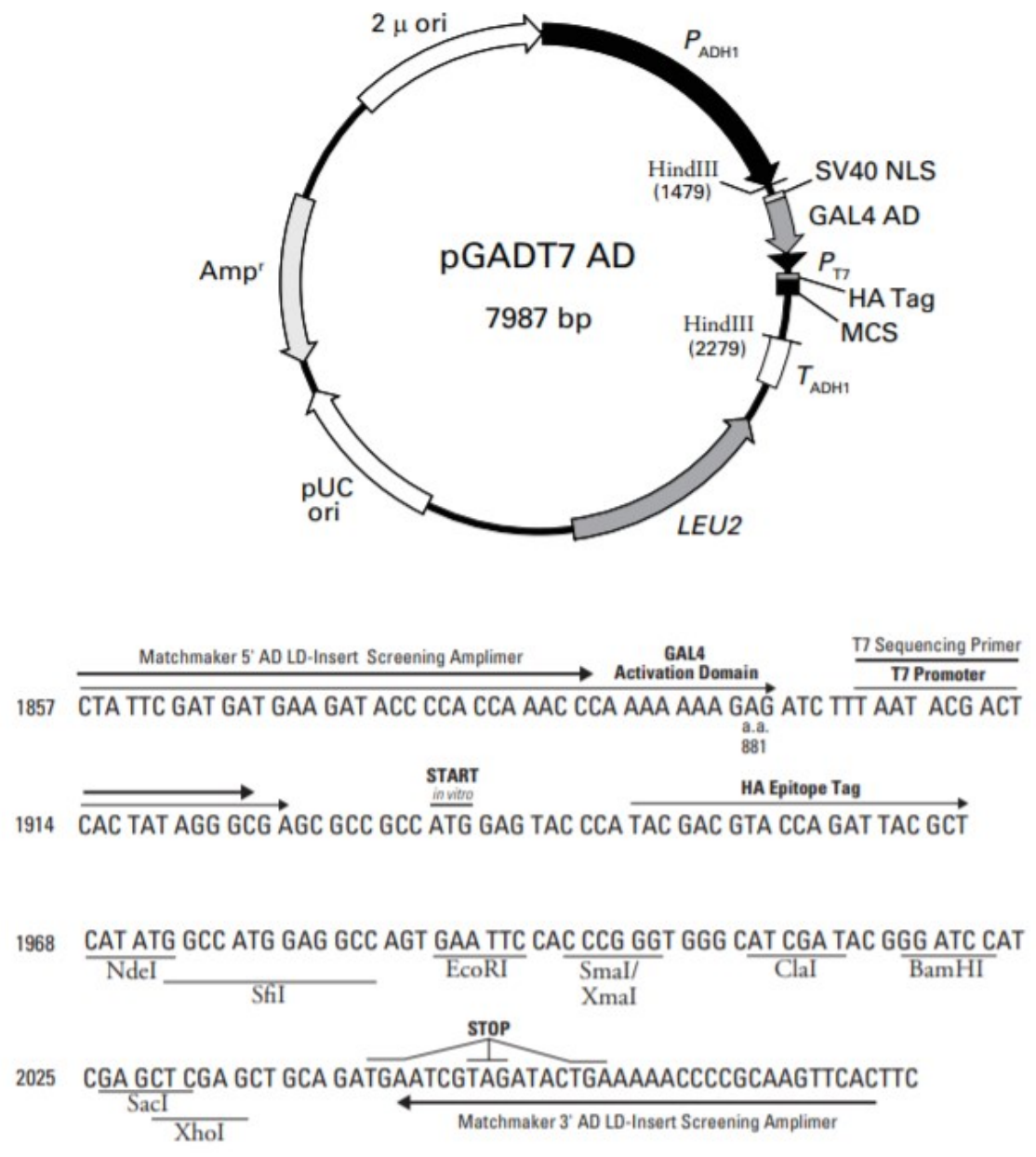

Supplemental Figure 10: Vector map of pGADT7-AD 